\title{
Promotion and support of breastfeeding
}

Citation for published version (APA):

Kools, E. J. (2004). Promotion and support of breastfeeding. [Doctoral Thesis, Maastricht University]. Maastricht University. https://doi.org/10.26481/dis.20041013ek

Document status and date:

Published: 01/01/2004

DOI:

10.26481/dis.20041013ek

Document Version:

Publisher's PDF, also known as Version of record

\section{Please check the document version of this publication:}

- A submitted manuscript is the version of the article upon submission and before peer-review. There can be important differences between the submitted version and the official published version of record.

People interested in the research are advised to contact the author for the final version of the publication, or visit the DOI to the publisher's website.

- The final author version and the galley proof are versions of the publication after peer review.

- The final published version features the final layout of the paper including the volume, issue and page numbers.

Link to publication

\footnotetext{
General rights rights.

- You may freely distribute the URL identifying the publication in the public portal. please follow below link for the End User Agreement:

www.umlib.nl/taverne-license

Take down policy

If you believe that this document breaches copyright please contact us at:

repository@maastrichtuniversity.nl

providing details and we will investigate your claim.
}

Copyright and moral rights for the publications made accessible in the public portal are retained by the authors and/or other copyright owners and it is a condition of accessing publications that users recognise and abide by the legal requirements associated with these

- Users may download and print one copy of any publication from the public portal for the purpose of private study or research.

- You may not further distribute the material or use it for any profit-making activity or commercial gain

If the publication is distributed under the terms of Article $25 \mathrm{fa}$ of the Dutch Copyright Act, indicated by the "Taverne" license above, 


\section{PROMOTION AND SUPPORT OF BREASTFEEDING}


ISBN $905278423 \mathrm{X}$

Lay-out: Els Kools, Nathalie Slangen, Epidemiologie, Universiteit Maastricht

Cover: C Pablo Picasso, Maternité [1963], c/o Beeldrecht Amsterdam 2004

Production: Datawyse, Universitaire Pers Maastricht

\section{(C) 2004 E.J. Kools}

All rights reserved. No part of this thesis may be reproduced or transmitted in any form or by any means, electronic or mechanical, including photocopying, recording or any information storage or retrieval system, without permission in writing from the author, or, when appropriate, from the publishers of the publications. 


\title{
PROMOTION AND SUPPORT OF BREASTFEEDING
}

\author{
PROEFSCHRIFT
}

ter verkrijging van de graad van doctor

aan de Universiteit Maastricht,

op gezag van de Rector Magnificus,

Prof. mr. G.P.M.F. Mols,

volgens het besluit van het College van Decanen,

in het openbaar te verdedigen

op woensdag 13 oktober om 16.00 uur

door

Elisabeth Johanna Kools

\section{$\mathrm{U}_{\mathrm{M}}^{\mathrm{N}}$}




\section{Promotores}

Prof. dr. H. de Vries

Prof. dr. ir. P.A. van den Brandt

\section{Co-promotor}

Dr. C.T.M.C.N. Thijs

\section{Beoordelingscommissie}

Prof. dr. C.P. van Schayck (voorzitter)

Prof. dr. B. van den Borne

Prof. dr. R.A. Hira Sing (VUMC Amsterdam en TNO-PG Leiden)

Prof. dr. C. Spreeuwenberg

Prof. dr. N.K. de Vries

\section{(1) ZonMw}

\section{nitutim}

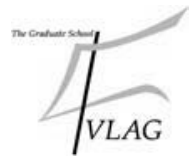

The development and evaluation plan was submitted as a grant proposal for the National Prevention Program of ZONMw ("Netherlands Organization for Health Research and Development").

The studies presented in this thesis were performed at the Nutrition and Toxicology Research Institute Maastricht (NUTRIM) that participates in the graduate school VLAG (Food Technology, Agro biotechnology, Nutrition and Health Sciences), accredited by the Royal Netherlands Academy of Arts and Sciences. 
There is no finer investment for any community than putting milk into babies

(Winston Churchill 1943)

In dierbare herinnering aan mijn ouders, Henry, Paul en Riet

Voor Bert, Jan-Pieter, Marie-Paule en Monique 


\section{CONTENTS}

1 Introduction 9

2 The $\mathrm{ABC}$ of Breastfeeding. A planning model for health promotion 15 applied to breastfeeding in the Netherlands

3 The Behavioral Determinants of Breastfeeding in the Netherlands: 39 Predictors for the Initiation of Breastfeeding

4 The Behavioral Determinants of Breastfeeding in the Netherlands: $\quad 55$ Factors explaining the Continuation of Breastfeeding

5 A Breastfeeding Promotion and Support Program in the Netherlands: 69 The randomized trial

$6 \quad$ General discussion $\quad 89$

$\begin{array}{ll}\text { Summary } & 109\end{array}$

$\begin{array}{ll}\text { Samenvatting } & 115\end{array}$

$\begin{array}{ll}\text { Dankwoord } & 121\end{array}$

$\begin{array}{ll}\text { About the author } & 125\end{array}$ 


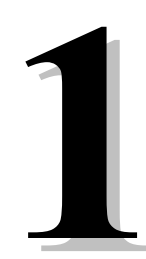

Introduction 


\section{INTRODUCTION}

In Europe, rates of breastfeeding vary but are in general low. In the Netherlands, $80 \%$ of mothers start to breastfeed their newborn, but only a small percentage continue to do so longer than a few months. ${ }^{1}$ Many initiatives have been developed; one shortcoming of these approaches being that they were often not grounded on health promotion planning principles. Studies in other fields have shown that the effectiveness of health promotion programs is greatly dependent on the quality of planning. ${ }^{2}$ With respect to health promotion, several models can be used to plan the process of program development, to unravel the relevant beliefs and to develop methods for interventions. In this thesis three models were used, namely, the ABC planning model for the planning process, the ASE model for the analysis of the behavioral determinants and the health counseling model for the behavioral change resulting in the initiation and continuation of breastfeeding (Table 1).

Table 1 The main models of health promotion used in this thesis

\begin{tabular}{llc}
\hline Models & & References \\
\hline ABC planning model & $\begin{array}{l}\text { An integration of various health promotion planning and theoretical models for } \\
\text { changing health behaviors. The model distinguishes three basic phases in the } \\
\text { process of health education and promotion: Analysis of the problem; } \\
\text { Behavioral change; Continued prevention by diffusion. }\end{array}$ \\
\hline ASE model & $\begin{array}{l}\text { States that behavior is best predicted by intention, which, in turn, is predicted } \\
\text { by Attitudes, Social influences, and self-Efficacy. }\end{array}$ & $5-7$ \\
\hline Health Counseling & $\begin{array}{l}\text { Is based on theories of behavioral change. The health counseling process } \\
\text { model }\end{array}$ & $\begin{array}{l}\text { Consists of three phases: Preparation of the advice; Implementation of the } \\
\text { Advice and Maintenance. }\end{array}$ \\
\hline
\end{tabular}

For the planning of a breastfeeding promotion program in the Netherlands, we used the $\mathrm{ABC}$ model, which is an integration of various planning models. The $\mathrm{ABC}$ model can be viewed as a comprehensive model for systematically planning health education and promotion activities. ${ }^{3,4}$ The model integrates principles of the Precede-Proceed framework, ${ }^{2}$ its simplified version by Kok, ${ }^{11}$ the Community Change model, ${ }^{12}$, and Roger's Diffusion of Innovations theory. ${ }^{13}$ The first phase, Analysis of the Health Problems, consists of five distinct steps, namely the problem identification, the problem factors, the target groups, the determinants of health promoting behavior, and the access points analysis. The second phase, Behavioral Change, builds on the results of the first phase and consists of three distinct steps: the development of overall goals and specific objectives that can be measured; the development and piloting of the program, and the testing of the program's effectiveness ${ }^{14}$ using a (quasi) experimental design. The third phase, Continuation, focuses on broad diffusion and implementation of effective programs for this. It is necessary to obtain support and intersectoral collaboration, in order to analyze facilitating and hindering factors for diffusion and to use this input for developing diffusion strategies. We used the ASE model to explain behavioral determinants of breastfeeding. This model has been developed in order to analyze the effects of three motivational factors that have been identified by many social-cognitive theories as important predictors of behavior: attitudes, social influences, and selfefficacy $^{15}$ (Figure 1). 


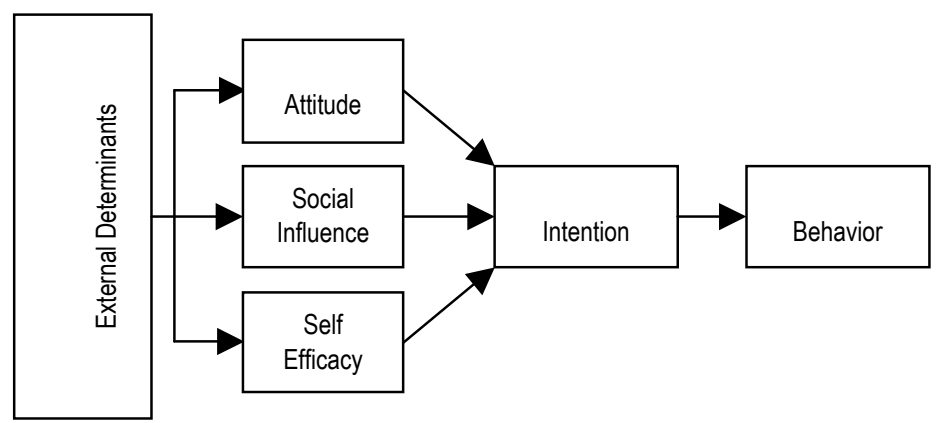

Figure 1 The ASE model (adapted from De Vries \& Mudde, 1998)

This model has been used to analyze various health behaviors and integrates concepts of several social cognitive theories, most notably Social Cognition Theory ${ }^{16}$ Theory of Reasoned Action, ${ }^{17}$ Health Belief Model,${ }^{18}$ and the Trans Theoretical Model. ${ }^{19}$ In the latter model, different stages are discerned in the process of behavioral change: precontemplation, contemplation preparation, action, and maintenance. For smoking, subjects in different motivational phases differed in their social determinants. ${ }^{20}$ Furthermore, in order to facilitate the counseling process for caregivers, the Health Counseling model was chosen since this model had already been applied successfully to other health promoting behaviors, such as smoking prevention..$^{21-23}$ Both process and effect evaluations revealed its feasibility, appeal and effectiveness. ${ }^{22}$ The Health Counseling process consists of three phases: Preparation of the advice, Implementation of the advice and Maintenance. Thus, the Health Counseling model pays attention to the ASE determinants at each stage of behavioral change. Using these three models, a plan was submitted as a grant proposal for the National Prevention Program of ZONMw ("Netherlands Organization for Health Research and Development"). It was approved in 1999 and started in 2000, and was named "The promotion and Support of Breastfeeding." The main objective of this project and the subject of this thesis are the development and testing of a new breastfeeding promotion and support program and the study of the determinants of breastfeeding initiating and duration. The general objective of this program was to prevent women weaning early and to enhance the breastfeeding rate at three months by $10 \%$, from $21 \%$ (in 1999) to $31 \%$. The rationale for the choice for three months took into account the health benefits of prolonged breastfeeding and the high rate of cessation in the first months so that, the greatest benefits for the population would be gained by increasing breastfeeding rates in the first months. Hence we formulated our operational goals as follows: to strengthen the support of continuation of breastfeeding (in addition to promotion of the initiation of breastfeeding), by:

(1) Health counseling: intervening on behavioral determinants of the duration of breastfeeding by enhancing the caregiver's performance to promote and support breastfeeding using health counseling principles. 
(2) Cooperation and continuity: to enhance cooperation, early signaling of breastfeeding problems and continuity of care by transfer of information on individual mothers between caregivers.

(3) Lactation consultancy: to enhance the access to lactation consultants and to take away financial and practical barriers for consulting them.

We used a randomized trial because it is the gold standard for evaluating effectiveness. ${ }^{24}$ Randomization gives the strongest evidence for effectiveness; group randomization is needed when an intervention is implemented at the group level and it prevents selection (of mothers, caregivers and organizations) and selective dropout of organizations so that the groups are prognostically comparable. Three out of five Home Health Care organizations in the province of Limburg, the most Southern province of the Netherlands, participated. In these regions, we had already studied the ASE determinants of breastfeeding in a small-scale study. ${ }^{25}$ In this randomized trial, we had the opportunity to study the ASE determinants on a larger scale and separately for breastfeeding initiation (starting with breastfeeding) and continuation (duration of breastfeeding).

\section{OUTLINE OF THIS THESIS}

Chapter 2 describes "The ABC of Breastfeeding: A planning model for health promotion applied to breastfeeding in the Netherlands."

Chapters 3 and 4 describe two studies. The third chapter describes the ASE determinants of Breastfeeding in the Netherlands that predict the initiation of Breastfeeding and the fourth chapter the ASE factors that explained the continuation of breastfeeding at least three months postpartum once mothers had initiated breastfeeding. Chapter 5 describes the effectiveness of "A Breastfeeding Promotion and Support Program in the Netherlands: The Randomized Trial."

Chapter 6 discusses in a broader way the main findings of the four studies described in this thesis. Furthermore, we discuss the strengths and weaknesses, and give recommendations for further research, for promotion and support of breastfeeding in practice, and for health care policy with regard to breastfeeding.

\section{REFERENCES}

1. Lanting CI, Herschderfer K, Van Wouwe JP, Reijneveld SA. Peiling melkvoeding van zuigelingen 2001/2002 en het effect van certificering op de borstvoedingscijfers. Leiden: TNO-PG; 2002. Report No.: 2002.309.

2. Green LW, \& Kreuter MW. Health Promotion Planning: An Educational and Ecological Approach. 3th. ed: California: Mayfield Publishing Company; 1999.

3. De Vries H, Kok G. Gezondheidsbevordering. Een toepassing van het ABCplanningsmodel. Gedrag en Gezondheid 1996;24:342-352.

4. De Vries H, Mudde AN, Dijkstra A, Willemsen MC. Differential beliefs, perceived social influences, and self-efficacy expectations among smokers in various motivational phases. Prev Med 1998;27:681-9. 
5. De Vries H, Mesters I, Van der Steegh H, Honing C. The general public's information needs and perception regarding hereditary cancer: an application of the integrated change model. Patient Educ Couns (in press).

6. De Vries H, Leszwijn J, Hol M, Van der Steeg M. Skin Cancer Prevention: Behavior and Motives of Dutch Adolescents. Eur J Cancer Prevention (accepted).

7. De Vries H, Mudde A, Kremers S, Wetzels J, Uiters E, Ariza C, et al. The European Smoking Prevention Framework Approach (ESFA): short-term effects. Health Educ Res 2003;18:649-63.

8. Gerards F. Health Counseling: Baarn: H. Nelissen; ISBN 90244 139892,1997.

9. Gerards F, Hospers H. Health Counselling: a strategy to accompany patient guidance. Nederlands Tijdschrift voor Diëtisten 1991;46:132-137.

10. Gerards F. Health Counseling. In: Damoiseaux V, van der Molen HT, Kok GJ. (Eds). Health education and behavioral change. Assen: Van Gorcum 1993: 353-361.

11. Damoiseaux V, Kok GJ. The planning of health education interventions. In: Damoiseaux V, van der Molen HT, Kok GJ, editors. Gezondheidsvoorlichting en gedragsverandering. Assen: Van Gorcum 1993;75-86.

12. Bracht N. Health promotion at the community level 2, new advances. Thoasand Oaks, London, New Delhi: Sage Publications; 1999.

13. Rogers EM. Diffusion of Innovations. New York: The Free Press; 1995.

14. Flay BR, Allred CG, Ordway N. Effects of the Positive Action program on achievement and discipline: two matched-control comparisons. Prev Sci 2001;2:71-89.

15. De Vries H, Mudde A. Predicting stage transitions for smoking cessation applying The Attitude-Social Influence-Efficacy model. Psych Health 1998;13:369-85.

16. Bandura A. Social foundations of thought and action: A social cognitive theory. Englewood Cliffs: New York: Prentice Hall; 1986.

17. Ajzen I, Fishbein M. Understanding attitudes and predicting social behavior: Englewood Cliffs, Prentice Hall; 1980.

18. Janz NK, Becker MH. The Health Belief Model: a decade later. Health Education Quarterly 1984;11:1-47.

19. Prochaska JO, DiClemente CC, Norcross JC. In search of how people change: Applications to addictive behaviors 1992;47:1102-14.

20. Bolman C, De Vries H. Psycho-social determinants and motivational phases in smoking behavior of cardiac inpatients. Prev Med 1998;27:738-47.

21. Pieterse ME, Seydel ER, De Vries H, Mudde AN, Kok GJ. Effectiveness of a minimal contact smoking cessation program for Dutch general practitioners: a randomized controlled trial. Prev Med 2001;32:182-90.

22. Bolman C, De Vries H, Van Breukelen G. A Minimal-Contact Intervention for Cardiac Inpatients: Long-Term effects on Smoking Cessation. Prev Med 2002;35:181-92.

23. Bakker MJ, Mullen PD, De Vries H, Van Breukelen G. Feasibility of implementation of a Dutch smoking cessation and relapse prevention protocol for pregnant women. Patient Educ Couns 2003;49:35-43.

24. Randomized controlled trials: the Gold Standard for assessing new treat-ments. In. http://www.schoolscience.co.uk/content/5/biology/mrc/trials/page4.html.

25. Termote M, De Vries H, Kools EJ, Thijs C. Psycho-social factors associated with the duration of breastfeeding. A longitudinal study. Submitted for publication 2004. 



\begin{abstract}
The goal of this paper was to analyze breastfeeding behavior in the Netherlands, to describe the planning process for the development of a program for promoting breastfeeding in the Dutch health care system/situation and to discuss how the program has been evaluated and implemented. For this purpose, we used the $\mathrm{ABC}$ planning model, an integration of various health promotion planning and theoretical models for changing health behaviors. The model distinguished three basic phases in the process of health education and promotion: analysis of the problem; behavioral change; continued prevention by diffusion.
\end{abstract}




\section{INTRODUCTION}

In Europe, rates of breastfeeding vary but are in general low. In the Netherlands, $80 \%$ of mothers start to breastfeed their newborn, but only a small percentage continue to do so longer than a few months. ${ }^{1}$ Many initiatives have been developed; one shortcoming of these approaches was that they were often not grounded on health promotion planning principles. Studies in other fields have shown that the effectiveness of health promotion programs is greatly dependent on the quality of planning. ${ }^{2}$

For the planning of a breastfeeding promotion program in the Netherlands, we used the $\mathrm{ABC}$ model, which is an integration of various planning models (Figure 1). The ABC model can be viewed as a comprehensive model for systematically planning health education and promotion activities. ${ }^{3,4}$ The model integrates principles of the PrecedeProceed framework, ${ }^{2}$ its simplified version by Kok, ${ }^{5}$ the Community Change model, ${ }^{6}$ and Roger's Diffusion of Innovations theory. ${ }^{7}$ The ABC model has been successfully applied mainly for smoking, ${ }^{8}$ such as the development of prevention programs, ${ }^{9,11}$ community programs, ${ }^{12,13}$ cessation programs for general practitioners $^{14}$ and cardiologists, ${ }^{15}$ as well for the development of expert or computer tailored programs, ${ }^{16}$ but also for other health problems. ${ }^{17,18}$ The first phase, Analysis of the Health Problems, consists of five distinct steps, namely the problem identification, the problem factors, the target groups, the determinants of health promoting behavior, and the access points analysis. The second phase, Behavioral Change, builds on the results of the first phase and consists of three distinct steps: the development of overall goals and specific objectives that can be measured; the development and piloting of the program, and the testing of the program's effectiveness ${ }^{19}$ using a (quasi) experimental design. The third phase, Continuation, focuses on broad diffusion and implementation of effective programs for this. It is necessary to obtain support and intersectoral collaboration, in order to analyze facilitating and hindering factors for diffusion and to use this input for developing diffusion strategies.

The goal of the present paper is, first, to analyze the problem of low breastfeeding rates. We have compared the Dutch situation with the international literature in order to learn from differences and from initiatives elsewhere. Second, we describe the development of a home care based breastfeeding promotion program, its goals, the choices made, and the way it is evaluated. Third, an analysis is made of the factors that may facilitate and/or hinder future program diffusion.

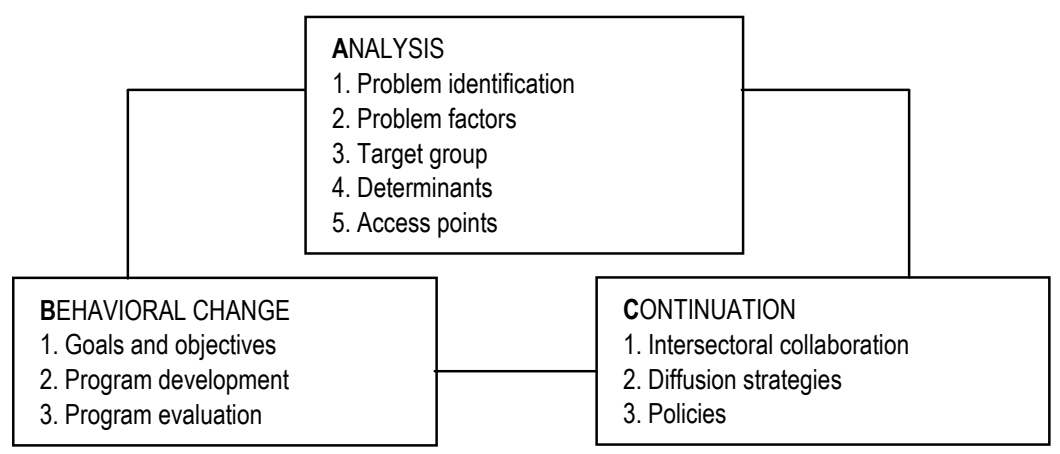

Figure 1 The $A B C$ model 


\section{METHODS}

\section{Definitions}

Exclusive breastfeeding is defined according the WHO definitions ${ }^{20}$ as breastfeeding without supplemental liquids or solid foods other than medicines or vitamins; and predominant breastfeeding, as breastfeeding with supplements of (sugar) water or water based drinks.

\section{Procedure}

In order to compare the Dutch situation with the international situation a systematic literature search was conducted in Medline (1966 to May 2003), The Cochrane Library 2003 Issue 4, Psychinfo (1966 to May 2003, Embase (1989 to May 2003) and on the internet website of the $\mathrm{WHO}^{21}$ and UNICEF. ${ }^{22}$ To identify the factors related to our problem i.e. (non) breastfeeding we conducted a search in Medline and in the WHO Global databank. ${ }^{23}$ Furthermore, to obtain the breastfeeding rates in Europe we contacted La Leche League Organization in Belgium and various authors of international publications in recent years. To identify the problem factors and the target group the following key words were used: "breastfeeding*" and "initiation", "duration", "weaning", "termination", "health promotion." References from potentially relevant studies were subsequently hand-searched for other studies. To identify the protective effects of breastfeeding the systematic search was restricted to meta-analyses, systematic reviews, randomized controlled trials, and cohort studies with less than $20 \%$ dropout, at least 100 participants in the high-risk group or at least 1000 participants in an unselected population, with blinded outcome and adequate control of confounding in multivariate analysis. To identify the behavioral determinants of the analysis phase, we used the key words "breastfeeding*", and "behavior", "intention", "attitude", "social influence", "self-efficacy." We attempted to identify Dutch studies published in national medical and health science journals, and studies published as reports. We searched on Internet, in the catalogs of the university and other libraries, e.g. from the Netherlands Organization for Applied Scientific Research (TNO), and we used references from relevant papers and reports. To identify the access points, we compared the Dutch literature with international intervention studies in order to identify what strategies were available to access pregnant women and young mothers. To determine which professional organizations and peer groups were responsible of breastfeeding in the Netherlands, we inspected official statements of professional societies, and we searched via the Internet.

\section{RESULTS}

\section{Analysis phase}

\section{Problem identification}

Epidemiological studies have demonstrated the health benefits of breastfeeding in industrialized countries, as they have previously done in developing countries. There is 
substantial evidence that exclusive breastfeeding confers either short or long term benefits on both mother and child (Table 1).

Table 1 Health effects of breastfeeding for mother and child

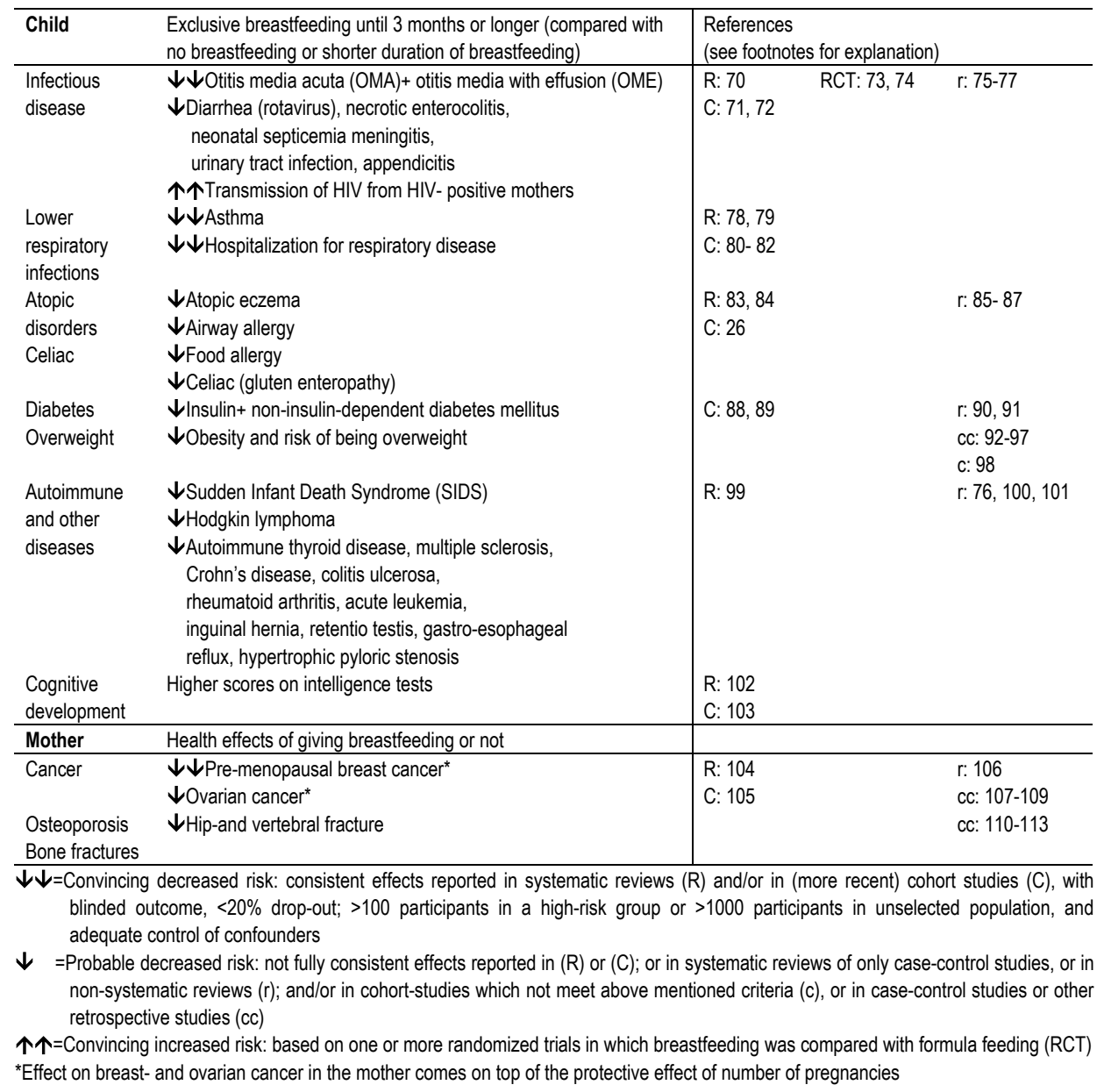

There are also limitations to the health benefits, or the proof thereof. Recent cohort studies have challenged the possible preventive effect against allergy and asthma, showing a possible deleterious effect on the child's asthma of breastfeeding by mothers who had asthma themselves ${ }^{24}$ or for allergy and asthma in the population as a whole. ${ }^{25,26}$ In addition, the causality of the association between breastfeeding and mother-infant bonding is difficult to prove in humans. The choice for breastfeeding may depend on preexisting maternal or social factors related to bonding, and breastfeeding continuation may be hampered by factors related to problematic bonding, for instance, when a mother cannot cope with a crying baby.

Nevertheless, the evidence in favor of health benefits of breastfeeding is overwhelming. Consequently, the international recommendation by the WHO is to stimulate mothers to perform exclusive breastfeeding for six months, with introduction of complementary 
foods and continued breastfeeding thereafter. ${ }^{20} \mathrm{~A}$ recent systematic review took notice of the benefits of exclusive breastfeeding for infants between four and six months. Thereby the pros were weighed against the possible cons, such as lower growth and the iron state of the infant. The conclusion was that with an adequate monitoring of the growth of the infant, the pros were larger than the cons. ${ }^{27}$

Breastfeeding rates vary greatly in Europe. There are countries with high initiation rates, such as the Scandinavian countries, Austria and Switzerland, and countries with lower initiation rates, such as Northern Ireland, Belgium and England and Wales (Table 2).

Table 2 Percentage of infants with exclusive breastfeeding in Europe

\begin{tabular}{|c|c|c|c|c|c|c|c|c|}
\hline Country (refs) & Year & At birth & $1 \mathrm{Mo}$ & $2 \mathrm{Mo}$ & $3 \mathrm{Mo}$ & $4 \mathrm{Mo}$ & $5 \mathrm{Mo}$ & $6 \mathrm{Mo}$ \\
\hline Iceland (23) & 2000 & & 88 & & 69 & 46 & & \\
\hline Sweden (23) & 1997 & & 94 & 81 & & 69 & & 42 \\
\hline Norway (114) & 1999 & & & & 92 & & & \\
\hline Finland (115) & 1995 & & & & & 68 & & \\
\hline Denmark (114) & 1992 & & 74 & 67 & 60 & 50 & 35 & 25 \\
\hline Scotland (114) & 1995 & 48 & & & & & & \\
\hline England+Wales (114) & 1995 & 62 & & & & & & \\
\hline Northern Ireland (114) & 1995 & 41 & & & & & & \\
\hline The Netherlands (1) & 2002 & 80 & 52 & 43 & 35 & 27 & 23 & 17 \\
\hline Belgium (Flanders) (128) & 2002 & $59^{* 11}$ & & & $25^{*}$ & $24^{*}$ & & \\
\hline Belgium (Walloon) (116) & 1998 & $63^{*}$ & & & & & & \\
\hline Luxembourg2) & $2001 / 02$ & & 64 & 59 & 52 & 40 & & \\
\hline Germany (23) & 1997 & & & 42 & & 33 & & 10 \\
\hline Poland (23) & 1997 & & 68 & 47 & 37 & 29 & 18 & 8 \\
\hline Hungary (23) & 1999 & & & & & 57 & & 29 \\
\hline Austria (23) & 1998 & & 92 & 85 & & & & 46 \\
\hline Switzerland (23) & 1994 & 92 & 80 & 71 & 48 & 32 & 11 & \\
\hline Italy (117) & 2000 & $78^{*}$ & & & & $45^{\star}$ & & \\
\hline Russia (23) & 1994 & 99 & & & & & & \\
\hline
\end{tabular}

${ }^{*} \mathrm{PBF}=$ predominant breastfeeding: breastfeeding with supplements of (sugar) water or water based drinks

$\mathrm{Mo}=$ month(s)

1) At the 5 th day postpartum

2) From the national breastfeeding coordinator in Belgium

In the Netherlands, the initiation rate of breastfeeding is intermediate, compared to other European countries, but only a small percentage of mothers continue to breastfeed their infant after a few months. In 2001, $80 \%$ of mothers started to breastfeed their newborn, but after the first month a sharp decline to $52 \%$ had occurred; after three months the percentage was $35 \%$, and after six months, it had fallen to $17 \%$. ${ }^{1}$ These percentages are low considering that the health effects increase with the duration of breastfeeding. 


\section{Problem factors}

Socio-cultural factors

The initiation and duration of breastfeeding have been positively associated with social class and educational level. ${ }^{28}$ Married women are significantly more likely to initiate breastfeeding than unmarried women. ${ }^{28}$ In the Netherlands, higher rates of breastfeeding were seen not only when the mother had a higher education, ${ }^{29,30}$ but also when the father had one. ${ }^{31}$

Cultural differences influence breastfeeding rates both between and within countries and when people move from one country to another. ${ }^{32}$ Within countries, there are often regional variations, which cannot completely be explained by socio-economic factors. ${ }^{33}$ Lower rates have been found consistently in the USA among black and Hispanic women when compared with white women. ${ }^{28}$ In the Netherlands, major differences in the initiation of breastfeeding are apparent amongst various ethnic groups. ${ }^{29}$

Most studies ${ }^{28}$ suggest that the intention to return to work is not negatively associated with the decision to breastfeed. However, women who did return to work had a shorter duration of breastfeeding.

With regard to commercial influences, advertisements, and media campaigns, a metaanalysis revealed that the distribution of commercial discharge packs with formula feeding had a detrimental effect on the duration of breastfeeding. ${ }^{34}$ The mass media promote a negative image of breastfeeding: in 1999 in the United Kingdom the television programs and newspapers showed formula feeding more often then breastfeeding and presented it as being less problematic; the health benefits of breastfeeding were rarely mentioned. ${ }^{35}$ Television commercials to promote breastfeeding created positive attitudes towards breastfeeding. ${ }^{36}$

\section{Psychological, behavioral and biological factors}

A review has reported that in some studies primiparas are more likely to initiate breastfeeding, while multiparas appear to continue breastfeeding for longer, but other studies have shown inconsistent results. ${ }^{28}$ Multiparas who had breastfed a previous baby were more likely to breastfeed than mothers who had not previously breastfed. ${ }^{37}$ Smoking women started less often with breastfeeding than non-smoking women and they weaned earlier. ${ }^{28}$ Mothers older than 25 years are more likely to choose to breastfeed and to breastfeed for longer periods than younger mothers. ${ }^{28}$ In the Netherlands, higher rates of breastfeeding were seen in older mothers ${ }^{30}$ and multiparas. ${ }^{29,30,38,39}$ Early mother-infant contact is associated with the breastfeeding duration on short and long term. $^{8}$ Breastfeeding on demand (unrestricted breastfeeding) is positively associated with the duration. It helps to prevent breast engorgement and associated problems. ${ }^{8}$

Lower rates of breastfeeding were seen in infants who were premature, dysmature or siblings. ${ }^{31}$ Early introduction of supplemental formula feeding and use of artificial teats (teats to protect the nipple) and pacifiers (dummies, soothers) ${ }^{28}$ resulted also in lower breastfeeding rates. Several studies have shown that the effect of a pacifier was only present if its use was continued for at least one month. ${ }^{8}$ A causal relation of these factors with the duration of breastfeeding has not been established, since it may be confounded by indication (sore nipples, crying babies). Combined oral contraceptives containing estrogen and progestagen decrease the milk output and adversely affect the duration. $^{40}$ 
Health care factors

Rooming-in (mother and baby 24 hours in the same room in the hospital) had beneficial effects on both initiation and duration. This effect may be partly because rooming-in made it easier to give feeding on demand. ${ }^{8} \mathrm{~A}$ review showed that there was no (consistent) association between Caesarean delivery and breastfeeding duration. ${ }^{28}$

With regard to breastfeeding promotion and support programs, since the 1980's there have been a number of key international and national initiatives to increase the rate of breastfeeding. Several organizations, such as La Leche League and the Association for Natural Breastfeeding, have been promoting breastfeeding for many years through national initiatives. Priority is given in perinatal health care to establishing breastfeeding as an integral part of the medical and nutritional management of pregnancy, childbirth, and infant feeding. A review ${ }^{8}$ has reported that postnatal breastfeeding support improves initiation and duration when it starts before discharge from the maternity facility; it enables mothers to establish breastfeeding, and prevents difficulties. Combinations of antenatal, in-hospital, and post-discharge support possibly act synergistically, but the evidence is weak. ${ }^{8}$ It is not exactly clear what kind of intervention is most effective. One-to-one counseling and help targeted at specific difficulties or crises of the mothers' confidence can be useful. Telephone calls are not useful on their own. ${ }^{8}$ Peer and lay support programs and individual or group health education sessions, delivered at a local level as part of a national program, have also been demonstrated to be effective. ${ }^{36,41}$ Institutional changes in hospital practices in order to promote breastfeeding can be effective at increasing both the initiation and duration, particularly in developing countries. These may include stand-alone interventions or combined interventions. ${ }^{36} \mathrm{~A}$ training program of the Baby Friendly Hospital Initiative led to improved hospital practices and higher breastfeeding rates at discharge and up to six months in highincome countries with modern healthcare systems. ${ }^{42}$ Use of lactation consultants improved the breastfeeding rates. ${ }^{43,44}$

In summary, the international literature reveals that the following factors are associated with the initiation and duration of breastfeeding: Both higher initiation rate and longer duration is seen in women with a higher social class, with a higher educational level, non working women, older women, multiparas, in women with previous breastfeeding experience, and non-smoking women. In addition, a longer duration is seen in married women and in those not using combined oral contraception after birth and it is associated with rooming-in, early mother-infant contact, feeding on demand, late introduction of formula supplements, and non-use of pacifiers and artificial teats. Whether these factors are causally related to breastfeeding is not always clear since many studies did not use a longitudinal design. With regard to breastfeeding promotion and support programs, postnatal breastfeeding support improved initiation and duration. One-to-one counseling improved the mother's confidence; peer group and lay support programs and health education sessions have also been shown to be effective. The Baby Friendly Hospital Initiative increased the rates of initiation and duration and the use of lactation consultants improved also the breastfeeding rates. Most of the effective programs used a mix of interventions.

\section{Target groups}

This section provides an overview of the groups that are relevant to target interventions. First, we review the target groups actually included in intervention studies, ${ }^{8,28}$ reviewed 
earlier by Fairbank. ${ }^{36}$ We compare the Dutch situation with the international literature. We found no Dutch intervention studies, and only a few cohort studies were available. $^{29,30,38,39}$

At the micro level, participants in intervention studies were pregnant women attending antenatal clinics, booked for antenatal care or for delivery, women who gave birth at the hospital, having their first baby in hospital, mothers with infants from 0-8 months, and mothers attending welfare clinics. ${ }^{36}$ Some studies included high-risk groups, such as younger mothers, or mothers with low incomes. Fathers were not listed as being approached. In the Netherlands, participants were pregnant women or women who wanted to give birth in hospital or mothers with a newborn who made use of the services of the child health care organization.

At the meso level, intermediaries in intervention studies were health staff of hospitals, health professionals, midwives, dieticians, lactation consultants, general practitioners, and peer support counselors. ${ }^{36}$ In the Netherlands, pediatricians, midwives, caregivers of the maternity and child health care, and lactation consultants are all involved in counseling of breastfeeding. For promotion and support of breastfeeding, it is important that the intermediaries reach the majority of (pregnant) mothers. In the Netherlands, peer counselors of La Leche League and of the Association for Natural Breastfeeding are active, but have a low reach because of problems with recruitment and continuity of the counselors. Pediatricians only reach mothers with sick infants. Midwives are very appropriate because they provide $76 \%$ (in 1998) of the prenatal obstetrical care; the rest of the obstetrical care is provided by general practitioners $(16 \%$ in 1998) and gynecologists. ${ }^{45}$ In the Netherlands, the maternity care concerns the prenatal care by a maternity nurse during the prenatal home visit and the postnatal care by a maternity assistant during the childbed until eight days after birth. Seventy-seven percent of the families ask for maternity care from the Home Health Care organization and the rest from the private organizations. After the birth, $97 \%$ of the mothers with a newborn visit the free service of the child health care regularly in the first year, where both nurses and doctors see them approximately monthly. The service offers prevention programs for children from birth up to the age of 19 years. The child health care is provided by the Home Health Care organizations for over $95 \%$ of the children and by private organizations in the remainder, mostly related to complementary medicine. A minority of health care centers employs certified lactation consultants, but others persons offer paid consultation as freelancers. They are potentially important intermediaries for support of breastfeeding for mothers with breastfeeding difficulties, but the extent to which their services are used in the Netherlands is not known.

At the macro or policy level, in 1981 the WHO adopted the International Code of marketing and of breastmilk substitutes ${ }^{46}$ which code prohibits aggressive infant formula market strategies. In 1991, UNICEF and the WHO introduced the international "Baby Friendly Hospital Initiative" campaign. In the Netherlands, several professional and breastfeeding organizations have been developing policies for promoting breastfeeding such as the "Baby Friendly Hospital Initiative" campaign (1996), and guidelines have been published, such as "the Standard for Breastfeeding",47 and the Guideline for Infant Feeding. ${ }^{48}$ In 2002, the national "Platform Breastfeeding" was established by the Ministry of Health, Welfare, and Sport, the goal of which was to follow the WHO recommendation to stimulate more women to give breastfeeding for at 
least six months through cooperation between professionals and breastfeeding organizations. ${ }^{20}$

\section{Behavioral determinants of breastfeeding}

International studies have revealed the impact of knowledge, attitudinal, social, and selfefficacy factors. In the Netherlands, a few studies using the ASE model have shown similar findings (Table 3).

Table 3 Results of studies on breastfeeding based on models of behavior and of behavioral change

\begin{tabular}{llc}
\hline Determinants & Model & Reference \\
\hline Intention & TRA & 118 \\
Previous behavior & TRA+TPB & 119 \\
Attitudes more predictive than norms & TRA & 120 \\
Social influence of significant other & TRA+TTM & 121 \\
Subjective norms & ASE & 122 \\
Positive attitude to BF, positive social norm, social pressure to FF & TPB & 123 \\
Prenatal attitudes, self-efficacy & & 120 \\
\hline Initiation & TRA & 13 \\
Self-efficacy (of pregnant women) & TRA \\
\hline Duration & TRA & 124 \\
Intended duration & ASE & 122 \\
Intention only if conditioned by enabling social support and subjective norms & ASE \\
Self-efficacy & TBP & 60 \\
Intention, social norm at work, self-efficacy & & 123 \\
Intentions (weakly) & & \\
\hline BF=breastfeeding; FF=formula feeding & & \\
TRA=Theory of Reasoned Action ${ }^{125,126}$ & & \\
TPB=Theory of Planned Behavior & & \\
TTM=Transtheoretical Model59 & & \\
ASE=Attitude Social influence Self Efficacy model61 & &
\end{tabular}

Determinants of breastfeeding intention were a positive attitude to breastfeeding, a positive social norm, and low social pressure to formula feeding. Positive breastfeeding experience was a predictor of breastfeeding intention. Furthermore, it was found that women wish to get more information and knowledge in order to realize their choice of infant feeding. The most important predictors of the duration of breastfeeding were the intention to continue breastfeeding, self-efficacy, and social norm at work. Women need instruction about how to breastfeed because most of them are unable to breastfeed for as long as they would like to. ${ }^{49}$

\section{Access point analysis}

The access point analysis concerns the inventory how best to reach the target groups for an intervention.

With regard to the micro level, a review ${ }^{36}$ has suggested several ways to access (pregnant) mothers, such as group education or counseling sessions during hospital stay; prenatal or/and postnatal home visits by nurse or community based health promoters; clinic visits; phone calls; contacts with midwives and physicians; peer or lay counselors; 
lactation consultants; distribution of educational material; and videos, posters, and media campaigns. In the Netherlands, pregnant women visit their midwives on a regular basis during pregnancy until six weeks after the birth; at that moment, they receive also support of breastfeeding. The maternity care and the child health care of the Home Health Care provide group education, prenatal and postnatal home visits, and assistance during the childbed, as well as consultations. The Association for Natural Breastfeeding and La Leche League organize information meetings, have information lines, and distribute leaflets. Lactation consultants give professional support to mothers and caregivers, but their service is only available to a limited extent and is not reimbursed by the health insurance. From the analysis phase, we know which women are at risk for low rates. There are two possibilities to reach pregnant or breastfeeding women: to approach all pregnant or breastfeeding women or only those pregnant or breastfeeding women who are at high risk for not breastfeeding. Special attention is necessary for low social class, low educational level, and younger mothers.

With regard to the meso level, the Dutch Health Care system is very different from other countries. In the Netherlands, midwives work independently in private practices (solo, or group) and are organized in regional networks. They should therefore be reached through these networks. Lactation consultants work in the hospitals, at child health centers or in private practices. The Guideline for Infant Feeding of the Health Care Inspectorate ${ }^{48}$ does not delineate the task and responsibilities of each professional group in relation to breastfeeding. The knowledge of breastfeeding of most of the Dutch pediatricians was shown to be insufficient ${ }^{50}$ and Dutch medical handbooks and teaching materials pay little attention to breastfeeding. ${ }^{51}$ Hence, access also implies improving these deficiencies.

With regard to the macro level, professional organizations can now be reached through the national "Platform Breastfeeding" founded in 2001. The Nutrition Center is responsible for the coordination of this platform.

\section{Summary of the analysis and implications for the development of a breastfeeding promotion program in the Netherlands}

- Breastfeeding for six months has health benefits for mother and child. In the Netherlands, the initiation rate of breastfeeding is high, but there is a rapid decline in the first months. Three months breastfeeding is a realistic goal with considerable health benefits for all.

- Promotion and support of breastfeeding is beneficial for the whole population, because early weaning does not differ so much between low and high-risk groups. With regard to the access points, special attention is necessary for low social class, poorly educated groups, younger women, smoking women and ethnicity. In the Netherlands, almost every woman can be reached through the maternity care; therefore, we have chosen all women attending maternity care as the target group.

- Intervention programs are effective if there is a mix of interventions. The use of lactation consultants improves breastfeeding rates.

- Behavioral determinants of breastfeeding intention are a positive social norm, attitude, and low social pressure to formula feeding. Positive previous breastfeeding experience predicts breastfeeding intention. The most important 
predictors of the duration of breastfeeding are the intention to continue, selfefficacy, and social norm at work. Local studies of determinants at the micro level and barriers at the meso level based on the ASE model are important. Development and implementation of interventions are needed based on this model and on stage of change. Findings of such studies in the Netherlands have suggested that mothers need more information and support for the realization of their choice. Therefore, emphasis in the contemplation and initiation phase of breastfeeding should be on attitudinal and social support, while in the continuation phase early signaling of breastfeeding difficulties, support at work and self-efficacy need the emphasis.

- In the Netherlands, we have noted a lack of cooperation and continuity of care together with insufficient uniformity in advices between the professionals of different organizations.

- Lactation consultancy is possibly underused.

\section{Behavioral change}

During the phase of behavioral change, goals and objectives of interventions are identified, methods are developed and the resulting program is evaluated. We provide a description of this process for our Dutch intervention program, based on the implications of the analysis phase.

\section{Goals and objectives}

The objective of our program was to stop women weaning early and to enhance the breastfeeding rate at three months by $10 \%$, from $21 \%$ (in 1999) to $31 \%$. The rationale for the choice for three months was based on the health benefits of breastfeeding for six months and the high rate of cessation in the first months. Therefore, the greatest benefits for the population would be gained by increasing breastfeeding rates in the first months. Hence, we formulated our operational goals as follows: to strengthen the support of breastfeeding (continuation) in addition to promotion of breastfeeding (initiation), by intervening on behavioral determinants of the duration of breastfeeding by:

(1) Health counseling: to enhance the caregiver's performance to promote and support breastfeeding, using health-counseling principles.

(2) Cooperation and continuity: to enhance cooperation, early signaling of breastfeeding problems and continuity of care by transfer of information on individual mothers between caregivers.

(3) Lactation consultancy: to enhance access to lactation consultants and to take away financial and practical barriers for consulting them.

\section{Program development}

Our program consisted of interventions targeting groups at micro and meso levels. At the micro level, we addressed pregnant women in their seventh month of the pregnancy until six months after birth in order to draw attention and to create positive motivation towards breastfeeding, and to support breastfeeding after birth. 
We developed a booklet to support breastfeeding, to enhance cooperation between caregivers of the maternity care and child health care systems, for early signaling of breastfeeding problems and for transfer of information between caregivers. In this booklet, we described the steps and mentioned the barriers mothers could encounter during each regular contact with caregivers. The maternity nurse distributed this booklet to each woman during the prenatal home visit and asked her to log her breastfeeding barriers, problems, and motivation to continue before each next regular contact with the caregivers. The caregivers used the booklet during each contact. In this booklet, the mother could also find a telephone number to reach the caregiver in case breastfeeding questions or problems arose.

For the caregivers we developed a protocol "Breastfeeding Step by Step" and a onepage summary for each group of caregivers: for the maternity nurse and for the child health care nurse and physician. The participation of the midwives in our study could not be guaranteed since their workload had increased in recent years. Therefore, caregivers of maternity and child health care organizations and lactation consultants remained the most appropriate intermediaries. The aim of this summary was a prompt for the steps and a resource for answering the questions. The summary consisted of answers to the most frequent questions and barriers regarding early weaning which women encountered with breastfeeding. In order to facilitate the counseling process for caregivers the Health Counseling model was chosen ${ }^{52-54}$ since this model had already been applied successfully to other health promoting behaviors, such as smoking prevention. ${ }^{14,15,55}$ Both process and effect evaluations revealed its feasibility, appeal and effectiveness. ${ }^{15}$ The Health Counseling model was based on theories of behavioral change. The Health Counseling process consisted of three phases: Preparation of the advice, Implementation of the advice and Maintenance. We worked the phases out in six steps using a program matrix to facilitate program development, a strategy suggested by McGuire ${ }^{56}$ and further adapted for health promotion ${ }^{57,58}$ (Table 4).

The program matrix integrated intervention factors with the Stages of Change: precontemplation, contemplation, preparation, action, and maintenance. ${ }^{59}$ Message factors described the characteristics of effective messages, channel factors referred to the methods by which messages were delivered, and source factors referred to the characteristics of caregivers who provided the program and messages.

In a four-hour session, we trained the caregivers in using the program and in counseling skills by demonstration and role-play, and gave instruction how to use the devices for early signaling of breastfeeding problems and cooperation between caregivers. The training was followed by a lesson of two hours about the role of lactation consultants and the indications for referring mothers to them. Practical problems were discussed during two refresh trainings of two hours. The following actions were undertaken to reduce financial and practical barriers for consulting lactation consultants: three lactation consultants in the region were appointed and paid by the research group of Maastricht University and their services were made free of charge. We made an agreement about the indications and procedures for referrals to them. The caregivers could fax their concerns or queries about breastfeeding on a structured form to the lactation consultant. After receiving the fax, the lactation consultant contacted the caregiver or the mother within 24 hours and tried to resolve the problems. If needed, the consultant could make home visits or follow-up calls. 
Table 4 An application of the program matrix to breastfeeding

\begin{tabular}{|c|c|c|c|}
\hline Steps & Message & Channel & Source \\
\hline $\begin{array}{l}\text { Step } 1 \text { Knowledge } \\
\text { Step } 2 \text { Motivation } \\
\text { Step } 3 \text { Ability } \\
\text { Step } 4 \text { Intention }\end{array}$ & $\begin{array}{l}\text { Supply information about BF } \\
\text { health benefits } \\
\text { Motivation to give BF? } \\
\text { Raise motivation } \\
\text { If necessary give more } \\
\text { information } \\
\text { Cope with barriers } \\
\text { Discuss/ show the way of } \\
\text { coping } \\
\text { Probe intention towards BF }\end{array}$ & $\begin{array}{l}\text { Prenatal home visit: } \\
\text { - Personal communication } \\
\text { - Leaflet } \\
\text { - Mother's booklet }\end{array}$ & $\begin{array}{l}\text { Maternity nurse } \\
\text { Lactation consultant }\end{array}$ \\
\hline Step 5 Practice & $\begin{array}{l}\text { Give practical instructions how } \\
\text { to give BF }\end{array}$ & $\begin{array}{l}\text { Home visit during childbed: } \\
\text { - Personal communication } \\
\text { - Mother's booklet }\end{array}$ & $\begin{array}{l}\text { Maternity assistant } \\
\text { Child health care } \\
\text { nurse } \\
\text { Lactation consultant }\end{array}$ \\
\hline Step 6 Continuation & Support women to continue BF & $\begin{array}{l}\text { Home visit/ consultations: } \\
\text { - Personal communication } \\
\text { - Mother's booklet } \\
\text { - Telephone calls }\end{array}$ & $\begin{array}{l}\text { Child health care } \\
\text { nurse } \\
\text { Child health care } \\
\text { physician } \\
\text { Lactation consultant }\end{array}$ \\
\hline
\end{tabular}

$\mathrm{BF}=$ breastfeeding

\section{Program evaluation and design}

The project started in 2000. We used a cluster-randomized design for the trial, which took place from December 2000 until December 2002. Ten child health care centers in three regions were randomly assigned to the program (intervention centers) or gave the usual care (control centers). Pregnant women who applied for maternity care in the intervention or control centers were enrolled and followed up from pregnancy until six months after giving birth. The primary endpoint was the rate of exclusive breastfeeding at three months. The sample size was calculated for an expected increase of $10 \%$ breastfeeding at three months (from $21 \%$ in the control centers to $31 \%$ in the intervention centers). With an alpha of 0.05 (for a one tailed test), a power of $80 \%$, we needed 253 participants in each group with complete follow up. Assuming a dropout rate of $25 \%$, we needed to include 300 pregnant women at baseline in each group. The questionnaires for (pregnant) mothers were based on the results of a preceding study concerning determinants of breastfeeding. ${ }^{60}$

The questionnaires for the caregivers to assess their motivation to provide breastfeeding counseling were also based on the ASE model. The objective was evaluated at two levels: at the level of the participants and at the level of caregivers and lactation consultants. Table 5 summarizes the instruments used for the evaluation. 
The ABC of Breastfeeding

Table 5 The evaluation of the goals by mothers, caregivers, and lactation consultants

\begin{tabular}{|c|c|c|c|c|c|}
\hline & & Mothers & Caregivers & & $\begin{array}{l}\text { Lactation } \\
\text { 1) }\end{array}$ \\
\hline \multirow[t]{2}{*}{ Goals } & Methods & Questionnaires & Registry form & Questionnaire & Structured form \\
\hline & & $\begin{array}{l}\text { BF at } 7-8 \text { mo } \\
\text { gestation } \\
\text { BF at } 1,3,6 \text { mo p.p. }\end{array}$ & $\begin{array}{l}\text { BF at 1, 3, } 6 \\
\text { mop.p. }\end{array}$ & $\begin{array}{l}3 \text { Mo after last } \\
\text { mother was } \\
\text { enrolled }\end{array}$ & $\begin{array}{l}\text { Record at each } \\
\text { contact }\end{array}$ \\
\hline $\begin{array}{l}\text { Primary } \\
\text { outcome }\end{array}$ & $\begin{array}{l}\text { Effectiveness } \\
\text { of the program }\end{array}$ & $\begin{array}{l}\text { Prenatal BF intention } \\
\text { BF at } 1,3,6 \text { mo p.p. }\end{array}$ & $\begin{array}{l}\text { BF at } 1,3,6 \\
\text { mo p.p. }\end{array}$ & & \\
\hline \multirow{4}{*}{$\begin{array}{l}\text { Secondary } \\
\text { outcomes } \\
\text { (related to } \\
\text { operational } \\
\text { goals) }\end{array}$} & $\begin{array}{l}\text { 1. Strengthen } \\
\text { BF support }\end{array}$ & $\begin{array}{l}\text { ASE determinants of } \\
\text { BF initiation+ } \\
\text { duration }\end{array}$ & & $\begin{array}{l}\text { ASE determinants } \\
\text { of } \mathrm{HC}\end{array}$ & \\
\hline & $\begin{array}{l}\text { 2. Enhance } \\
\text { caregiver's } \\
\text { performance }\end{array}$ & $\begin{array}{l}\text { Satisfaction of: } \\
\text { - Infant feeding } \\
\text { advice } \\
\text { - Reach of caregivers }\end{array}$ & & $\begin{array}{l}\text { Promotion of BF } \\
\text { Time spent on } \mathrm{HC} \\
\text { Satisfaction of } \\
\text { program }^{1)}\end{array}$ & \\
\hline & $\begin{array}{l}\text { 3. Enhance } \\
\text { - Cooperation } \\
\text { - Early signaling } \\
\text { - Continuity of care }\end{array}$ & $\begin{array}{l}\text { Uniformity of advice } \\
\text { Use and satisfaction } \\
\text { of mother's booklet }\end{array}$ & & $\begin{array}{l}\text { Perceived } \\
\text { cooperation } \\
\text { Continuity of care } \\
\text { Uniformity of } \\
\text { advice }\end{array}$ & $\begin{array}{l}\text { Record of } \\
\text { problems and } \\
\text { advice }\end{array}$ \\
\hline & $\begin{array}{l}\text { 4. Take away } \\
\text { - Financial barriers } \\
\text { - Practical barriers to } \\
\text { lactation consultants }\end{array}$ & $\begin{array}{l}\text { Reasons and number } \\
\text { of references to: } \\
\text { - Lactation } \\
\text { consultants } \\
\text { - Home physicians }\end{array}$ & & & $\begin{array}{l}\text { Record of } \\
\text { - Reasons+ } \\
\text { number of } \\
\text { references } \\
\text { - Number of } \\
\text { contacts } \\
\text { - Follow-up } \\
\text { activities } \\
\text { - Time spent on } \\
\text { consultation }\end{array}$ \\
\hline
\end{tabular}

1) Only in intervention group

$\mathrm{BF}=$ breastfeeding

$\mathrm{HC}=$ Health Counseling

Mo=months

p.p. $=$ postpartum

\section{Continuation}

Traditionally, while efforts for continuation often take place after the development of an intervention, ${ }^{7}$ health promotion theories and practice suggest that developing ownership with the intervention should be developed as early as possible. ${ }^{2,6,61}$ Hence, various steps were undertaken to facilitate this process.

\section{Intersectoral collaboration}

We considered that intersectoral collaboration between our research team and organizations that were actively involved in breastfeeding promotion was important for the quality of the evaluation and for the subsequent implementation of the program. As a model for intersectoral collaboration, we chose the linkage approach ${ }^{62}$ (Figure 2). All groups involved in the promotion of breastfeeding are represented in a linkage system. 
The establishment of a linkage group enables stakeholders to participate in the process of program preparation, testing, and diffusion. It is important to realize the advantages or disadvantages for them to participate, and to create a synergy. In the perfect situation, the linkage group consists of representatives of the research, resource, target, support, and intermediary finance groups. ${ }^{58}$ The Home Health Care initiated the development of the program in cooperation with Maastricht University. Early in the process of development, a steering committee was set up to serve as a linkage group. This committee included members of organizations involved in the promotion of breastfeeding at the macro level, such as the Royal Dutch Organization of Midwives, the Dutch Association of Child Health Care, the Dutch Association for Lactation Consultants, the Care for Breastfeeding Foundation and the Association for Natural Breastfeeding. Issues, which were discussed at regular meetings, were, for instance, the goals and objectives of the program, the development of the materials, the publication plan, the design of the evaluation study and implementation strategies.

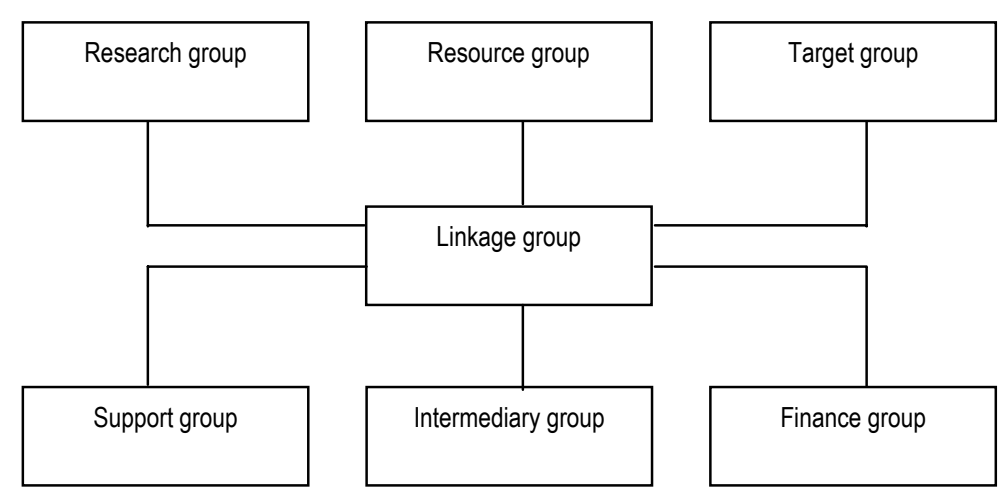

Figure 2 The linkage group

\section{Diffusion strategies}

The goal of this step was to evaluate the factors (motivational, financial, structural) that stimulate or hinder program providers and users to adopt, implement, and continue the program. Therefore, it was important to assess the determinants of adoption in order to tailor the diffusion strategies. ${ }^{63}$

\section{Policies}

To achieve successful adoption and implementation of a breastfeeding promoting and supporting intervention, supportive policies may be needed to facilitate diffusion in a broader context. Breastfeeding is a subject of political discussion, the Ministry of Health, Welfare, and Sport established the national "Platform Breastfeeding." Hence, effective programs will need to be integrated in a National promotion program such as the Master Plan, elaborated by the national "Platform Breastfeeding". To realize 
continuity of advice, the program duration has to be extended and should include groups that had not yet been included, such as midwives, caregivers of the maternity care, child health care and the departments of pediatrics in the hospitals. Program dissemination will be facilitated using their expertise and networks.

At the meso level, adoption and implementation by organizations such as the Royal Dutch Organization of Midwives and the Youth Health Care will be facilitated if this task becomes a standard procedure within their care systems. Integrating the training protocol into the general curriculum for midwives and caregivers or in the training for the Baby Friendly Hospital Initiative can also stimulate facilitation of adoption. Caregivers must obtain sufficient time to counsel mothers on breastfeeding behavior and to follow training in the program and both caregivers and mothers must have free access to lactation consultants. Furthermore, standard monitoring of breastfeeding rates (based on WHO definitions) needs to be built up throughout Europe.

\section{DISCUSSION}

There are several planning models; all promote a step-wise approach to health problems. ${ }^{64,65}$ All the models differ in their details but each acknowledges distinct stages in their planning process, requiring different research strategies. A precondition for program development is the analysis of the determinants and barriers at the micro level (of the pregnant mother) and at the meso level (of the health intermediaries). We have already described the results of studies on behavioral determinants that used several models. For the planning of our intervention, we studied the behavioral determinants using the ASE model. ${ }^{60}$ We notice that all studies (including ours) focused on the micro level and not on the meso level. For an optimal application of the program after implementation, it is necessary to promote, support, and evaluate the application by the health intermediaries. For a thorough insight in the effect of the program, it is important that the program be evaluated both at the micro and at the meso levels. This exemplifies the advantage of a planning model so that the steps and decisions can be made clear and become open for discussion. This approach is more likely to avoid certain pitfalls, such as the development of interventions addressing the wrong determinants, the utilization of materials not suited for the target group, insufficient anticipation of implementation, or lack of motivation for implementation of the program by caregivers or organizations.

The Home Health Care initiated our program, and this setting limited the choices of target groups and access points at the meso level. We noticed that the ABC model paid no attention to empowerment. During the process, we realized that empowerment could have an added value in the development of the program by involving local persons such as caregivers, mothers, or peer groups. ${ }^{66}$ In the paper of Scott et al, ${ }^{67}$ the basis for the linkage approach in the $\mathrm{ABC}$ model, the role of empowerment of stakeholders at the micro level is undervalued.

The choice of a randomized trial to evaluate the program implies certain restrictions, such as the choice of professionals to be included in the intervention. We could not employ midwives, maternity assistants or pediatricians in our program since their practices overlapped the child health care centers to such an extent that it would not be possible to separate intervention and control centers. Furthermore, we were limited to reporting, we could not report in local magazines and in the mass media, so that 
elements from the intervention could not contaminate the control regions. Another disadvantage was the long duration of the trial and limited possibilities for any interim evaluation and improvement during it. Such restrictions are inherent in multiintervention trials but can be resolved by small trials of separated elements. This is the subject of the current debate on the new health promotion. ${ }^{68,69}$

\section{ACKNOWLEDGEMENTS}

The development and evaluation plan was submitted as a grant proposal for the National Prevention Program of ZONMw ("Netherlands Organization for Health Research and Development") approved in 1999 and started in 2000. The authors would like to thank ZONMw and the CZ-group for their financial support. Furthermore, we would like to express our gratitude to the following Home Health Care organizations for their collaboration: The Home Health Care West-Mining Area, The Home Health Care Middle-Limburg, and ZorggroepThuis South-East Limburg. Finally, we would like to thank the members of the steering committee for their advice and support during the research project.

\section{REFERENCES}

1. Lanting CI, Herschderfer K, Van Wouwe JP, Reijneveld SA. Peiling melkvoeding van zuigelingen 2001/2002 en het effect van certificering op de borstvoedingscijfers. Leiden: TNO-PG; 2002. Report No.: 2002.309.

2. Green LW, \& Kreuter MW. Health Promotion Planning: An Educational and Ecological Approach. 3th ed: California: Mayfield Publishing Company; 1999.

3. De Vries H, Mudde AN, Dijkstra A, Willemsen MC. Differential beliefs, perceived social influences, and self-efficacy expectations among smokers in various motivational phases. Prev Med 1998;27:681-9.

4. De Vries H, Kok G. Health promotion:an application of the ABC planning model. Gedrag en Gezondheid 1996;342-52.

5. Damoiseaux V, Kok GJ. The planning of health education interventions. In: Damoiseaux V, van der Molen HT, Kok GJ, editors. Gezondheidsvoorlichting en gedragsverandering. Assen: Van Gorcum; 1993:75-86.

6. Bracht N. Health promotion at the community level 2, new advances. Thoasand Oaks, London, New Delhi: Sage Publications; 1999.

7. Rogers EM. Diffusion of Innovations. New York: The Free Press; 1995.

8. WHO. Evidence for the ten steps to successful breastfeeding. Geneva; 1998.

9. De Vries H, Weijts W, Dijkstra M, Kok GJ. The utilization of qualitative and quantitative data for health education program planning, implementation, and evaluation: a spiral approach. Health Educ Q 1992;19:101-15.

10. De Vries H, Backbier E. Self-efficacy as an important determinant of quitting among pregnant women who smoke: the phi-pattern. Prev Med 1994;23:167-74.

11. Dijkstra M, De Vries H, Parcel GS. The linkage approach applied to a school-based smoking prevention program in The Netherlands. J School Health 1993;63:339-42.

12. Mudde AN, De Vries H. The reach and effectiveness of a national mass media-led smoking cessation campaign in The Netherlands. Am J Public Health 1999;89:346-50. 
13. Mudde AN, De Vries H, Dolders MG. Evaluation of a Dutch community-based smoking cessation intervention. Prev Med 1995;24:61-70.

14. Pieterse ME, Seydel ER, De Vries H, Mudde AN, Kok GJ. Effectiveness of a minimal contact smoking cessation program for Dutch general practitioners: a randomized controlled trial. Prev Med 2001;32:182-90.

15. Bolman C, De Vries H, Van Breukelen G. A minimal-contact intervention for cardiac inpatients: long-term effects on smoking cessation. Prev Med 2002;35:181-92.

16. Ausems M, Mesters I, Van Breukelen G, De Vries H. Short-term effects of a randomized computer-based out-of-school smoking prevention trial aimed at elementary schoolchildren. Prev Med 2002;34:581-9.

17. De Nooijer J, Lechner L, De Vries H. Tailored versus general information on early detection of cancer: a comparison of the reactions of Dutch adults and the impact on attitudes and behaviors. Health Educ Res 2002;17:239-252.

18. Bakker RH, Groenewegen PP, Jabaaij L, Meijer W, Sixma H, De Veer A. 'Burnout' among Dutch midwives. Midwifery 1996;12:174-81.

19. Flay BR, Allred CG, Ordway N. Effects of the Positive Action program on achievement and discipline: two matched-control comparisons. Prev Sci 2001;2:71-89.

20. WHO. The optimal duration of exclusive breastfeeding. Results of a WHO systematic review. In. www.who.int/inf-pr-2001/en/note2001-07.html ed: World Health Organization; 2001.

21. WHO. WHO internet website. In. www.who.int ed.

22. UNICEF. UNICEF internet website. In. www.unicef.org/htcgi/htsearch ed.

23. WHO. Nutrition Data Banks. Global Data Bank on breastfeeding. In: www.who.int/nut/db_bfd.htm ed. Geneva: Nutrition Breastfeeding System, World Health Organization; 2002.

24. Wright AL, Holberg CJ, Taussig LM, Martinez F. Material asthma status alters relation of infant feeding to asthma childhood. Adv Exp Med Biol 2000;478:131-7.

25. Sears MR, Greene JM, Willan AR, Taylor DR, Flannery EM, Cowan JO, et al. Long-term relation between breastfeeding and development of atopy and asthma in children and young adults: a longitudinal study. Lancet 2002;360:901-7.

26. Wetzig H, Schulz R, Diez U, Herbarth O, Viehweg B, Borte M. Associations between duration of breast-feeding, sensitization to hens' eggs and eczema infantum in one and two year old children at high risk of atopy. Int J Hyg Environ Health 2000;203:17-21.

27. Kramer MS, Kakuma R. Optimal duration of exclusive breastfeeding (Cochrane Review). Cochrane Library. Oxford: Update Software 2002 (Issue 1).

28. Scott JA, Aitkin I, Binns CW, Aroni RA. Factors associated with the duration of breastfeeding amongst women in Perth, Australia. Acta Paediatr 1999;88:416-21.

29. Van der Wal MF. Breast feeding among autochthonous and allochthonous mothers in Amsterdam, 1992-1993. Ned Tijdschr Geneeskd 1995;139:19-22.

30. Bulk Bunschoten AMW, Van Bodegom S, Reerink JD, Pasker de Jong PCM, De Groot CJ. Reluctance to continue breastfeeding in The Netherlands. Acta Paediatr 2001;90:10471053.

31. Burgmeijer RJF. Groei van borstgevoede kinderen. In: Centrum TPeGLUM, editor. De vierde Landelijke Groeistudie. Presentatie nieuwe groeidiagrammen; 1998. p. 37-53.

32. Perez-Escamilla R. Breastfeeding in Africa and the Latin American and Caribbean region: the Potential Role of Urbanization. J Trop Pediatr 1994;40: 137-43.

33. Martinez GA, Dodd DA, Samartgedes JA. Milk feeding patterns in the United States during the first 12 months of life. Pediatrics 1981;68:863-8.

34. Perez Escamilla R, Pollitt E, Lonnerdal B, Dewey KG. Infant feeding policies in maternity wards and their effect on breast-feeding success: an analytical overview. Am J Public Health 1994;84:89-97. 
35. Henderson L, Kitzinger J, Green J. Representing infant feeding: content analysis of British media portrayals of bottle feeding and breast feeding. BMJ 2000;321: 1196-1198.

36. Fairbank L, O'Meara S, Renfrew MJ, Woolridge M, Sowden AJ, Lister Sharp D. A systematic review to evaluate the effectiveness of interventions to promote the initiation of breastfeeding. Health Technol Assess 2000;4:1-171.

37. Rogers IS, Emmett PM, Golding J. The incidence and duration of breast feeding. Early Human Dev 1997;49 Suppl:S45-74.

38. Van Hagen EE, Van Wouwe JP, Van Buuren S, Burgmeijer RJF, Hirasing RA, De Jonge GA. Peiling veilig slapen 1999. Leiden: TNO-PG; 2000. Report No.: PG/JGD/2000.047.

39. Brugman E. Peilingen in de jeugdgezondheidszorg PGO-Peiling 1997/1998. Leiden: TNO PG; 1999. Report No.: 90-6743-608-9.

40. Anonymous. Progestogen-only contraceptives during lactation: I. Infant growth. World Health Organization Task force for Epidemiological Research on Reproductive Health; Special Program of Research, Development and Research Training in Human Reproduction. Contraception 1994;50:35-53.

41. Haider R, Ashworth A, Kabir I, Huttly SRA. Effect of community-based peer counselors on exclusive breastfeeding practices in Dhaka, Bangladesh: a randomized controlled trial. The Lancet 2000;356:1643-1647.

42. Cattaneo A, Buzzetti R. Effect on rates of breast feeding of training for the baby friendly hospital initiative. BMJ 2001;323:1358-62.

43. Quarles A, Williams PD, Hoyle DA, Brimeyer M, Williams AR. Mothers' intention, age, education and the duration and management of breastfeeding. Matern Child Nurs $\mathrm{J}$ 1994;22:102-8.

44. Humphreys AS, Thompson NJ, Miner KR. Intention to breastfeed in low-income pregnant women: the role of social support and previous experience. Birth 1998;25:169-74.

45. Hingstman 1, Wiegers TA. Verloskundigen: Aanbod verloskundigen. In. http://www.nivel.nl/verloskundige/verlosaanbod1.shtml ed: NIVEL; 2001.

46. WHO. International code of marketing of breast-milk substitutes. WHO Chronicle 1981;35:112-7.

47. NVJG. Standaard JGZ Advisering Borstvoeding. Houten: Bohn Stafleu Van Loghum; 1997. ISBN 90-313-2430-2.

48. IGZ-bulletin. Voeding van zuigelingen en peuters. Den Haag: Inspectie voor de Gezondheidszorg IGZ bulletin. Voedingscentrum; 1999.

49. Steenbakkers WHL. Determinanten van zuigelingenvoeding: Een studie naar factoren die van invloed zijn op de keuze tussen borstvoeding en flesvoeding en op de duur van borstvoeding onder moeders met een eerste kind in Maastricht. Thesis Maastricht: Rijksuniversiteit Limburg; 1987.

50. Rodrigues Pereira R. Have Dutch pediatricians an interest in breastfeeding? Tijdschr Kindergeneeskd 1998;66:68-71.

51. Blaauw M. A closer look at "breastfeeding" in medical handbooks and teaching materials in The Netherlands; A report on the attention paid to breastfeeding in the education of health professionals in the Netherlands. Amsterdam: Weten-schapswinkel Vrije Universiteit; 2000.

52. Gerards F, Hospers H. Health Counseling: a strategy to accompany patient guidance. Nederlands Tijdschr Dietisten 1991;46:132-7.

53. Gerards F. Health Counseling: Baarn: H.Nelissen; ISBN 90244 139892, 1997.

54. Gerards F. Health Counseling. In: Damoiseaux V, van der Molen HT, \& Kok GJ. (Eds.). Health education and behavioral change. Assen: Van Gorcum 1993:353-361.

55. Bakker MJ, Mullen PD, De Vries H, Van Breukelen G. Feasibility of implementation of a Dutch smoking cessation and relapse prevention protocol for pregnant women. Patient Educ Couns 2003;49:35-43. 
56. McGuire WJ. Attitudes and attitude change. In: Lindzey G, Aronson E, editors. Handbook of Social Psychology. New York: Lawrence Erlbaum Associates; 1985.

57. De Vries H, Kok GJ. From determinants of smoking behavior to the implications for a prevention program. Health Educ Res 1986;1:85-94.

58. De Vries H. Planning and evaluating health promotion. In: Scott D, Weston R, eds. Evaluating Health Promotion. Cheltenham: Stanley Thornes 1998:92-108.

59. Prochaska JO, DiClemente CC, Norcross JC. In search of how people change: Applications to addictive behaviors. Am Psychol 1992;47:1102-14.

60. Termote M, De Vries H, Kools EJ, Thijs C. Psycho-social factors associated with the duration of breastfeeding. A longitudinal study. Submitted for publication 2004.

61. De Vries H, Dijkstra M, Kuhlman P. Self-efficacy: the third factor besides attitude and subjective norm as predictor of behavioral intentions. Health Educ Res 1988; 3:273-282.

62. Orlandi MA, Landers C, Weston R, \& Haley N. Diffusion of health promotion interventions. In: K. Glanz, Lewis FM, Rimer BK, editors. Health behavior and health education: Theory, research, and practice. San Francisco: Jossey-Bass; 1990:288-313.

63. Bolman C, De Vries H, \& Van Breukelen G. Evaluation of a nurse-managed minimalcontact smoking cessation intervention for cardiac inpatients. Health Educ Res 2002;17:99-116.

64. Green LW, Kreuter MW. Health Promotion Planning: an Educational and Environmental Approach. Toronta: Mayfield Publishing Co; 1991.

65. McKenzie, Smeltzer. Planning, implementing and evaluating health promotion programs: A primer. Boston: Allyn and Bacon; 2001.

66. Colomer C, Hospers H, Barry M, Bronks B, Davies J, Lindstrom B, De Vries N. European training in health promotion: quality assurance based on collaboration and empowerment. Promot Educ 2002;9:52-4.

67. Scott D, Weston R. Evaluating health promotion. Cheltenham: Stanley Thornes Ltd; 1998.

68. McQueen DV, Anderson LM. What counts as evidence: issues and debates on evidence relevant to the evaluation of community health promotion programs. In: Rootman I, Goodstadt M, Mc Queen D, Potvin L, Springett J, and Ziglio E (eds). Evaluation in Health Promotion: Principles and Perspectives. Copenhagen: WHO (Euro); 2000.

69. Mackenbach JP, Gunning Schepers LJ. How should interventions to reduce inequalities in health be evaluated? J Epidemiol Community Health 1997;51:359-364.

70. Uhari M, Mantysaari K, Niemela M. A meta-analytic review of the risk factors for acute otitis media. Clin Infect Diseases 1996;22:1079-83.

71. Paradise JL, Rockette HE, Colborn DK, Bernard BS, Smith CG, Kurs Lasky M, Janoski J.E. Otitis media in 2253 Pittsburgh-area infants: prevalence and risk factors during the first two years of life. Pediatrics 1997;99:318-33.

72. Duffy LC, Faden H, Wasielewski R, Wolf J, Krystofik D. Exclusive breastfeeding protects against bacterial colonization and day care exposure to otitis media. Pediatrics 1997; 100:E7.

73. Nduati R, John G, Mbori Ngacha D, Richardson B, Overbaugh J, Mwatha A, et al. Effect of breastfeeding and formula feeding on transmission of HIV-1: a randomized clinical trial. JAMA 2000;283:1167-74.

74. Mbori Ngacha D, Nduati R, John G, Reilly M, Richardson B, Mwatha A, et al. Morbidity and mortality in breastfed and formula-fed infants of HIV-1-infected women: A randomized clinical trial. JAMA 2001;286:2413-20.

75. Hanson LA. Breastfeeding provides passive and likely long-lasting active immunity. Ann Allergy Asthma Immunol 1998;81:523-33.

76. Oddy WH. Breastfeeding protects against illness and infection in infants and children: a review of the evidence. Breastfeed Rev 2001;9:11-8. 
77. Humphrey J, Iliff P. Is breast not best? Feeding babies born to HIV-positive mothers: bringing balance to a complex issue. Nutr Rev 2001;59:119-27.

78. Gdalevich M, Mimouni D, Mimouni M. Breast-feeding and the risk of bronchial asthma in childhood: a systematic review with meta-analysis of prospective studies. J Pediatr 2001;139:261-6.

79. Bachrach VR, Schwarz E, Bachrach LR. Breastfeeding and the Risk of Hospitalization for Respiratory Disease in Infancy: A Meta-analysis. Arch Pediatr Adolesc Med 2003;157:237-43.

80. Kull I, Wickman M, Lilja G, Nordvall SL, Pershagen G. Breast feeding and allergic diseases in infants-a prospective birth cohort study. Arch Dis Child 2002;87:478-81.

81. Oddy WH, Holt PG, Sly PD, Read AW, Landau LI, Stanley FJ, et al. Association between breast feeding and asthma in 6 year old children: findings of a prospective birth cohort study. BMJ 1999;319:815-9.

82. Oddy WH. Breastfeeding and asthma in children: findings from a West Australian study. Breastfeed Rev 2000;8:5-11.

83. Gdalevich M, Mimouni D, David M, Mimouni M. Breast-feeding and the onset of atopic dermatitis in childhood: a systematic review and meta-analysis of prospective studies. J Am Acad Dermatol 2001;45:520-7.

84. Mimouni Bloch A, Mimouni D, Mimouni M, Gdalevich M. Does breastfeeding protect against allergic rhinitis during childhood? A meta-analysis of prospective studies. Acta Paediatr 2002;91:275-279.

85. Ahmed T, Fuchs GJ. Gastrointestinal allergy to food: a review. J Diarrhoeal Dis Res 1997;15:211-23.

86. Halken S, Jacobsen HP, Host A, Holmenlund D. The effect of hypo-allergenic formulas in infants at risk of allergic disease. Eur J Clin Nutr 1995;49:1,s77-s83.

87. Ivarsson A, Persson LA, Hernell O. Does breast-feeding affect the risk for coeliac disease? Adv Exp Med Biol 2000;478:139-49.

88. Wadsworth M, Marshall S, Hardy R, Paul A. Breast feeding and obesity. Relation may be accounted for by social factors. BMJ 1999;319:1576.

89. O'Callaghan MJ, Williams GM, Andersen MJ, Bor W, Najman JM. Prediction of obesity in children at 5 years: a cohort study. J Paediatr Child Health 1997;33:311-6.

90. Gerstein HC. Cow's milk exposure and type I diabetes mellitus. A critical overview of the clinical literature. Diabetes Care 1994;17:13-9.

91. Norris JM, Scott FW. A meta-analysis of infant diet and insulin-dependent diabetes mellitus: do biases play a role? Epidemiology 1996;7:87-92.

92. Meloni T, Marinaro AM, Mannazzu MC, Ogana A, La Vecchia C, Negri E, et al. IDDM and early infant feeding. Sardinian case-control study. Diabetes Care 1997;20:340-2.

93. Gimeno SG, De Souza JM. IDDM and milk consumption. A case-control study in Sao Paulo, Brazil. Diabetes Care 1997;20:1256-60.

94. Perez Bravo F, Carrasco E, Gutierrez Lopez MD, Martinez MT, Lopez G, de los Rios MG. Genetic predisposition and environmental factors leading to the development of insulin-dependent diabetes mellitus in Chilean children. J Mol Med 1996;74:105-9.

95. Von Kries R, Koletzko B, Sauerwald T, von Mutius E, Barnert D, Grunert V, et al. Breast feeding and obesity: cross sectional study. BMJ 1999;319:147-50.

96. Hediger ML, Overpeck MD, Kuczmarski RJ, Ruan WJ. Association between infant breastfeeding and overweight in young children. JAMA 2001;285:2453-60.

97. Gillman MW, Rifas Shiman SL, Camargo CA, Jr., Berkey CS, Frazier AL, Rockett HR, et al. Risk of overweight among adolescents who were breastfed as infants. JAMA 2001;285:2461-7. 
98. Pettitt DJ, Forman MR, Hanson RL, Knowler WC, Bennett PH. Breastfeeding and incidence of non-insulin-dependent diabetes mellitus in Pima Indians. Lancet 1997;350:166-8.

99. McVea KL, Turner PD, Peppler DK, Cunningham AS. The role of breastfeeding in sudden infant death syndrome. More on crib death and breastfeeding. J Hum Lact 2000; $16: 13-20$.

100. Davis MK. Review of the evidence for an association between infant feeding and childhood cancer. Int J Cancer Suppl 1998;33:1129-33.

101. Wall G. Outcome of breastfeeding versus formula feeding. In. www.washington.edu/medical/uwmc/uwmc_clinics/matern/current_biospec.doc ed: University of Washington; 2001.

102. Anderson JW, Johnstone BM, Remley DT. Breast-feeding and cognitive development: a meta-analysis. Am J Clin Nutr 1999;70:525-35.

103. Rao MR, Hediger ML, Levine RJ, Naficy AB, Vik T. Effect of breastfeeding on cognitive development of infants born small for gestational age. Acta Paediatr 2002;91:267-274.

104. Beral V, Banks E, Reeves G. Evidence from randomized trials on the long-term effects of hormone replacement therapy. Lancet 2002;360:942-4.

105. Tryggvadottir L, Tulinius H, Eyfjord JE, Sigurvinsson T. Breastfeeding and reduced risk of breast cancer in an Icelandic cohort study. Am J Epidemiol 2001;154:37-42.

106. Bernier MO, Plu Bureau G, Bossard N, Ayzac L, Thalabard JC. Breastfeeding and risk of breast cancer: a meta-analysis of published studies. Hum Reprod Update 2000;6:374-86.

107. Siskind V, Green A, Bain C, Purdie D. Breastfeeding, menopause, and epithelial ovarian cancer. Epidemiology. 1997;8:188-91.

108. John EM, Whittemore AS, Harris R, Itnyre J. Characteristics relating to ovarian cancer risk: collaborative analysis of seven U.S. case-control studies. Epithelial ovarian cancer in black women. Collaborative Ovarian Cancer Group. J Natl Cancer Inst 1993;85:142-7.

109. Greggi S, Parazzini F, Paratore MP, Chatenoud L, Legge F, Mancuso S, et al. Risk factors for ovarian cancer in central Italy. Gynecol Oncol 2000;79:50-4.

110. Cumming RG, Klineberg RJ. Breastfeeding and other reproductive factors and the risk of hip fractures in elderly women. Int J Epidemiol 1993;22:684-91.

111. Chan HH, Lau EM, Woo J, Lin F, Sham A, Leung PC. Dietary calcium intake, physical activity and the risk of vertebral fracture in Chinese. Osteoporos Int 1996;6:228-32.

112. Clark P, De la Pena F, Gomez Garcia F, Orozco JA, Tugwell P. Risk factors for osteoporotic hip fractures in Mexicans. Arch Med Res 1998;29:253-7.

113. Boonyaratavej N, Suriyawongpaisal P, Takkinsatien A, Wanvarie S, Rajatanavin R, Apiyasawat P. Physical activity and risk factors for hip fractures in Thai women. Osteoporos Int 2001;12:244-8.

114. Foster K, Lader D, Cheesbrough S. Infant feeding 1995: Office for National Statistics:The Stationery Office: London; 1997.

115. Yngve A, Sjostrom M. Breastfeeding in countries of the European Union and EFTA: current and proposed recommendations, rationale, prevalence, duration and trends. Public Health Nutr 2001;4:631-45.

116. Flies E. Bevordering van Borstvoeding. Resultaten van het onderzoek door VBBB in opdracht van M. Colla, federaal Minister van Volksgezondheid 1997. Tijdschr Ver Begeleiding en Bevordering Borstvoeding 1997;4:8-11.

117. Giovanni M, Banderali G, Pederiva C.Progretti Puer2: indagine sull' allatamento al seno in Italia 2000. Bolletino della Società Italiana di Nutrizione Pediatrica. In: Doctor Pediatrica 2000;9/2000.

118. Manstead ASR, Proffitt C, Smart JL. Predicting and Understanding Mothers' InfantFeeding Intentions and Behavior: Testing the theory of reasoned Action. J Pers Soc Psychol 1983;44:657-671. 
119. Kloeblen Tarver AS, Thompson NJ, Miner KR. Intent to breast-feed: the impact of attitudes, norms, parity, and experience. Am J Health Behav 2002;26:182-7.

120. Kessler LA, Gielen AC, Diener West M, Paige DM. The effect of a woman's significant other on her breastfeeding decision. J Hum Lact 1995;11:103-9.

121. Humphreys AS, Thompson NJ, Miner KR. Assessment of breastfeeding intention using the Transtheoretical Model and the Theory of Reasoned Action. Health Educ Res 1998;13:331-341.

122. Rademakers GM. Determinanten van de keuze en de duur van borstvoeding. [Thesis]. Maastricht: Universiteit Maastricht; 1998.

123. Wambach KA. Breastfeeding intention and outcome: a test of the theory of planned behavior. Res Nurs Health 1997;20:51-9.

124. Goksen F. Normative vs. attitudinal considerations in breastfeeding behavior: multifaceted social influences in a developing country context. Soc Sci Med 2002;54:1743-53.

125. Fishbein M, Ajzen I. Beliefs, attitudes, intention, and behavior: an introduction to theory and research. Reading, Mass: Addison Wesley; 1975.

126. Ajzen I, Fishbein M. Understanding attitudes and predicting social behavior. Englewood Cliffs NJ: Prentice Hall; 1980.

127. Ajzen I. Attitudes, Personality, and Behavior: Milton Keynes: Open University Press; 1988.

128. Goffin I, Lenaers S. Onderzoek naar de voedingssituatie van jonge kinderen;ISBN 9075262-34-5, 2002. 



\begin{abstract}
Objectives. The aim of this study was to evaluate the behavioral determinants of the initiation of breastfeeding at birth.

Methods. A prospective cohort study using the ASE model in 373 pregnant women in ten child health care centers.

Results. Prenatally, $72 \%$ of the women had the intention to breastfeed; and $73 \%$ actually started with breastfeeding at birth. Mothers who initiated breastfeeding differed in almost all the ASE determinants (attitude, social support, self-efficacy) from mothers who initiated formula feeding. Intention was a very strong predictor of the initiation of breastfeeding.

Conclusion. The ASE model is valid to explain and predict the initiation of breastfeeding. In the discussion, we used the results to target interventions such as health counseling.
\end{abstract}




\section{INTRODUCTION}

Although breastfeeding has been endorsed as the optimal method of infant feeding by the World Health Organization (WHO) and UNICEF, many infants are breastfed only briefly in industrialized countries such as the Netherlands. Concern over the unpopularity of breastfeeding and desire for higher rates of both frequency and duration led to promotional efforts in several countries and to the publication of the WHO code. ${ }^{1}$ The Baby Friendly Hospital Initiative and the Ten Steps to Successful Breastfeeding ${ }^{2}$ organized by UNICEF and the WHO are moving towards implementation.

In the Netherlands $80 \%$ of the mothers start with breastfeeding, but the breastfeeding rate drops rapidly to $52 \%$ at one month postpartum. ${ }^{3}$ Despite significant benefits of breastfeeding for mother and child, many women choose to formula feed their infant. Insight in the behavioral determinants that encourage or discourage initiation of breastfeeding is essential to design tailored interventions for pregnant women to increase breastfeeding effectively.

Many factors have been found to be associated with choosing breastfeeding or formula feeding. A higher initiation of breastfeeding is seen in women characterized by: having higher social economic status, ${ }^{4}$ higher educational levels,${ }^{4-6}$ being married, ${ }^{4}$ older, ${ }^{4,6}$ multiparas, ${ }^{5-8}$ being non-smokers, ${ }^{4}$ having no paid work, ${ }^{4}$ and having no previous breastfeeding experience. ${ }^{7}$

Among the many studies that identified socio-cultural, psychological, biological, and health care factors to influence the initiation of breastfeeding, few studied the behavioral determinants of breastfeeding in a systematic way, using socialpsychological models. ${ }^{9-17}$ Determinants of breastfeeding intention were social influence of significant others, positive social norm, positive attitude towards breastfeeding, and low social pressure towards formula feeding. Positive previous experience with breastfeeding also predicted the intention. ${ }^{16}$

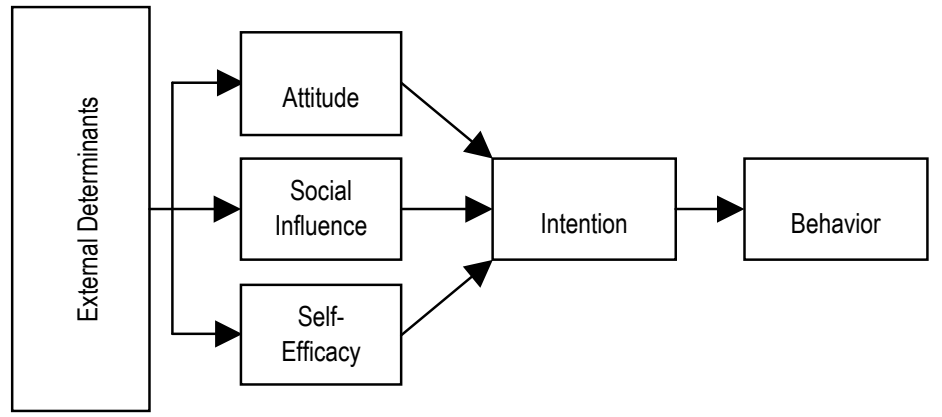

Figure 1 The ASE model (adapted from De Vries \& Mudde, 1998)

The aim of the present study was to evaluate the determinants of the initiation of breastfeeding at birth. The study is based on a social-psychological model, the ASE model (Attitude-Social influence-Self Efficacy-model), ${ }^{18,19}$ that originated from The Theory of Reasoned Action of Fishbein \& Ajzen ${ }^{20}$ and Bandura's Social Cognitive 
Theory et al. ${ }^{21}$ The ASE model states that behavior is best predicted by intention, which, in turn, is predicted by attitudes, social influences, and self-efficacy (see Figure 1).

While the ASE model has many similarities with Ajzen's Theory of Planned Behavior, the models differs by assessing e.g. social influences more elaborately ${ }^{22}$ and by integrating the stage concepts from the Theory of Planned Behavior. ${ }^{23}$ A more detailed description about the model in comparison with other social cognitive models can be found elsewhere. ${ }^{24}$ The ASE model has been used to explain various types of healthrelated behavior, such as dieting and smoking. ${ }^{25-27}$

\section{METHODS}

\section{Design and study population}

The data were obtained from the control group (usual care) of a group-randomized trial of the efficacy of a breastfeeding promotion and support program (published elsewhere). ${ }^{28}$ Three Home Health Care organizations in the province of Limburg, the Netherlands, participated. The study received approval of the medical ethical committee of Maastricht University.

\section{Inclusion criteria and recruitment}

Study candidates were pregnant women who applied for maternity care at three Home Health Care services from December 2000-December 2002.

In the Netherlands, the obstetric care is provided by midwives, general practitioners, and gynecologists. In addition, maternity care is provided by public Home Health Care organizations $(70 \%)$ and private organizations $(30 \%)$, and includes one prepartum home visit in the seventh or eighth month by a maternity nurse and - of mostly at eight days postpartum- home care by the maternity assistant. From two weeks postpartum onwards, care is taken over by the nurses and physicians of the child health care of the Home Health Care Organizations ( $>95 \%)$. Typically, pregnant Dutch women apply between the sixth and seventh months of pregnancy for maternity care; they then receive a home visit by a maternity care nurse on the seventh or eighth month. The candidates from the intake list of the maternity care were sent an informed consent letter before the first home visit. In this letter, the study goal was explained by describing that the aim was to investigate feeding practices and opinions about these practices of new mothers (the aim to promote breastfeeding was concealed). At the same time, the new mothers received the first questionnaire to be returned during the prenatal home visit. Those who agreed to participate received a follow-up questionnaire during the postnatal home visit of the child health care nurse fourteen days postpartum, to be returned during the consultation to the child health center one month postpartum. If participants failed to return a questionnaire, a telephone call was made in order to obtain the most essential follow-up information, including breastfeeding initiation. Mothers with infants $<2000 \mathrm{~g}$ birth weight were excluded from the analysis. 


\section{Measurements of behavioral determinants}

The prenatal questionnaire measured the intention to give breastfeeding or formula feeding, and the ASE determinants. The ASE items were based on results of an earlier pilot study ${ }^{17}$ and could be used for our study because they are formulated in general terms not specially referring to starting or continuing.

Attitudes. Attitudes toward breastfeeding were assessed by asking the perceived advantages of breastfeeding (pros) in relation to the mother herself, to her infant, and to her partner, with eleven questions (such as, when I give breastfeeding: "I have more contact with my baby"; "I save money"; "I give my baby more resistance to infection"; "it is more easy because the feed is directly ready for use"), on 5-point scales ranging from 1 ("fully agree") to 5 ("fully disagree"). The perceived disadvantages (cons) of breastfeeding for the mother herself, infant, and partner were measured by sixteen questions such as when I give breastfeeding: "I have to pay more attention to what I eat or drink"; "I am uncertain about the growth of my baby"; "my partner gets a bonding with my baby less quickly"), on 5-point scales ranging from 1 ("fully agree") to 5 ("fully disagree").

Social influence. Beliefs of the mother regarding social norms and support were measured from significant others (such as partner, mother, sister, friends, midwife, maternity and child health care nurse and physician, colleague, employer). Social norms of significant others as well as from those at the workplace were asked about with eight questions on 5-point scales ranging from 1 ("I must certainly breastfeed") to 5 ("I must certainly formula feed"). The social support of breastfeeding of significant others as well as from those at the workplace was asked about with eight questions on 5-point scales, scores ranging from 1 ("very often support") to 5 ("never any support") to give breastfeeding. Similar questions on norms and support were asked for formula feeding. Self-efficacy. A distinction was made between self-efficacy to breastfeed and to formula feed assessing both situational and stress self-efficacy for both types of feeding. Questions used 7-point scales ranging from 1 ("very difficult") to 7 ("very easy"). Situational self-efficacy for breastfeeding was assessed by asking how difficult women perceived breastfeeding for the following seven situations: on a journey, on a visit, during a visit from acquaintances, in a public place, at night, at the workplace, expressing breast milk and for six situations for formula feeding. Stress self-efficacy for breastfeeding was assessed in three situations (when the mother is stressed, tired and when the infant is ill). Similar questions were asked for formula feeding. In addition, the prenatal questionnaire included questions on co variables such as maternal age; maternal education; paid or non-paid work; smoking and alcohol consumption; family history of asthma, eczema, or (food) allergy; previous breastfeeding experience; and the moment when the decision was made to breastfeed or not. Furthermore, the prenatal questionnaire asked about the main reasons and the main influence on the intention of breastfeeding or formula feeding.

\section{Follow-up measurement}

The postnatal questionnaire asked which method of infant feeding was given after birth. In this study, initiation of breastfeeding is defined as all feeding practices in combination with breast milk (exclusive breastfeeding; feeding of expressed maternal 
milk; or breastfeeding with complementary liquids or with complementary formula feeding). Formula feeding meant feeding with formula feeds without any breastfeeding.

\section{Statistical analyses}

Chi-square tests for categorical variables and t-tests for continuous variables were used when comparing breast and formula feeding mothers. For each category of ASE determinants, a mean score was computed by averaging the scores on the items. Reliability analyses assessed the internal consistency (expressed as Cronbach's alpha ${ }^{29,30}$ of the perceived pros and cons, social influences and self-efficacy scores. The relationships of the external determinants and the ASE variables with breastfeeding initiation were examined by means of multivariate logistic regression analysis giving odds ratios (with 95\% confidence intervals) as a measure of the strength of the associations (and their precision) between the determinants and breastfeeding initiation. First, the external determinants were included in the model with the initiation of breastfeeding as the outcome variable. Next, each ASE variable was added separately to this model in order to evaluate its association with breastfeeding initiation (controlling for the external determinants but not for the other ASE determinants). Next, all ASE variables (except intention) were added together to the model (so that the independent contribution of each ASE variable was assessed, controlling for interdependencies between the ASE variables). Then, intention was added to test whether the influence of the ASE variables was mediated by the intention. We considered P-values $<0.05$ as statistically significant. The analysis was carried out in STATA 7.0. ${ }^{31}$

\section{RESULTS}

\section{Subjects and follow-up rate}

Of the 519 candidates on the intake list for maternity care, 373 of the pregnant women gave informed consent and filled in the prenatal questionnaire. Of these 373 participants, 341 (91\%) completed the postnatal follow-up questionnaire, and this differed only slightly of participants with prenatal intention to breastfeed $(243 / 268=91 \%)$ compared with women with the intention of formula feeding $(98 / 105=93 \%)$, Table 1 . Neither did the follow-up rate differ much according to the other determinants. The mean age of the participants was 31 years, ranging from 18 to 42 years. Nineteen percent had a low level of education (primary or basic vocational school), $58 \%$ a medium level (secondary vocational or high school) and $23 \%$ a high level (higher vocational school or university).

\section{Intention and external determinants}

In the prenatal questionnaire, $72 \%(268 / 373)$ of the participants had the intention to breastfeed (Table 1). More women had the intention of breastfeeding if they were older, had a higher education, or did not smoke. Of the 268 pregnant women with the intention to breastfeed, 188 (70\%) had made the decision before the pregnancy, 75 (28\%) during the pregnancy and $5(2 \%)$ did not remember the time of the decision. 


\section{ASE differences between breast feeders and formula feeders}

At the follow-up until birth $73 \%$ (248/341) of the mothers reported that they had initiated breastfeeding. Mothers who had initiated breastfeeding differed on all the ASE determinants from mothers who initiated formula feeding, except for social support for formula feeding at the workplace (Table 2). Mothers who initiated breastfeeding were more convinced of the advantages of breastfeeding and less convinced on the advantages of formula feeding; perceived a social norm more favoring breastfeeding than formula feeding; encountered more social support from significant others for breastfeeding and less for formula feeding (but social support at work for breastfeeding only) and felt more self-confident to breastfeed and less to formula feed in situational and stress situations.

Table 1 Socio-economic and external determinants of prenatal intention and of initiating breastfeeding at birth

\begin{tabular}{|c|c|c|c|c|c|c|}
\hline \multirow[t]{2}{*}{ Determinants } & \multicolumn{3}{|c|}{ Baseline } & \multicolumn{3}{|c|}{ Follow-up after birth } \\
\hline & $\begin{array}{l}\text { Prenatal intention } \\
\text { breastfeeding } \\
\mathrm{N}=268(72 \%)\end{array}$ & $\begin{array}{c}\text { Total } \\
\mathrm{N}=373(100 \%)\end{array}$ & P-value ${ }^{1)}$ & $\begin{array}{c}\text { Breastfeeding initiation } \\
\text { At birth } \\
\mathrm{N}=248(73 \%)\end{array}$ & $\begin{array}{c}\text { Total } \\
\mathrm{N}=341(100 \%)\end{array}$ & P-value ${ }^{1)}$ \\
\hline \multicolumn{7}{|l|}{ Prenatal intention } \\
\hline $\mathrm{BF}$ & & & 0.00 & $238(98 \%)$ & 243 & 0.00 \\
\hline FF or unknown & & & & $10(10 \%)$ & 98 & \\
\hline \multicolumn{7}{|l|}{ Maternal age } \\
\hline$<25 \mathrm{yr}$ & $19(54 \%)$ & 35 & 0.05 & $16(62 \%)$ & 26 & 0.30 \\
\hline $25-30 \mathrm{yr}$ & $117(73 \%)$ & 161 & & $108(72 \%)$ & 151 & \\
\hline$\geq 31 \mathrm{yr}$ & $132(75 \%)$ & 177 & & $124(76 \%)$ & 164 & \\
\hline \multicolumn{7}{|l|}{ Maternal education } \\
\hline Low & $44(61 \%)$ & 72 & 0.02 & $37(60 \%)$ & 62 & 0.01 \\
\hline Middle & $153(72 \%)$ & 214 & & $145(73 \%)$ & 198 & \\
\hline High & $71(82 \%)$ & 87 & & $66(81 \%)$ & 81 & \\
\hline \multicolumn{7}{|l|}{$\begin{array}{l}\text { Alcohol use before } \\
\text { pregnancy }\end{array}$} \\
\hline Yes & $132(72 \%)$ & 183 & 0.91 & $121(74 \%)$ & 163 & 0.55 \\
\hline No & $136(72 \%)$ & 190 & & $127(72 \%)$ & 178 & \\
\hline \multicolumn{7}{|c|}{ Smoking before pregnancy } \\
\hline Yes & $65(63 \%)$ & 103 & 0.02 & $54(61 \%)$ & 88 & 0.01 \\
\hline No/not daily & $203(75 \%)$ & 270 & & $194(77 \%)$ & 253 & \\
\hline \multicolumn{7}{|l|}{$\begin{array}{l}\text { Asthma, eczema, } \\
\text { (food) allergy in family }\end{array}$} \\
\hline Yes & $133(74 \%)$ & 180 & 0.40 & $126(76 \%)$ & 166 & 0.20 \\
\hline No/not known & $135(70 \%)$ & 193 & & $122(70 \%)$ & 175 & \\
\hline \multicolumn{7}{|c|}{ Previous BF experience } \\
\hline No, multiparas & & & & $14(30 \%)$ & 46 & 0.00 \\
\hline Yes, multiparas & & & & $93(88 \%)$ & 106 & \\
\hline No, primiparas & & & & $141(75 \%)$ & 189 & \\
\hline \multicolumn{7}{|l|}{ Decision to BF/ FF } \\
\hline Before pregnancy & $188(75 \%)$ & 251 & 0.03 & $179(75 \%)$ & 238 & 0.21 \\
\hline During pregnancy & 75 (68\%) & 110 & & $64(68 \%)$ & 94 & \\
\hline Not known & $5(42 \%)$ & 12 & & $5(56 \%)$ & 9 & \\
\hline
\end{tabular}

$\mathrm{BF}=$ breastfeeding; $\mathrm{FF}=$ formula feeding

1) Pearson chi square test

\section{Predictors of breastfeeding initiation}

Intention was highly predictive for actual initiation of breastfeeding: of the women intending to breastfeed $98 \%(238 / 243)$ actually started with breastfeeding; of the 
women not intending to breastfeed $10 \%(10 / 98)$ started with breastfeeding (Table 1). The initiation of breastfeeding was related to breastfeeding experience: among multiparas with previous breastfeeding experience $88 \%(93 / 106)$ initiated breastfeed this time, whereas this was only $30 \%(14 / 46)$ of those without previous breastfeeding experience. The rate in primiparas was closer to the first group, namely $75 \%(141 / 189)$.

Table 2 The mean scores and odds ratios of the ASE determinants of pregnant women ( $N=341)$, who initiated breastfeeding or formula feeding at birth

\begin{tabular}{|c|c|c|c|c|c|c|c|c|}
\hline & & & & $\begin{array}{c}\text { Initiated } \\
\text { Breastfeeding }\end{array}$ & $\begin{array}{c}\text { Initiated } \\
\text { Formula feeding } \\
\end{array}$ & & & \\
\hline Determinants & No item & Scale & $\begin{array}{l}\text { Cronbach's } \\
\text { Alpha }\end{array}$ & 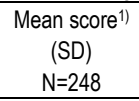 & $\begin{array}{c}\text { Mean score }{ }^{1)} \\
(\mathrm{SD}) \\
\mathrm{N}=93 \\
\end{array}$ & P-value ${ }^{1)}$ & $\mathrm{OR}^{2)}$ & $\left.95 \% \mathrm{Cl}^{2}\right)$ \\
\hline Pros BF & 11 & $1-5^{3)}$ & 0.80 & $3.46(0.48)$ & $2.63(0.50)$ & 0.000 & 23.36 & $10.6-51.7$ \\
\hline Cons BF & 16 & $1-5^{3)}$ & 0.73 & $2.68(0.38)$ & $3.11(0.41)$ & 0.000 & 0.05 & $0.02-0.13$ \\
\hline Social norm BF significant others & 6 & $1-5^{4)}$ & 0.78 & $3.70(0.51)$ & $2.94(0.40)$ & 0.000 & 164.64 & $41.2-658.4$ \\
\hline Social norm BF work & 2 & $1-5^{4)}$ & 0.54 & $3.14(0.47)$ & $2.98(0.33)$ & 0.003 & 2.66 & $1.31-5.37$ \\
\hline Social support BF significant others & 6 & $1-5^{5)}$ & 0.83 & $2.92(1.01)$ & $1.80(0.92)$ & 0.000 & 2.91 & $2.09-4.05$ \\
\hline Social support BF work & 2 & $1-5^{5)}$ & 0.79 & $1.57(0.99)$ & $1.25(0.69)$ & 0.004 & 1.44 & $0.99-2.09$ \\
\hline Social support FF significant others & 6 & $1-5^{5)}$ & 0.88 & $2.02(1.03)$ & $2.48(1.11)$ & 0.000 & 0.61 & $0.46-0.79$ \\
\hline Social support FF work & 2 & $1-5^{5)}$ & 0.82 & $1.40(0.87)$ & $1.46(0.97)$ & 0.589 & 0.81 & $0.60-1.09$ \\
\hline Situational self-efficacy BF & 7 & $1-7^{6)}$ & 0.81 & $4.32(1.03)$ & $3.52(1.04)$ & 0.000 & 2.01 & $1.51-2.68$ \\
\hline Stress self-efficacy BF & 3 & $1-7^{6)}$ & 0.83 & $3.37(1.07)$ & $2.71(1.05)$ & 0.000 & 1.83 & $1.37-2.45$ \\
\hline Situational self-efficacy FF & 6 & $1-7^{6)}$ & 0.76 & $5.22(0.92)$ & $5.76(0.79)$ & 0.000 & 0.52 & $0.37-0.73$ \\
\hline Stress self-efficacy FF & 3 & $1-76)$ & 0.84 & $4.95(1.05)$ & $5.28(1.10)$ & 0.009 & 0.80 & $0.61-1.04$ \\
\hline
\end{tabular}

$\mathrm{BF}=$ breastfeeding; $\mathrm{FF}=$ formula feeding

1)From t-tests

2)From multivariate logistic regression analysis with the following co variables in the model: maternal age, maternal education, alcohol consumption, smoking, and previous breastfeeding experience. For each ASE determinant separately, the odds ratio means the increase of the odds for one point increase on the scale

3)1=fully disagree, $5=$ fully agree with advantages (pros); or with disadvantages (cons) of breastfeeding

4) $1=$ I must certainly formula feed, $5=1$ must certainly breastfeed

5)1=never support, $5=$ very often support for breastfeeding; or for formula feeding

6)1=very difficult, $7=$ very easy to give breastfeeding; or formula feeding

Among the external determinants in the multivariate logistic regression analysis, the strongest independent predictor of breastfeeding initiation was previous breastfeeding experience. In comparison with mothers with a first-born infant (primiparas without breastfeeding experience), multiparas with breastfeeding experience had an almost double chance of breastfeeding initiation (odds ratio=2.16), while multiparas without breastfeeding experience had a much lower chance (odds ratio=0.15) (Table 3, Model 1). When the ASE variables were added, the pros and cons of breastfeeding and the social norm to breastfeeding of significant others were found to make a strong independent and significant contribution to the initiation of breastfeeding (Table 3 , Model 2). Each point increase on the 1-5 scale increased the odds of breastfeeding initiation with factor 14.5 for the pros of breastfeeding, with factor 0.04 for the cons of breastfeeding, and with factor 14.7 for the social norm of breastfeeding of significant others. None of the demographic variables such as maternal age or maternal education were independently predicting the initiation of breastfeeding, once ASE variables were included in the model, indicating that their predictive value was fully mediated by the ASE variables. 
A model with intention as the determinant, controlling for external determinants (Model 3) showed that intention was a strong predictor of breastfeeding initiation. Intention mediated all influences of the external and ASE variables (according to the assumptions of the ASE model) and could therefore not be entered in a model with ASE variables together.

Table 3 Predictors of breastfeeding initiation ( $\mathrm{N}=341$ )

\begin{tabular}{|c|c|c|c|c|c|c|c|c|}
\hline \multirow[t]{2}{*}{ Variable } & & \multirow[t]{2}{*}{ Scale } & \multicolumn{2}{|l|}{ Model 1} & \multicolumn{2}{|l|}{ Model 2} & \multicolumn{2}{|l|}{ Model 3} \\
\hline & & & $\mathrm{OR}^{1)}$ & $95 \% \mathrm{Cl}$ & $\mathrm{OR}^{1)}$ & $95 \% \mathrm{Cl}$ & $\mathrm{OR}^{1)}$ & $95 \% \mathrm{Cl}$ \\
\hline \multirow[t]{3}{*}{ Maternal age ${ }^{2)}$} & $<25 \mathrm{yr}$ & & 0.83 & $0.31-2.22$ & 1.69 & $0.21-13.6$ & 2.55 & $0.29-22.7$ \\
\hline & $25-30 \mathrm{yr}$ & & 1.00 & Reference & 1.00 & Reference & 1.00 & Reference \\
\hline & $\geq 31 \mathrm{yr}$ & & 1.21 & $0.67-2.17$ & 1.08 & $0.35-3.35$ & 1.28 & $0.39-4.23$ \\
\hline \multirow[t]{3}{*}{ Maternal education²) } & Low & & 0.65 & $0.33-1.30$ & 0.46 & $0.14-1.50$ & 0.47 & $0.11-2.03$ \\
\hline & Middle & & 1.00 & Reference & 1.00 & Reference & 1.00 & Reference \\
\hline & High & & 1.12 & $0.56-2.25$ & 1.65 & $0.45-6.10$ & 0.90 & $0.22-3.68$ \\
\hline \multicolumn{2}{|c|}{ Alcohol use before pregnancy2) } & & 0.99 & $0.58-1.69$ & 1.00 & $0.37-2.66$ & 0.94 & $0.31-2.85$ \\
\hline \multicolumn{2}{|c|}{ Smoking before pregnancy²) } & & 0.62 & $0.34-1.12$ & 0.99 & $0.36-2.75$ & 0.44 & $0.12-1.64$ \\
\hline \multicolumn{2}{|c|}{ Asthma, eczema, (food) allergy in family²) } & & 1.27 & $0.74-2.18$ & 0.83 & $0.31-2.20$ & 1.36 & $0.46-4.03$ \\
\hline \multicolumn{2}{|c|}{ Multiparas without previous BF experience } & & $0.15^{\star * *}$ & $0.07-0.32$ & 1.63 & $0.41-6.41$ & 0.67 & $0.15-2.95$ \\
\hline \multicolumn{2}{|c|}{ Multiparas with previous BF experience } & & $2.16^{*}$ & $1.07-4.35$ & 2.90 & $0.72-11.7$ & 1.43 & $0.36-5.67$ \\
\hline \multicolumn{2}{|c|}{ Primiparas without previous BF experience } & & 1.00 & Reference & 1.00 & Reference & 1.00 & Reference \\
\hline \multicolumn{3}{|c|}{ Intention BF } & & & & & $405.8^{* *}$ & $120.8-1362.9$ \\
\hline \multicolumn{2}{|l|}{ Pros BF } & $1-5^{3)}$ & & & $14.5^{\star \star \star}$ & $4.46-47.3$ & & \\
\hline \multicolumn{2}{|l|}{ Cons BF } & $1-5^{3)}$ & & & $0.04^{* * *}$ & $0.01-0.19$ & & \\
\hline \multicolumn{2}{|c|}{ Social norm significant others } & $1-5^{4)}$ & & & $14.7^{* *}$ & $2.78-77.6$ & & \\
\hline \multicolumn{2}{|c|}{ Social norm work: colleague } & $1-5^{4)}$ & & & 1.80 & $0.46-7.10$ & & \\
\hline \multicolumn{2}{|c|}{ Social norm work: employer } & $1-5^{4)}$ & & & 0.32 & $0.66-1.52$ & & \\
\hline \multicolumn{2}{|c|}{ Social support BF significant others } & $1-5^{5)}$ & & & 2.02 & $0.96-4.23$ & & \\
\hline \multicolumn{2}{|c|}{ Social support BF work } & $1-5^{5)}$ & & & 1.11 & $0.42-2.91$ & & \\
\hline \multicolumn{2}{|c|}{ Social support FF significant others } & $1-5^{5)}$ & & & 0.55 & $0.29-0.96$ & & \\
\hline \multicolumn{2}{|c|}{ Social support FF work } & $1-5^{5)}$ & & & 0.82 & $0.35-1.89$ & & \\
\hline \multicolumn{2}{|c|}{ Situational self-efficacy BF } & $1-7^{6)}$ & & & 0.73 & $0.40-1.35$ & & \\
\hline \multicolumn{2}{|c|}{ Stress self-efficacy BF } & $1-7^{6)}$ & & & 1.63 & $0.92-2.90$ & & \\
\hline \multicolumn{2}{|c|}{ Situational self-efficacy FF } & $1-7^{6)}$ & & & 0.77 & $0.38-1.56$ & & \\
\hline \multicolumn{2}{|c|}{ Stress self-efficacy FF } & $1-7^{6)}$ & & & 1.04 & $0.60-1.81$ & & \\
\hline Likelihood Ratio test & & & Model 2 & nodel 1: $P=0$. & & Model 3 vs & model 2: $\mathrm{F}$ & $=0.000$ \\
\hline $\begin{array}{l}\text { BF=breastfeeding; FF } \\
{ }^{*} \mathrm{P}<.05 ;{ }^{* *} \mathrm{P}<.01 ; \text {; }{ }^{* *} \mathrm{P}\end{array}$ & $\begin{array}{l}\text { formula feeding } \\
001 \text {, from Likelihood }\end{array}$ & Ratio tes & & & & & & \\
\hline $\begin{array}{l}\text { Test for trend: matern } \\
\text { 1)Odds ratio, results fr }\end{array}$ & $\begin{array}{l}\text { I age, maternal educe } \\
\text { m multivariate logistic }\end{array}$ & $\begin{array}{l}\text { tion } P>0 \text {. } \\
\text { regressic }\end{array}$ & $\begin{array}{l}\text { in all moc } \\
\text { analysis }\end{array}$ & & & & & \\
\hline 2) "No"= reference cat & gory & & & & & & & \\
\hline 3) $1=$ fully disagree, $5=$ & lly agree with advante & ges (pros & or with di & antages (c & is) of breas & eding & & \\
\hline 4) $1=$ I must certainly fo & mula feed, $5=I$ must $c$ & rtainly br & astfeed & & & & & \\
\hline 5) $1=$ never support, $5=$ & ery often support of b & eastfeed & $g$; or of $\mathrm{fc}$ & feeding & & & & \\
\hline 6) $1=$ very difficult, $7=v$ & $y$ easy to give breast & eeding; & & f. & & & & \\
\hline
\end{tabular}

\section{Reasons and influences to initiate breastfeeding or formula feeding}

Pregnant women with the intention of breastfeeding reported the following three main reasons for choosing breastfeeding: "breastfeeding is the most natural feeding" $(89 \%)$, "the health of mother and infant" (87\%), and "the contact between mother and infant" $(84 \%)$. When we asked about the three main reasons for giving formula feeding, pregnant women with the intention of formula feeding mentioned "my partner can give 
formula feeding" (74\%), "better combination with work" (52\%), and "too busy, no time for breastfeeding" (27\%), (Table 4).

Table 4 The proportion of pregnant women responding to the main reasons and influences to give breastfeeding or formula feeding

\begin{tabular}{|c|c|c|}
\hline & $\begin{array}{l}\text { Intention BF } \\
\mathrm{N}=268\end{array}$ & $\begin{array}{l}\text { Intention FF } \\
\mathrm{N}=105\end{array}$ \\
\hline \multicolumn{3}{|l|}{ Main reasons to give breastfeeding } \\
\hline Breastfeeding is the most natural feeding & $238(89 \%)$ & $6(6 \%)$ \\
\hline The health of mother and infant & $233(87 \%)$ & $8(8 \%)$ \\
\hline Contact between mother and infant & $224(84 \%)$ & $5(5 \%)$ \\
\hline The convenience & $103(38 \%)$ & $1(1 \%)$ \\
\hline Other reasons & $31(12 \%)$ & $1(1 \%)$ \\
\hline Reason not known & $10(4 \%)$ & $3(3 \%)$ \\
\hline \multicolumn{3}{|l|}{ Main reasons to give formula feeding } \\
\hline My partner can give formula feeding & $8(3 \%)$ & $78(74 \%)$ \\
\hline Better combination with work & $11(4 \%)$ & $55(52 \%)$ \\
\hline Too busy, no time for breastfeeding & $2(1 \%)$ & $28(27 \%)$ \\
\hline Bad previous breastfeeding experience & $2(1 \%)$ & $25(24 \%)$ \\
\hline Alcohol use or smoking & $2(1 \%)$ & $20(19 \%)$ \\
\hline Other reasons & $4(1 \%)$ & $36(34 \%)$ \\
\hline Not known, unknown & $4(1 \%)$ & $8(8 \%)$ \\
\hline Breastfeeding is not allowed: use of medicines & $1(0 \%)$ & $16(15 \%)$ \\
\hline Breastfeeding contains detrimental substances & $1(0 \%)$ & $11(10 \%)$ \\
\hline Use of marihuana, hash, cannabis & $1(0 \%)$ & $8(8 \%)$ \\
\hline \multicolumn{3}{|l|}{ Main influences to give breastfeeding } \\
\hline Own initiative & $255(95 \%)$ & $10(10 \%)$ \\
\hline Partner & $173(65 \%)$ & $5(5 \%)$ \\
\hline Family, friends & $125(47 \%)$ & $3(3 \%)$ \\
\hline Magazine, radio, television & $75(28 \%)$ & $1(1 \%)$ \\
\hline Midwife & $65(24 \%)$ & $4(4 \%)$ \\
\hline Child health care nurse & $22(8 \%)$ & $0(0 \%)$ \\
\hline Someone else & $20(7 \%)$ & $2(2 \%)$ \\
\hline Information on internet & $20(7 \%)$ & $0(0 \%)$ \\
\hline Hospital nurse & $19(7 \%)$ & $1(1 \%)$ \\
\hline Child health care physician & $18(7 \%)$ & $0(0 \%)$ \\
\hline \multicolumn{3}{|l|}{ Main influences to give formula feeding } \\
\hline Own initiative & $7(3 \%)$ & $91(87 \%)$ \\
\hline Partner & $3(1 \%)$ & $52(50 \%)$ \\
\hline Family, friends & $3(1 \%)$ & $37(35 \%)$ \\
\hline Someone else & $4(1 \%)$ & $11(10 \%)$ \\
\hline Midwife & $2(1 \%)$ & $8(8 \%)$ \\
\hline Magazines, radio, television & $1(0 \%)$ & $5(5 \%)$ \\
\hline Information on internet & $1(0 \%)$ & $4(4 \%)$ \\
\hline Hospital nurse & $1(0 \%)$ & $4(4 \%)$ \\
\hline Child health care nurse & $1(0 \%)$ & $4(4 \%)$ \\
\hline Child health care physician & $1(0 \%)$ & $3(3 \%)$ \\
\hline
\end{tabular}

$\mathrm{BF}=$ breastfeeding; $\mathrm{FF}=$ formula feeding

The percentage concerns the three main influences; therefore, the sum exceeds $100 \%$

When we asked about the three main influences on the intention to give breastfeeding or formula feeding most women with the intention to breastfeed mentioned, "own 
initiative" (95\%) followed by "partner" (65\%), "family, and friends" (47\%). A minority mentioned professional caregivers such as hospital nurses; health care nurses or physicians were as belonging to the three most important influences. About a quarter of women with the intention of breastfeeding mentioned midwives $(24 \%)$, but also mass media $(28 \%)$ as influential (Table 4$)$.

\section{DISCUSSION}

This study showed that intention to breastfeed was a very strong predictor of breastfeeding initiation, and mediated all variance of the preceding ASE factors and external factors, as is the assumption of the model. ${ }^{18}$ Almost all ASE variables were found to be related to breastfeeding initiation. The results of the logistic regression analysis with all ASE variables in one model revealed that the strongest factors that explained breastfeeding initiation were: the attitude (pros and cons), and the social norm of significant others.

Before discussing these findings, we review possible limitations of this study. Selective respons with regard to breastfeeding intention was avoided by concealing the aim of the study in the informed consent letter; however, we cannot preclude that some nonresponse is related to breastfeeding or its determinants, for instance low education. In spite of this, we do not believe that under-representation of lowly educated women bias the relations between breastfeeding and its determinants very much. There was no differential loss to follow-up, because the follow-up rates were quite similar for women with and without prenatal intention to breastfeed. With respect to the validity of the ASE questionnaires, reliability analysis showed reasonable internal consistency of the ASE scales; and the different ASE categories were sufficiently distinct to allow multivariate analysis. By studying ASE determinants in a prospective way, we avoided recall bias, and biases caused by the mother's attribution of her intentions to external influences, and by justification of one's behavior with hindsight. The information about self-reported reasons to start formula feeding may however complement the information on the ASE determinants and may help explaining them. Our results correspond with the study of Rademakers, ${ }^{16}$ also based on the ASE model. She showed that the determinants of intention to breastfeed were a positive attitude, positive social norm, and social pressure to formula feed; and that positive previous breastfeeding experience predicted breastfeeding intention. These findings support the usefulness of the ASE model for explaining and predicting the initiation of breastfeeding.

Self-efficacy is found to be an important predictor for other behaviors such as smoking cessation $^{32}$ but not in breastfeeding initiation. This may be explained in part by the correlation between the cons of breastfeeding and situational self-efficacy, because the difficulty of breastfeeding in different situations (for instance in public) may be perceived as a disadvantage of breastfeeding. This implicates that to realize that cons are turned into pros, first the situational self-efficacy has to be improved.

Our results show that previous breastfeeding experience, higher maternal education, and non-smoking mothers (before the pregnancy) are associated with a higher initiation of breastfeeding. This is in line with other studies. ${ }^{4,6,7}$ In our multivariate analysis without the ASE determinants, previous breastfeeding experience was the single independent predictor of breastfeeding initiation, and maternal age, education and non-smoking were 
not independently associated with breastfeeding. Maternal education and maternal age are correlated with previous breastfeeding experience; one of the reasons not to breastfeed is a bad previous experience. Especially low educated women may have an increased risk on getting a first baby at young age, on having a bad breastfeeding experience and a low self-efficacy in giving breastfeeding next time. After discussing these findings, we review possible limitations of this study. Selective response with regard to breastfeeding intention was avoided by concealing the aim of the study in the informed consent letter. However, we cannot preclude that some non-response is related to breastfeeding or its determinants, for instance low education. In spite of this, we do not believe that under-representation of lowly educated women bias the relations between breastfeeding and its determinants very much. There was no differential loss to follow-up, because the follow-up rates were quite similar for women with and without prenatal intention to breastfeed. With respect to the validity of the ASE questionnaires, reliability analysis showed reasonable internal consistency of the ASE scales; and the different ASE categories were sufficiently distinct to allow multivariate analysis. By studying ASE determinants in a prospective way, we avoided recall bias, and biases caused by the mother's attribution of her intentions to external influences, and by justification of one's behavior with hindsight. The information about self-reported reasons to start formula feeding may however complement the information on the ASE determinants and may help explaining them. Self reported reasons for giving formula feeding such as "too busy, no time for breastfeeding" are related to self-efficacy, and indicate that interventions could be focused on strengthening self-efficacy and professional support for breastfeeding. The reason "better combination with work" is related with ASE determinants at work. We found low levels of social support for breastfeeding and of social support for breastfeeding at work. This indicates that there is still room for improvement.

\section{Implications for research}

The latest version of the ASE model, now referred to as the I-Change Model ${ }^{33-35}$ suggests the importance of goal setting strategies by formulating action plans. Current studies about one type of action plans, namely implementation intentions ${ }^{36,37}$ also highlight the benefits of goal setting strategies and recommend to very clearly specify the goals in terms of time and place. More research is needed to analyze the impact of goal setting techniques to predict initiation and maintenance of breastfeeding.

\section{Implications for practice}

The results of the present study may have several practical implications. It is important to obtain insight into the determinants of the initiation of breastfeeding and to find out how pregnant women can be stimulated with theory-based interventions to promote breastfeeding. Previous breastfeeding and social norm of significant others were of a major influence. This indicates that a greater effect can be reached by including significant others in the prenatal counseling and education of breastfeeding and by offering lay or peer group support. In addition to interventions directed at the parents (micro level), attention should be paid to the social environment of the mother (meso 
level). The impact of the perceived pros of breastfeeding suggests that caregivers need to focus their intervention on the advantages of breastfeeding.

Because actual breastfeeding initiation is highly predicted by intention, prenatal can be targeted in the following way: in women not intending to breastfeed, the counselor's attention can be focused on promoting the initiation of breastfeeding; and in women intending to breastfeed, the emphasis can be shifted towards supporting the continuation of breastfeeding. The Theory of Behavioral Change of Prochaska et $a{ }^{31}{ }^{31}$ that incorporated the ASE model, implies that changing ASE determinants in non-intenders (pre-contemplators) can result in a change to intention to breastfeed (contemplators) and consequently actual breastfeeding initiation (action). Relevant for this is the timing of the intervention directed on precontemplators, and on intermediary groups. The majority of women in the Netherlands decide on breastfeeding before or during the pregnancy. The fact that hospital nurses and physicians and nurses of the child health care were mentioned by a minority as belonging to the three main influences means that the pregnant women have to pick up information on the pros and the cons from midwives and from other sources, such as the mass media. Midwives are very appropriate to promote and support breastfeeding because in 1998 they provide in the Netherlands $76 \%$ of the prenatal obstetrical care $^{38}$ (while the remainder is covered by general practitioners and gynecologists). Breastfeeding counseling is an official part of counseling given by midwives, but the responsibility for breastfeeding promotion and support is not described explicitly in their job descriptions. Hence we recommend that breastfeeding counseling be included in the tasks of the midwives, and to make the training of breastfeeding counseling a structural part into their general curriculum.

Prenatal peer groups for instance prenatal exercises groups offers opportunities to promote the initiation by increasing social norm and support, especially when the partner can be involved.

Formula feeders had low scores of social support of breastfeeding, especially at the workplace. This means, there is still room for improvement compared to when everyone had high scores. Women have to inform their employer and colleagues already during the pregnancy that they are intending to give breastfeeding, and have to demand their support and facilities in combining breastfeeding and work. A number of women have insufficient possibilities to breastfeed at the workplace $e^{39,40}$ in spite of legal rules.

\section{ACKNOWLEDGEMENTS}

The development and evaluation plan was submitted as a grant proposal for the National Prevention Program of ZONMw ("Netherlands Organization for Health Research and Development") approved in 1999 and started in 2000. The authors would like to thank ZONMw and the CZ-group for their financial support. Furthermore, we would like to express our gratitude to the following Home Health Care organizations for their collaboration: The Home Health Care West-Mining Area, The Home Health Care Middle-Limburg, and ZorggroepThuis South-East Limburg. Finally, we would like to thank the steering committee for their advice and support during the research project. 


\section{REFERENCES}

1. WHO. International code of marketing of breast-milk substitutes. WHO Chronicle 1981;35:112-7.

2. WHO. Evidence for the ten steps to successful breastfeeding. Geneva; 1998.

3. Lanting CI, Herschderfer K, Van Wouwe JP, Reijneveld SA. Peiling melkvoeding van zuigelingen 2001/2002 en het effect van certificering op de borstvoedingscijfers. Leiden: TNO-PG; 2002. Report No.: 2002.309.

4. Scott JA, Aitkin I, Binns CW, Aroni RA. Factors associated with the duration of breastfeeding amongst women in Perth, Australia. Acta Paediatr 1999;88:416-21.

5. Van der Wal MF. Breast feeding among autochthonous and allochthonous mothers in Amsterdam, 1992-1993. Ned Tijdschr Geneeskd 1995;139:19-22.

6 Bulk Bunschoten AMW, Van Bodegom S, Reerink JD, Pasker de Jong PCM, De Groot CJ. Reluctance to continue breastfeeding in The Netherlands. Acta Paediatr 2001;90:1047-1053.

7. Rogers IS, Emmett PM, Golding J. The incidence and duration of breast feeding. Early Hum Dev 1997;49 Suppl:S45-74.

8. Van Hagen EE, Van Wouwe JP, Van Buuren S, Burgmeijer RJF, Hirasing RA, De Jonge GA. Peiling veilig slapen 1999. Leiden: TNO-PG; 2000. Report No.: PG/JGD/2000.047.

9. Manstead ASR, Proffitt C, Smart JL. Predicting and Understanding Mothers' InfantFeeding Intentions and Behavior: Testing the theory of reasoned Action. J Pers Soc Psychol 1983;44:657-71.

10. Kloeblen Tarver AS, Thompson NJ, Miner KR. Intent to breast-feed: the impact of attitudes, norms, parity, and experience. Am J Health Behav 2002;26:182-7.

11. Kessler LA, Gielen AC, Diener West M, Paige DM. The effect of a woman's significant other on her breastfeeding decision. J Hum Lact 1995;11:103-9.

12. Humphreys AS, Thompson NJ, Miner KR. Assessment of breastfeeding intention using the Transtheoretical Model and the Theory of Reasoned Action. Health Educ Res 1998; 13:331-341.

13. Quarles A, Williams PD, Hoyle DA, Brimeyer M, Williams AR. Mothers' intention, age, education and the duration and management of breastfeeding. Maternal Child Nursing Journal 1994;22:102-8.

14. Goksen F. Normative vs. attitudinal considerations in breastfeeding behavior: multifaceted social influences in a developing country context. Soc Sci Med 2002;54:1743-53.

15. Wambach KA. Breastfeeding intention and outcome: a test of the theory of planned behavior. Res Nurs Health 1997;20:51-9.

16. Rademakers GM. Determinanten van de keuze en de duur van borstvoeding. [Scriptie]. Maastricht: Universiteit Maastricht; 1998.

17. Termote M, De Vries H, Kools EJ, Thijs C. Psycho-social factors associated with the duration of breastfeeding. A longitudinal study. Submitted for publication 2004.

18. De Vries H, Mudde A. Predicting stage transitions for smoking cessation applying The Attitude-Social Influence-Efficacy model. Psych Health 1998;13:369-85.

19. De Vries H, Dijkstra M, Kuhlman P. Self-efficacy: the third factor besides attitude and subjective norm as predictor of behavioral intentions. Health Educ Res 1988;3:273-282.

20. Fishbein M, Ajzen I. Beliefs, attitudes, intention, and behavior: an introduction to theory and research: Reading, Mass: Addison Wesley; 1975.

21. Bandura A. Social foundations of thought and action: A social cognitive theory. Englewood Cliffs: New York: Prentice Hall; 1986. 
22. De Vries H, Backbier E, Kok G, Dijkstra M. The impact of social influences in the context of attitude, self-efficacy, intention, and previous behavior as predictors of smoking onset. J Appl Social Psychol 1995;25:237-257.

23. Ajzen I. Attitudes, Personality, and Behavior: Open University Press; 1988.

24. De Vries H, Mudde AN, Dijkstra A, Willemsen MC. Differential beliefs, perceived social influences, and self-efficacy expectations among smokers in various motivational phases. Prev Med 1998;27:681-9.

25. Pieterse ME, Seydel ER, De Vries H, Mudde AN, Kok GJ. Effectiveness of a minimal contact smoking cessation program for Dutch general practitioners: a randomized controlled trial. Prev Med 2001;32:182-90.

26. Bakker MJ, Mullen PD, De Vries H, Van Breukelen G. Feasibility of implementation of a Dutch smoking cessation and relapse prevention protocol for pregnant women. Patient Educ Couns 2003;49:35-43.

27. Bolman C, De Vries H, Van Breukelen G. Evaluation of a nurse-managed minimalcontact smoking cessation intervention for cardiac inpatients. Health Educ Res 2002;17:99-116.

28. Kools EJ, Thijs C, Van den Brandt PA, De Vries H. A Breastfeeding Promotion and Support Program in the Netherlands: The Randomized Trial. Prev Med (accepted).

29. Reliability and Item Analysis. In. http://www.statsoft.com/textbook/streliab.html.

30. Cortina JM. What Is Coefficient Alpha? An Examination of Theory and Applications. J Appl Psychol 1993;78:98-104.

31. StataCorp. Stata statistical software release 7.0: In: College Station TX: Stata corporation; 2001.

32. Bolman C, De Vries H. Psycho-social determinants and motivational phases in smoking behavior of cardiac inpatients. Prev Med 1998;27:738-47.

33. De Vries H, Mudde A, Leijs I, Charlton A, Vartiainen E, Buijs G, et al. The European Smoking prevention Framework Approach (ESFA): an example of integral prevention. Health Educ Res 2003;18:611-26.

34. De Vries H, Leszwijn J, Hol M, Van der Steeg M. Skin Cancer Prevention: Behavior and Motives of Dutch Adolescents. Eur J Cancer Prevention (accepted).

35. De Vries H, Mesters I, Van der Steegh H, Honing C. The general public's information needs and perception regarding hereditary cancer: an application of the integrated change model. Pat Educ Couns (in press) 2004.

36. Gollwitzer P. Implementation Intentions. Strong Effects of Simple Plans. American Psychologist 1999:493-503.

37. Sheeran P, Silverman M. Evaluation of three interventions to promote workplace health and safety: evidence for the utility of implementation intentions. Soc Sci Med. 2003;56:2153-63.

38. Hingstman 1, Wiegers TA. Verloskundigen: Aanbod verloskundigen. In. http://www.nivel.nl/verloskundige/verlosaanbod1.shtml ed: NIVEL; 2001.

39. Duberstein-Lindberg L. Women's decisions about breastfeeding and maternal employment. Journal of Marriage and the Family 1996;58:239-251.

40. Hills Bonczyk SG, Avery MD, Savik K, Potter S, Duckett LJ. Women's experiences with combining breastfeeding and employment. Journal of Nurse Midwifery 1993;38:257-66. 



\begin{abstract}
Objective. The aim was to evaluate the behavioral determinants of the continuation of breastfeeding until three months.

Study design. A prospective cohort study using the ASE model in ten child health care centers.

Results. At the birth, $73 \%$ of the mothers started with breastfeeding and $39 \%$ of them continued at least three months. Mothers who continued for three months differed in almost all the ASE (attitude, social support, self-efficacy) determinants from mothers who discontinued. In the multivariate logistic regression analysis, social support for formula feeding from significant others and situational self-efficacy for breastfeeding made a significant independent contribution to the continuation of breastfeeding. Among the external determinants, the strongest predictor of continuation was the intention to return to work at one month postpartum.

Conclusions. The ASE model is valid for investigating the continuation of breastfeeding. In the discussion, we use the results to target interventions.
\end{abstract}




\section{INTRODUCTION}

Although breastfeeding has been endorsed as the optimal method of infant feeding by the WHO (World Health Organization) and UNICEF, many babies are breastfed only briefly in the industrialized countries such as the Netherlands. Concern over the unpopularity of breastfeeding and desire for higher rates of both frequency and continuation has led to promotional efforts in several countries and to the publication of the WHO code. ${ }^{1}$ The international recommendation by the WHO is to stimulate mothers to perform exclusive breastfeeding for six months, with introduction of complementary foods and continued breastfeeding thereafter. ${ }^{2}$ The Ten Steps to Successful Breastfeeding $^{3}$ organized by UNICEF and the WHO are moving towards implementation.

In the Netherlands, $80 \%$ of women start with breastfeeding, but the breastfeeding rate drops rapidly to $52 \%$ at one month postpartum. After three months the rate is $35 \%$ but after six months it falls to $17 \% .{ }^{4}$ Insight in the behavioral determinants that encourage or discourage continuation of breastfeeding may be helpful in order to design interventions in the child health care that can increase breastfeeding effectively.

Many studies have identified socio-cultural, psychological, biological, and health care factors, which influence breastfeeding. A longer continuation of breastfeeding is seen in women characterized by: having a higher socio-economical status, ${ }^{5}$ higher educational levels ${ }^{5,6}$ older age, ${ }^{5,6}$ not returning to work, ${ }^{5}$ not combining breastfeeding with oral contraception after birth, ${ }^{7}$ not smoking, ${ }^{5}$ having previous breastfeeding experience, ${ }^{8}$ and experiencing postnatal breastfeeding support. ${ }^{3}$ Moreover, a longer continuation is associated with infants: with early mother-infant contact, ${ }^{3}$ with rooming-in, ${ }^{3}$ with feeding on demand, ${ }^{3}$ without health problems, ${ }^{5}$ without early introduction of formula supplements, ${ }^{5}$ without an artificial teat, and without the use of a pacifier. ${ }^{3}$ Few studies have identified the behavioral determinants of the duration of breastfeeding in a systematic way using social-psychological models, such as the ASE model. Behavioral determinants of breastfeeding duration were intention, social norm at work and selfefficacy. ${ }^{9,10}$

The aim of the present study was to evaluate the determinants of breastfeeding until at least three months postpartum once mothers had initiated breastfeeding. The rationale for the choice for three months was the increasing health benefits with increasing breastfeeding duration and the high rate of cessation in the first months. Therefore, the greatest benefits for the population would be gained by increasing breastfeeding rates in the first months. ${ }^{11}$

We used the ASE model (Attitude-Social influence-Self-Efficacy model), ${ }^{12,13}$ (Figure 1) that originated in The Theory of The Reasoned Action of Fishbein \& Ajzen, ${ }^{14}$ which has evolved in several areas since Bandura's concept of self-efficacy ${ }^{15}$ was added to it. The ASE model states that behavior is best predicted by intention, which in turn, is predicted by attitudes, social influences, and self-efficacy. The ASE model has been used to explain various types of health-related behavior, such as dieting and smoking. ${ }^{16-18}$ 


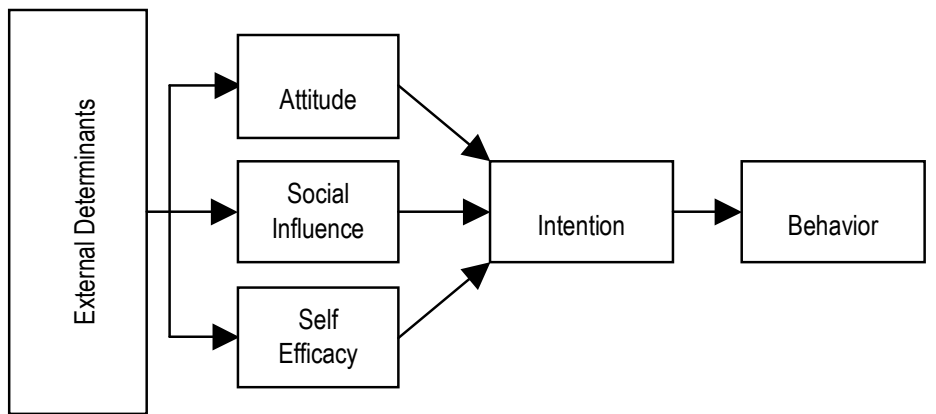

Figure 1 The ASE model (adapted from De Vries \& Mudde, 1998)

\section{METHODS}

\section{Design and study population}

The data were obtained from the control group (usual care) within a group-randomized trial of the efficacy of a breastfeeding promotion and support program. Three Home Health Care organizations in the province of Limburg, the Netherlands, participated. The study received approval of the medical ethical committee of Maastricht University.

\section{Inclusion criteria and recruitment}

Study candidates were pregnant women who applied for maternity care at the Home Health Care services from December 2000-December 2002. About 60\% of pregnant mothers were users of this maternity care; the remaining others used similar care facilities from commercial organizations (not included in this study). The candidates from the intake lists of the maternity care were sent an informed consent letter before the first home visit. At the same time, they received the first questionnaire (T0) to be returned during the prenatal home visit. Those who agreed to participate received two follow-up questionnaires, the first (T1) of which had to be returned during the consultations at one month, and the second (T2) at three months postpartum. If participants failed to return a questionnaire, a telephone call was made in order to obtain the most essential follow-up information, including breastfeeding continuation. For the present analyses, mothers were included when they had initiated breastfeeding (as reported in the second questionnaire). Mothers with infants $<2000 \mathrm{~g}$ birth weight were excluded from the analysis.

\section{Measurements}

In the prenatal questionnaire (T0) the following characteristics were measured: maternal age, maternal education, the intention to give breastfeeding or formula feeding, the moment of decision to breastfeed, the previous breastfeeding experience, and the ASE 
determinants including the intention to breastfeed. The ASE items were based on results of an earlier pilot study. ${ }^{10}$

Attitudes. Attitudes toward breastfeeding were assessed by asking the perceived advantages (pros) for the mother herself, her infant, and her partner. Eleven questions measured the advantages (such as, when I give breastfeeding: "I have more contact with my baby"; "I save money"; "I give my baby more resistance to infection"; "It is easy, because the food is directly ready for use"), using 5-point scales ranging from 1 ("fully agree") to 5 ("fully disagree"). The perceived disadvantages (cons) of breastfeeding for the mother herself, infant, and partner were measured by sixteen questions such as when I give breastfeeding: "I have to pay more attention to what I eat or drink"; "I am uncertain about the growth of my baby"; "My partner gets a bonding with my baby less quickly", on 5-point scales ranging from 1 ("fully agree") to 5 ("fully disagree").

Social influence. We measured beliefs of the mother regarding social norms and support from significant others (such as partner, mother, sister, friends, midwife, maternity nurse and child health care nurse and physician) as well from those at the workplace (colleague, employer). Social norms were investigated about with eight questions on 5point scales ranging from 1 ("I must certainly breastfeed") to 5 ("I must certainly formula feed"). Social support of breastfeeding was measured by eight questions on 5point scales, scores ranging from 1 ("very often support") to 5 ("never any support") to giving breastfeeding. Similar questions on support were asked for formula feeding.

Self-efficacy. A distinction was made between self-efficacy to breastfeed and to formula feed, assessing situational and stress self-efficacy for both types of feeding. Questions used 7-point scales ranging from 1 ("very difficult") to 7 ("very easy"). Situational selfefficacy for breastfeeding was assessed by asking how difficult women perceived breastfeeding in the following seven situations: on a journey, on a visit, during a visit from acquaintances, in a public place, at night, at the workplace, expressing breast milk. Stress self-efficacy was asked about with three questions (when mother was stressed, very tired, when the infant was ill). Similar questions were asked for formula feeding. In the postpartum questionnaire (T1), we asked about the place and type of delivery, whether the infant stayed in hospital or at home after birth, alcohol consumption, maternal smoking, asthma, eczema, (food) allergy in family, intention to return to work and the information pertinent to the exclusion criterion: the use of maternity care of the Home Health Care organization and the birth weight of the infant. Intention to return to work was only asked of women who gave breastfeeding and were intending to return to work.

\section{Outcome measurement}

The questionnaire at three months postpartum asked whether the mother used exclusive breastfeeding, complementary breastfeeding, or formula at that moment and the number of weeks of exclusive or complementary breastfeeding continuation. In this study, initiation of breastfeeding was defined as all feeding practices in combination with breast milk (exclusive breastfeeding; feeding of expressed maternal milk; or breastfeeding with complementary liquids or with complementary formula feeding). Formula feeding meant feeding with formula feeds without any breastfeeding. 


\section{Statistical analyses}

Chi-square tests for categorical variables and t-tests for continuous variables were used to compare breast and formula feeding mothers. For each ASE concept, a mean score was computed by averaging the scores on the items. Reliability analyses assessed the reliability (expressed as Cronbach's alpha) of the perceived pros and cons, social influences and self-efficacy scores. The predictors of breastfeeding continuation were analyzed using multivariate logistic regression analysis. First, the external determinants were included in the model (Model 1). Second, the external and ASE factors were entered (Model 2). Because we did not know how previous breastfeeding fitted in the ASE model we performed these analyses with and without previous breastfeeding in the models. We considered the P-value $<0.05$ as statistically significant. The analysis was carried out using STATA 7.0. ${ }^{19}$

\section{RESULTS}

\section{Subjects and follow-up rate}

Of the 519 candidates on the intake list of the maternity care, 373 of the pregnant women gave informed consent and filled in the prenatal questionnaire. Of these 373 participants, 341 (91\%) completed the questionnaire at one month postpartum, and 272 (73\%) completed the questionnaire at three months postpartum.

\section{Initiation of breastfeeding}

After the birth, 248 of the 341 participants 73\% initiated breastfeeding and 132 (53\%) of them continued breastfeeding for at least three months (Table 1). More mothers started with breastfeeding if they had a higher education, were not (daily) smokers, or were multiparas with previous breastfeeding experience. Of the mothers who initiated breastfeeding $72 \%$ (179/248) made the decision before the pregnancy, $26 \%(64 / 248)$ during the pregnancy and $2 \%(4 / 248)$ did not remember the time of decision. Asthma, eczema, or food allergy in the family was not predictive for the initiation of breastfeeding.

\section{Descriptives of women who did or did not continue breastfeeding}

Table 1 shows the external and ASE characteristics of the participants. Most of the participants were older than 30 years, had a middle school education, and were primiparas. The intervention and control cohorts were largely comparable at baseline. External factors that were statistically significant for predicting breastfeeding continuation were non- (daily) smoking; previous breastfeeding experience; time of decision before the pregnancy; and the intention to return to work after birth. Of the non- (daily) smoking mothers, 57\% (113/197) continued breastfeeding, compared with $26 \%(7 / 27)$ of the smoking mothers. Furthermore, 61\% (57/93) of the multiparas with previous breastfeeding experience continued, compared with $33 \%(8 / 24)$ of the multiparas without previous experience and with $51 \%(67 / 131)$ of the primiparas. When 
the decision was made before pregnancy, 59\% (106/179) of the breastfeeding mothers continued, compared with $41 \%(26 / 64)$ of the mothers who made the decision during pregnancy. The continuation rate was higher in mothers who intended to return to work than in those who did not. Breastfeeding continued in $60 \%(27 / 41)$ of those planning to return to work less than halftime and in $67 \%(62 / 92)$ of those planning to return to work halftime or more. This could be compared with $34 \%$ (31/91) in those who had no intention at all of returning to work. There was no difference in the continuation of breastfeeding between mothers when a child had or did not have asthma, or whether there was a history of eczema or food allergy in the family.

Table 1 Baseline characteristics according to breastfeeding at delivery and the continuation of breastfeeding at 3 months

\begin{tabular}{|c|c|c|c|c|c|c|c|}
\hline \multirow{3}{*}{ Determinants } & & \multicolumn{3}{|c|}{ Feeding at the birth } & \multicolumn{3}{|c|}{$\begin{array}{l}\text { Breastfeeding } \\
\text { continuation at } 3 \text { months }\end{array}$} \\
\hline & & Total & $\begin{array}{l}\text { Formula } \\
\text { feeding }\end{array}$ & Breastfeeding & Yes & No & \\
\hline & & $\mathrm{N}=341(100 \%)$ & $\mathrm{N}=93$ & $\mathrm{~N}=248(73 \%)$ & $\mathrm{N}=132(53 \%)$ & $\mathrm{N}=116$ & P-value \\
\hline \multirow[t]{3}{*}{ Maternal age } & $<25 \mathrm{yr}$ & 26 & 10 & $16(62 \%)$ & $5(31 \%)$ & 11 & 0.14 \\
\hline & $25-30 \mathrm{yr}$ & 151 & 43 & $108(72 \%)$ & $56(52 \%)$ & 52 & \\
\hline & $\geq 31 \mathrm{yr}$ & 164 & 40 & $124(76 \%)$ & $71(57 \%)$ & 53 & \\
\hline \multirow[t]{3}{*}{ Maternal education } & Low & 62 & 25 & $37(60 \%)$ & $13(35 \%)$ & 24 & 0.01 \\
\hline & Middle & 198 & 53 & $145(73 \%)$ & $75(52 \%)$ & 70 & \\
\hline & High & 81 & 15 & $66(81 \%)$ & $44(67 \%)$ & 22 & \\
\hline \multirow[t]{3}{*}{ Alcohol use last months } & Yes & 62 & 16 & $46(74 \%)$ & $24(52 \%)$ & 22 & 0.93 \\
\hline & No & 244 & 66 & $178(73 \%)$ & $96(54 \%)$ & 82 & \\
\hline & Missing & 35 & 11 & $24(69 \%)$ & $12(50 \%)$ & 12 & \\
\hline \multirow[t]{3}{*}{ Smoking last months } & Yes & 49 & 22 & $27(55 \%)$ & $7(26 \%)$ & 20 & 0.01 \\
\hline & No/ Not daily & 257 & 60 & $197(77 \%)$ & $113(57 \%)$ & 84 & \\
\hline & Missing & 35 & 11 & $24(69 \%)$ & $12(50 \%)$ & 12 & \\
\hline \multirow{4}{*}{$\begin{array}{l}\text { Asthma, eczema, } \\
\text { (food) allergy in family } \\
\text { Place of delivery }\end{array}$} & Yes & 166 & 40 & $126(76 \%)$ & $67(53 \%)$ & 59 & 0.99 \\
\hline & No, not known & 175 & 53 & $122(70 \%)$ & $65(53 \%)$ & 57 & \\
\hline & At home/Policlinic & 195 & 56 & $139(71 \%)$ & $76(55 \%)$ & 63 & 0.61 \\
\hline & Hospital & 146 & 37 & $109(75 \%)$ & $56(51 \%)$ & 53 & \\
\hline \multirow[t]{2}{*}{ Type of delivery } & Normal & 254 & 70 & $184(72 \%)$ & $102(55 \%)$ & 82 & 0.24 \\
\hline & Artificial $\left.^{1}\right)$ & 87 & 23 & $64(74 \%)$ & $30(47 \%)$ & 34 & \\
\hline \multirow[t]{2}{*}{ Stay of infant at birth } & At home & 269 & 69 & $200(74 \%)$ & $110(55 \%)$ & 90 & 0.25 \\
\hline & In hospital & 72 & 24 & $48(67 \%)$ & $22(46 \%)$ & 26 & \\
\hline \multirow{3}{*}{$\begin{array}{l}\text { Previous breastfeeding } \\
\text { experience }\end{array}$} & No, multiparas & 62 & 38 & $24(39 \%)$ & $8(33 \%)$ & 16 & 0.04 \\
\hline & Yes, multiparas & 106 & 13 & $93(88 \%)$ & $57(61 \%)$ & 36 & \\
\hline & No, primiparas & 173 & 42 & $131(76 \%)$ & $67(51 \%)$ & 64 & \\
\hline \multirow{4}{*}{$\begin{array}{l}\text { Decision } \\
\text { to breastfeeding or } \\
\text { formula feeding }\end{array}$} & Before pregnancy & 238 & 59 & $179(75 \%)$ & $106(59 \%)$ & 73 & 0.00 \\
\hline & During pregnancy & 94 & 30 & $64(68 \%)$ & $26(41 \%)$ & 38 & \\
\hline & Not known & 7 & 3 & $4(57 \%)$ & $0(0 \%)$ & 4 & \\
\hline & Missing & 2 & 1 & $1(50 \%)$ & $0(0 \%)$ & 1 & \\
\hline \multirow{4}{*}{$\begin{array}{l}\text { Intention to return } \\
\text { to work') }\end{array}$} & No & & & 91 & $31(34 \%)$ & 60 & 0.00 \\
\hline & Less than halftime & & & 41 & $27(60 \%)$ & 14 & \\
\hline & Halftime or more & & & 92 & $62(67 \%)$ & 30 & \\
\hline & Missing & & & 24 & $12(50 \%)$ & 12 & \\
\hline
\end{tabular}

1)Artificial delivery: delivery with Caesarea section, forceps, suction, or with breech presentation

2)By questionnaire 1 month postpartum (T1)

Mothers who continued breastfeeding for at least three months differed on all the ASE determinants from mothers who did not do, except for social support for breastfeeding of significant others, social support for formula feeding at work and for situational stress 
self-efficacy to formula feeding (Table 2). This was also reflected in the crude odds ratios.

Table 2 The mean scores of ASE determinants of mothers at delivery compared with mothers at 3 months $(\mathrm{N}=243)$

\begin{tabular}{|c|c|c|c|c|c|c|c|c|}
\hline \multirow[b]{3}{*}{ Determinants } & \multirow[b]{3}{*}{$\begin{array}{l}\text { No } \\
\text { items }\end{array}$} & \multirow[b]{3}{*}{ Scale } & \multirow[b]{3}{*}{$\begin{array}{l}\text { Cronbach's } \\
\text { alpha }\end{array}$} & \multicolumn{2}{|c|}{$\begin{array}{l}\text { Breastfeeding continuation } \\
\text { at } 3 \text { months }\end{array}$} & \multirow[b]{3}{*}{ P-value ${ }^{1)}$} & \multirow[b]{3}{*}{$\begin{array}{l}\text { Crude } \\
\mathrm{OR}^{2}\end{array}$} & \multirow[b]{3}{*}{$\left.95 \% \mathrm{Cl}^{2}\right)$} \\
\hline & & & & Yes (N=132) & No $(\mathrm{N}=116)$ & & & \\
\hline & & & & Mean (SD) & Mean (SD) & & & \\
\hline Pros BF & 11 & $1-5^{3)}$ & 0.78 & $3.47(0.51)$ & $3.19(0.50)$ & 0.000 & 2.90 & $1.54-5.44$ \\
\hline Cons BF & 16 & $1-5^{3)}$ & 0.74 & $2.78(0.36)$ & $3.06(0.46)$ & 0.000 & 0.22 & $0.10-0.48$ \\
\hline $\begin{array}{l}\text { Social norm BF significant } \\
\text { others }\end{array}$ & 6 & $1-5^{4)}$ & 0.87 & $3.91(0.58)$ & $3.51(0.57)$ & 0.000 & 4.46 & $2.39-8.32$ \\
\hline Social norm BF at work & 2 & $1-5^{4)}$ & 0.66 & $3.17(0.49)$ & $3.04(0.40)$ & 0.019 & 2.21 & $1.09-4.48$ \\
\hline $\begin{array}{l}\text { Social support BF significant } \\
\text { others }\end{array}$ & 6 & $\left.1-5^{5}\right)$ & 0.90 & $3.50(0.78)$ & $3.31(0.93)$ & 0.069 & 1.30 & $0.90-1.87$ \\
\hline Social support BF at work & 2 & $1-5^{5)}$ & 0.87 & $2.02(1.19)$ & $1.63(1.01)$ & 0.005 & 1.25 & $0.94-1.66$ \\
\hline $\begin{array}{l}\text { Social support FF significant } \\
\text { others }\end{array}$ & 6 & $1-5^{5)}$ & 0.92 & $1.84(0.93)$ & $2.56(1.00)$ & 0.000 & 0.44 & $0.31-0.61$ \\
\hline Social support FF at work & 2 & $1-5^{5)}$ & 0.91 & $1.50(0.93)$ & $1.65(1.10)$ & 0.231 & 0.70 & $0.50-1.00$ \\
\hline Situational self-efficacy BF & 7 & $1-7^{6)}$ & 0.81 & $4.71(0.96)$ & $4.01(0.96)$ & 0.000 & 2.36 & $1.68-3.30$ \\
\hline Stress self-efficacy BF & 3 & $1-7^{6)}$ & 0.84 & $3.74(1.24)$ & $3.15(1.06)$ & 0.000 & 1.64 & $1.25-2.16$ \\
\hline Situational self-efficacy FF & 6 & $1-7^{6)}$ & 0.81 & $5.11(0.95)$ & $5.30(0.90)$ & 0.110 & 0.80 & $0.58-1.08$ \\
\hline Stress self-efficacy FF & 3 & $1-7^{6)}$ & 0.85 & $4.97(1.11)$ & $5.05(1.01)$ & 0.531 & 0.80 & $0.59-1.08$ \\
\hline
\end{tabular}

$\mathrm{BF}=$ breastfeeding; $F F=$ formula feeding

1)From t-tests

2)From multivariate logistic regression, for each ASE determinant separately, the crude odds ratio means the increase of the odds for one point increase on the scale

3) $1=$ fully disagree, $5=$ fully agree with advantages (pros); or with disadvantages (cons) of breastfeeding

4) $1=1$ must certainly formula feed, $5=1$ must certainly breastfeed

5) $1=$ never support, $5=$ =very often support of breastfeeding; or of formula feeding

6) $1=$ very difficult, $7=$ =very easy to give breastfeeding; or to give formula feeding

\section{Predictors of breastfeeding continuation}

In the multivariate logistic regression analysis, the strongest independent predictor amongst the external determinants of breastfeeding continuation was the intention to return to work at birth (odds ratio 2.93 for less than half time and 3.40 for half time or more), Table 3, Model 1. Mothers who smoked (daily) during the last months of pregnancy had less chance of breastfeeding continuation compared with non-smoking mothers (odds ratio 0.35). When the ASE variables were added to the model, the following were found to make an independent and significant contribution to the continuation of breastfeeding: low social support for formula feeding from significant others; and high situational self-efficacy for breastfeeding (Table 3, Model 2: each point increase on the 1-5 scale increased the odds of breastfeeding continuation with factors of 0.47 for social support of formula feeding from significant others and 2.09 for each point on the 1-7 scale of situational self-efficacy of breastfeeding). The relations between the external determinants and the ASE determinants were independent of previous breastfeeding experience (odds ratios did not change much between models when previous breastfeeding was omitted from the models, results not shown). 
Factors Explaining the Continuation of Breastfeeding

Table 3 Predictors of breastfeeding continuation, multivariate logistic regression analysis $(\mathrm{N}=248)$

\begin{tabular}{|c|c|c|c|c|c|c|}
\hline \multicolumn{3}{|l|}{ Variable } & \multicolumn{2}{|c|}{ Model 1} & \multicolumn{2}{|c|}{ Model 2} \\
\hline & & & $\mathrm{OR}^{1)}$ & $95 \% \mathrm{Cl}$ & $\mathrm{OR}^{1)}$ & $95 \% \mathrm{Cl}$ \\
\hline \multirow[t]{3}{*}{ Maternal age } & $<25 \mathrm{yr}$ & & 0.62 & $0.17-2.19$ & 0.38 & $0.07-2.05$ \\
\hline & $25-30 \mathrm{yr}$ & & 1.00 & Reference & 1.00 & Reference \\
\hline & $\geq 31 \mathrm{yr}$ & & 1.18 & $0.64-2.17$ & 1.41 & $0.66-3.00$ \\
\hline \multirow[t]{3}{*}{ Maternal education } & Low & & 0.81 & $0.34-1.96$ & 0.81 & $0.29-2.30$ \\
\hline & Middle & & 1.00 & Reference & 1.00 & Reference \\
\hline & High & & 1.37 & $0.70-2.67$ & 1.75 & $0.75-4.09$ \\
\hline \multicolumn{7}{|c|}{ Alcohol use last month } \\
\hline Yes (vs. no) & & & 0.67 & $0.32-1.38$ & 0.46 & $0.17-1.23$ \\
\hline \multicolumn{7}{|l|}{ Smoking last month } \\
\hline Yes (vs. no, not da & aily) & & $0.35^{*}$ & $0.13-0.97$ & $0.18^{*}$ & $0.48-0.71$ \\
\hline \multicolumn{7}{|c|}{ Asthma, eczema, (food) allergy in family } \\
\hline Yes (vs. no, not kn & lown) & & 0.91 & $0.51-1.61$ & 0.79 & $0.38-1.63$ \\
\hline \multicolumn{7}{|c|}{ Place of delivery } \\
\hline Hospital (vs. at hol & me/ policlinic) & & 1.10 & $0.55-2.20$ & 0.85 & $0.36-1.98$ \\
\hline \multicolumn{7}{|c|}{ Type of delivery } \\
\hline Artificial') (vs. natu & & & 0.78 & $0.36-1.70$ & 0.97 & $0.36-2.61$ \\
\hline \multicolumn{7}{|c|}{ Stay of infant at birth } \\
\hline In hospital (vs. at $\mathrm{r}$ & ome) & & 0.71 & $0.33-1.50$ & 1.00 & $0.40-2.52$ \\
\hline \multicolumn{7}{|c|}{ Previous experience breastfeeding } \\
\hline \multicolumn{3}{|c|}{ No, multiparas } & 1.00 & Reference & 1.00 & Reference \\
\hline \multicolumn{3}{|l|}{ Yes, multiparas } & 2.50 & $0.73-8.58$ & 2.24 & $0.55-9.10$ \\
\hline \multicolumn{3}{|l|}{ No, primiparas } & 2.64 & $0.73-9.53$ & 2.53 & $0.55-11.6$ \\
\hline \multicolumn{7}{|l|}{ Decision to BF/FF } \\
\hline \multicolumn{3}{|l|}{ Before pregnancy } & 1.00 & Reference & 1.00 & Reference \\
\hline \multicolumn{3}{|c|}{ During pregnancy } & 0.59 & $0.30-1.16$ & 0.74 & $0.33-1.66$ \\
\hline \multicolumn{7}{|c|}{ Intention to return to work } \\
\hline \multicolumn{3}{|c|}{ No } & 1.00 & Reference & 1.00 & Reference \\
\hline \multicolumn{3}{|l|}{ Less than half-time } & $2.93^{*}$ & $1.24-6.89$ & 2.63 & $0.85-8.10$ \\
\hline \multicolumn{3}{|l|}{ Half-time or more } & $3.40^{* *}$ & $1.69-6.85$ & $3.40^{*}$ & $1.33-8.71$ \\
\hline \multicolumn{2}{|l|}{ ASE variables } & Scale & & & & \\
\hline Pros breastfeeding & & $1-5^{3)}$ & & & 2.30 & $0.96-5.55$ \\
\hline Cons breastfeedin & & $1-5^{3)}$ & & & 0.57 & $0.20-1.69$ \\
\hline Social norm BF sid & ynificant others & $1-5^{4)}$ & & & 2.30 & $0.87-6.04$ \\
\hline Social norm at wor & & $1-5^{4)}$ & & & 1.01 & $0.36-2.86$ \\
\hline Social support BF & significant others & $1-5^{5)}$ & & & 1.01 & $0.53-1.94$ \\
\hline Social support BF & at work & $1-5^{5)}$ & & & 0.92 & $0.55-1.54$ \\
\hline Social support FF & significant others & $1-5^{5)}$ & & & $0.47^{\star \star}$ & $0.28-0.79$ \\
\hline Social support at $v$ & vork & $1-5^{5)}$ & & & 0.86 & $0.49-1.53$ \\
\hline Situational self-effi & cacy BF & $1-7^{6)}$ & & & $2.09^{\star *}$ & $1.32-3.31$ \\
\hline Stress self-efficacy & $\mathrm{BF}$ & $1-7^{6)}$ & & & 1.08 & $0.74-1.57$ \\
\hline Situational self-effi & cacy FF & $1-7^{6)}$ & & & 0.76 & $0.44-1.35$ \\
\hline Stress self-efficacy & $\mathrm{FF}$ & $1-7^{6)}$ & & & 1.02 & $0.66-1.58$ \\
\hline Likelihood Ratio test & & Model & model & 0.000 & & \\
\hline
\end{tabular}

$\mathrm{BF}=$ breastfeeding; $\mathrm{FF}=$ formula feeding

${ }^{*} \mathrm{P}<0.05 ;{ }^{* *} \mathrm{P}<0.01$

Test for trend: Maternal age $P>0.10$; Maternal education $P>0.19$; Intention to return to work model 1 and $2: P=0.00$; model 3 and $4: P>0.01$

1)From multivariate logistic regression analysis: are given for each unit increase on the 1-5 scale of the ASE score

2)Artificial delivery: delivery with section Caesarea, forceps, suction, or with breech presentation

3) 1 =fully disagree, $5=$ fully agree with advantages (pros) or with disadvantages (cons) of breastfeeding

4) $1=$ I must certainly formula feed, $5=\mid$ must certainly breastfeed

5) $1=$ never support, $5=$ very often support of breastfeeding or of formula feeding

${ }^{6) 1} 1=$ very difficult, $7=$ very easy to give breastfeeding give formula feeding 


\section{Reasons and influences for introducing formula feeding}

At the three months follow-up the main reasons for introducing formula feeding after birth were the following: "the quantity of breastfeeding decreased" (54\%), "the breastfeeding was painful" (33\%), "the baby was crying too much" (33\%); "formula feeding better to combine with work" (29\%); and "doubts about the growth of the infant" (24\%), Table 4 . The main influences for introducing formula feeding at the three months follow-up were: "own initiative" (96\%); followed by the influence of "partner" (69\%); of "family, friends, and acquaintances" (33\%); of "someone else" (18\%); and of "the child health care nurse" (17\%). A minority mentioned hospital nurse, information on Internet and magazines, radio and television as belonging to the three most important influences.

Table 4 The perception at 3 months postpartum of mothers who initiated breastfeeding at delivery of the three main reasons and influences for introducing formula feeding

\begin{tabular}{|c|c|c|}
\hline & \multicolumn{2}{|c|}{ Breastfeeding continuation at 3 months $(\mathrm{N}=220)^{*}$} \\
\hline & No $(\mathrm{N}=101)$ & Yes $(N=119)$ \\
\hline \multicolumn{3}{|l|}{ Main reasons for introducing formula feeding } \\
\hline Breastfeeding decreased & $55(54 \%)$ & $15(13 \%)$ \\
\hline Breastfeeding was painful & $33(33 \%)$ & $5(4 \%)$ \\
\hline Baby was crying too much & $33(33 \%)$ & $5(4 \%)$ \\
\hline Formula feeding is better to combine with work & $29(29 \%)$ & $12(10 \%)$ \\
\hline Doubts about the growth of the infant & $24(24 \%)$ & $4(3 \%)$ \\
\hline Bad drinking technique of infant & $22(22 \%)$ & $3(3 \%)$ \\
\hline Other reasons & $20(20 \%)$ & $9(8 \%)$ \\
\hline Problems with starting breastfeeding & $20(20 \%)$ & $1(1 \%)$ \\
\hline Partner can give the bottle & $19(19 \%)$ & $5(4 \%)$ \\
\hline No time for breastfeeding & $12(12 \%)$ & $2(2 \%)$ \\
\hline Bad previous experience with breastfeeding & $6(6 \%)$ & $1(1 \%)$ \\
\hline Hospital admission of infant & $5(5 \%)$ & $2(2 \%)$ \\
\hline Medicines use & $4(4 \%)$ & $0(0 \%)$ \\
\hline Alcohol consumption/ smoking & $4(4 \%)$ & $0(0 \%)$ \\
\hline Detrimental substances in breastfeeding & $4(4 \%)$ & $0(0 \%)$ \\
\hline Unknown & $3(3 \%)$ & $0(0 \%)$ \\
\hline Use of marihuana, hash, cannabis & $2(2 \%)$ & $0(0 \%)$ \\
\hline \multicolumn{3}{|l|}{ Main influences for introducing formula feeding } \\
\hline Own initiative & $97(96 \%)$ & $24(20 \%)$ \\
\hline Partner & $70(69 \%)$ & $18(15 \%)$ \\
\hline Family, friends, acquaintances & $34(33 \%)$ & $6(5 \%)$ \\
\hline Someone else & $18(18 \%)$ & $1(1 \%)$ \\
\hline Child health care nurse & $17(17 \%)$ & $5(4 \%)$ \\
\hline Child health care physician & $15(15 \%)$ & $4(3 \%)$ \\
\hline Hospital nurse & $10(10 \%)$ & $1(1 \%)$ \\
\hline Information on internet & $3(3 \%)$ & $0(0 \%)$ \\
\hline Magazines, radio, television & $2(2 \%)$ & $1(1 \%)$ \\
\hline
\end{tabular}

*28 were missing

The percentages concern the three main influences; therefore, the sum exceeds $100 \%$ 


\section{DISCUSSION}

Almost all ASE determinants were related to the continuation of breastfeeding, except social support for breastfeeding from significant others, social support of formula feeding at work and stress self-efficacy for formula feeding. Multivariate logistic regression analysis suggested that the strongest independent predictors were low social support for formula feeding of significant others and high self-efficacy beliefs to be able to continue breastfeeding in different situations. The impact of self-efficacy has also been reported in other Dutch studies. ${ }^{10,20}$

External factors related to breastfeeding continuation were previous breastfeeding experience, intention to return to work, and non-smoking. In addition, continuation rate was higher when the mother had already taken the decision to breastfeed before pregnancy. This may reflect previous breastfeeding experience, and timing of the decision was not predictive any more if previous breastfeeding was accounted for in the multivariate analysis. In the multivariate analysis, it also appeared that the influence of these external factors was not mediated by the ASE determinants or the effect of external determinants and was largely independent. This is not in agreement with the ASE model as depicted in Figure 1, since in this model there is no direct influence from external factors on the behavior. The model has been extended to include tooth brushing, ${ }^{21}$ to induce habit information, and previous experience fits in that extended model.

Knowledge of ASE determinants can be used as a basis for interventions in populations. However, some caution is necessary, since the effect may be limited if the influences are already optimally exploited. This is also true for determinants, which show the largest independent effect in the multivariate model. As a corollary, factors that do not contribute any more in the multivariate model may nevertheless be worthwhile addressing in interventions, since the room for improvement may be substantial. For instance, social support for breastfeeding at work was not predictive in the multivariate model, but this may be the factor with the largest room for improvement since the scores were lower than for any other determinant (both in the mothers who continued and those who discontinued breastfeeding).

In an earlier study, we studied the determinants of initiation. The most important ones were the attitudes (the pros and cons) towards breastfeeding and social norm of significant others to breastfeeding. ${ }^{22}$ It is important to note that determinants of continuation differed from the determinants of initiation. It is possible that self-selection played a role at this. For instance, perceived advantages of breastfeeding were found to be a major determinant of breastfeeding initiation (with an odds ratio $>10$ ), ${ }^{22}$ and mothers who actually started breastfeeding may all have been fairly convinced of these advantages, so that the room for an influence on breastfeeding continuation was limited. However, the influence of pros and cons might have been higher if we had asked specifically about the advantages of continued breastfeeding. The difference between determinants of initiation and continuation can be used to fine tune counseling pre- and postnatal.

Intention to return to work at one month postpartum and smoking in the last months of pregnancy was strong external determinants independent of the ASE determinants. In other studies, the intention to return to work had no influence on the breastfeeding rates. $^{23,24}$ On the contrary, it has been found that returning to work was the most 
important reason for weaning at six months postpartum. ${ }^{23,25}$ Non-smoking was associated with a longer continuation. This result has also been reported in other studies. ${ }^{5}$

The reasons for introducing formula feeding, such as "the breastfeeding decreased", "the breastfeeding was painful", "the baby was crying" and "formula feeding is better to combine with work", agreed fully with other studies. ${ }^{6,10,26,27}$ Fear of insufficient milk seems universally to be the most import reason for introducing formula feeding. ${ }^{27}$ The decision to introduce formula feeding was primarily made on the mother's own initiative. This has also been mentioned in another Dutch study. ${ }^{6}$ The advantage of the way we measured the ASE determinants is that it was done prospectively (they are related to prediction and prevention). On the other hand, the reasons afterwards are retrospective. Humans are inclined to lay guilt beside him; they try to present themselves as desirable as possible; within the limits of credibility. ${ }^{28}$ It is unclear to what extent reasons afterwards completed the ASE determinants, and whether they could help to focus interventions. However, the reasons for introducing formula feeding "breastfeeding decreased" or "breastfeeding was painful" are related to self-efficacy to resolve problems, and indicate that interventions could be focused on strengthening selfefficacy and professional support for lactation crisis and painful breastfeeding. The reason "formula feed is better to combine with work" is related with ASE determinants at work.

The results of the present study have several practical implications. Special support is necessary for mothers $<25$ year, mothers with a low education, for smoking mothers, and for mothers with no experience with breastfeeding. The fact that low social support from significant others for formula feeding and high situational self-efficacy of breastfeeding has a major influence on the continuation of breastfeeding indicates that more can be gained, from influencing partners, mothers, sisters, friends, midwives and caregivers of the maternity and child health care to increase the support of breastfeeding and self-efficacy in different situations. With regard to the social support, professionals working with (pregnant) mothers need to focus their interventions on coping with breastfeeding problems, such as the insufficient milk syndrome and how to latch on the baby. With regard to situational self-efficacy, women are embarrassed to give breastfeeding in a public place, for instance in a store or in a restaurant. In general, in those places there are not enough possibilities for breastfeeding in a separate room, in stores, mothers use dressing cubicles or toilets to give breastfeeding. Three approaches can be used: to raise the self-efficacy to give breastfeeding in public places; to influence the social norm so that it becomes more accepted; and to create separate rooms for breastfeeding mothers in public places.

In the Netherlands, pregnancy is a strong stimulation for smoking cessation. In the PIAMA study, ${ }^{29} 23.7 \%$ had quit during the pregnancy (counting from 12 weeks before the beginning of the pregnancy). In addition, not smoking in the presence of a baby has been the subject of a mass media campaign in recent years. Less is known about the disadvantages of combining breastfeeding and smoking. It has recently been found that the prevalence of colic was twofold higher among infants of smoking mothers. ${ }^{30}$ Health benefits for mother and child can be obtained by supporting mothers with smoking cessation in the first year postpartum. ${ }^{29}$ This may be used as an action for a combined intervention for breastfeeding continuation with smoking cessation in selected 
subgroups of mothers. Pilot studies are needed to test the feasibility of such a combined approach, since it may be difficult to achieve two goals in one intervention.

\section{ACKNOWLEDGMENTS}

The development and evaluation plan was submitted as a grant proposal for the National Prevention Program of ZONMw ("Netherlands Organization for Health Research and Development") approved in 1999 and started in 2000. The authors would like to thank ZONMw and the CZ-group for their financial support. Furthermore, we would like to express our gratitude to the following Home Health Care organizations for their collaboration: The Home Health Care West-Mining Area, The Home Health Care Middle-Limburg, and ZorggroepThuis South-East Limburg. Finally, we would like to thank the steering committee for their advice and support during the research project.

\section{REFERENCES}

1. WHO. International code of marketing of breast-milk substitutes. WHO Chronicle 1981;35:112-7.

2. WHO. The optimal duration of exclusive breastfeeding. Results of a WHO systematic review. In: http://www.who.int/inf-pr2001/en/note2001-07 WHO; 2001.

3. WHO. Evidence for the ten steps to successful breastfeeding. Geneva; 1998.

4. Lanting CI, Herschderfer K, Van Wouwe JP, Reijneveld SA. Peiling melkvoeding van zuigelingen 2001/2002 en het effect van certificering op de borstvoedingscijfers. Leiden: TNO-PG; 2002 December. Report No.: 2002.309.

5. Scott JA, Binns CW. Factors associated with the initiation and duration of breastfeeding: a review of the literature. Breastfeeding Rev 1999;7:5-16.

6. Bulk Bunschoten AMW, Van Bodegom S, Reerink JD, Pasker de Jong PCM, De Groot CJ. Reluctance to continue breastfeeding in The Netherlands. Acta Paediatr 2001;90:1047-1053.

7. Anonymous. Progestogen-only contraceptives during lactation: I. Infant growth. World Health Organization Task force for Epidemiological Research on Reproductive Health; Special Program of Research, Development and Research Training in Human Reproduction. Contraception 1994;50:35-53.

8. Rogers IS, Emmett PM, Golding J. The incidence and duration of breast feeding. Early Human Dev 1997;49 Suppl:S45-74.

9. Quarles A, Williams PD, Hoyle DA, Brimeyer M, Williams AR. Mothers' intention, age, education and the duration and management of breastfeeding. Matern Child Nurs $\mathrm{J}$ 1994;22:102-8.

10. Termote M, De Vries H, Kools EJ, Thijs C. Psycho-social factors associated with the duration of breastfeeding. A longitudinal study. Submitted for publication 2004.

11. Kools EJ, Thijs C, De Vries H. The ABC of Breastfeeding. A Planning model for health promotion applied to breastfeeding in the Netherlands. A window to the future. Submitted for publication 2004.

12. De Vries H, Mudde A. Predicting stage transitions for smoking cessation applying The Attitude-Social Influence-Efficacy model. Psych Health 1998;13: 369-85. 
13. De Vries H, Dijkstra M, Kuhlman P. Self-efficacy: the third factor besides attitude and subjective norm as predictor of behavioral intentions. Health Educ Res 1988;3:273-282.

14. Fishbein M, Ajzen I. Beliefs, attitudes, intention, and behavior: an introduction to theory and research. Reading, Mass: Addison Wesley; 1975.

15. Bandura A. Social foundations of thought and action: A social cognitive theory. Englewood Cliffs: New York: Prentice Hall; 1986.

16. Pieterse ME, Seydel ER, De Vries H, Mudde AN, Kok GJ. Effectiveness of a minimal contact smoking cessation program for Dutch general practitioners: a randomized controlled trial. Prev Med 2001;32:182-90.

17. Bakker MJ, Mullen PD, De Vries H, Van Breukelen G. Feasibility of implementation of a Dutch smoking cessation and relapse prevention protocol for pregnant women. Patient Educ Couns 2003;49:35-43.

18. Bolman C, De Vries H, Van Breukelen G. A minimal-contact intervention for cardiac inpatients: long-term effects on smoking cessation. Prev Med 2002;35:181-92.

19. StataCorp. Stata statistical software release 7.0. In: College Station TX: Stata corporation; 2001.

20. Rademakers GM. Determinanten van de keuze en de duur van borstvoeding. [Scriptie]. Maastricht: Universiteit Maastricht; 1998.

21. Wind M. Tandenpoetsen op de basisschool: onbewust een averechts effect? [Scriptie]. Maastricht: Universiteit Maastricht; 2003. ISBN 90-807932-3-X.

22. Kools EJ, Thijs C, De Vries H. The behavioral Determinants of Breastfeeding in the Netherlands: Predictors for the initiation of Breastfeeding. Submitted for publication 2003.

23. Visness CM, Kennedy KI. Maternal employment and breast-feeding: findings from the 1988 National Maternal and Infant Health Survey. Am J Public Health 1997;87:945-50.

24. Scott JA, Aitkin I, Binns CW, Aroni RA. Factors associated with the duration of breastfeeding amongst women in Perth, Australia. Acta Paediatr 1999;88:416-21.

25. Bourgoin GL, Lahaie NR, Rheaume BA, Berger MG, Dovigi CV, Picard LM, et al. Factors influencing the duration of breastfeeding in the Sudbury region. Can J Public Health 1997;88:238-41.

26. Burgmeijer RJF. Reasons of early weaning. Leiden: Netherl Org Apllied Scentific Research; 2001. Report No.: PG/JGD/2001.51.

27. Renfrew MJ, Lang S, Woolridge MW. Early versus delayed initiation of breastfeeding. The Cochrane Library 2000:1-5.

28. Meertens RM, editor. Desirability and credibility. The influence of the social context on causal explanations for success and failure. Thesis. Nijmegen: Datawyse Maastricht/Krips Repro Meppel; ISBN 905291 043X, 1990.

29. Wijga A, Smit HA, Brunekreef B, Gerritsen J, Kerkhof M, Koopman LP, et al. Are children at high familial risk of developing allergy born into a low risk environment? The PIAMA Birth Cohort Study. Prevention and Incidence of Asthma and Mite Allergy. Clin Exp Allergy 2001;31:576-81.

30. Reijneveld SA, Brugman E, Hirasing RA. Infantile colic: maternal smoking as potential risk factor. Arch Dis Child 2000;83:302-3. 



\begin{abstract}
Background. In the Netherlands, the initiation rate of breastfeeding was $80 \%$ in 2002 , but only $35 \%$ of the mothers continued to breastfeed for three months. This study examined the effectiveness of a breastfeeding promotion program to increase the continuation of breastfeeding.

Methods. A cluster randomized intervention trial was used. Ten child health care centers in three regions of the Home Health Care were randomly allocated to the program or usual care. Elements in the program were health counseling, measures to enhance cooperation, early signaling of breastfeeding problems and continuity of care, and lactation consultancy. Pregnant mothers who applied for home health care in the intervention or usual care regions were enrolled and were followed up from pregnancy until six months postpartum $(\mathrm{N}=683)$. The primary outcome measure was the continuation of breastfeeding until at least three months.

Results. The three months breastfeeding rate was $32 \%$ in the intervention and $38 \%$ in the control groups $(\mathrm{OR}=0.79,95 \% \mathrm{CI}=0.58-1.08)$.

Conclusion. The program was not effective. We discuss possible explanations from the design and execution of the trial and give some points for improvement of our program, such as the categories of caregivers involved and the number and duration of contacts after parturition.
\end{abstract}




\section{INTRODUCTION}

In the Netherlands, $80 \%$ of mothers start with breastfeeding, but the rate drops rapidly during the first month postpartum to $52 \%$, to decrease further to $35 \%$ at three months and $17 \%$ at six months. ${ }^{1}$ To improve breastfeeding practices, initiatives have concentrated on procedures and policies in health care. Considering the low rate of long-term breastfeeding, more emphasis is needed to promote and support the continuation of breastfeeding in addition promoting its initiation. At present, Dutch programs are mainly based on increasing knowledge and not on actual support of breastfeeding. Counseling of breastfeeding is an important part of the responsibilities of the Dutch caregivers in departments of maternity and child health care. Early detection of barriers and problems of breastfeeding and monitoring of mothers at risk for early weaning are currently not embedded structurally in programs of maternity and child health care. The great popularity and the easy accessibility of the public services for maternity and child health care by the Dutch home health care organizations and their professionalism provide relevant gateways to access mothers to promote breastfeeding and preventing discontinuation.

Several programs on breastfeeding promotion and support have been developed, and reviews of randomized trials have shown that some programs were effective, while others were not. ${ }^{2,3}$ Effective interventions generally comprised a mix of elements. The goal of the study is to develop and test a program for Dutch women. Program planning was guided by the application of a planning model $^{4}$ and on analysis of behavioral determinants of breastfeeding duration, ${ }^{5}$ using the I-change model. ${ }^{6-8}$

The main goal of the program was to prevent mothers to refrain from discontinuation and to enhance the breastfeeding rate at three months by $10 \%$, from $21 \%$ (in 1999 in the participating centers) to $31 \%$. The rationale for the choice for three months is that the greatest health benefits can be reached for the baby during the first six months. We formulated our operational goals as follows ${ }^{4}$ : to strengthen the support of continuation of breastfeeding (in addition to promotion of the initiation of breastfeeding), by:

(1) Health counseling: intervening on behavioral determinants of the duration of breastfeeding by enhancing the caregiver's performance to promote and support breastfeeding using health counseling principles.

(2) Cooperation and continuity: to enhance cooperation, early signaling of breastfeeding problems and continuity of care by transfer of information on individual mothers between caregivers.

(3) Lactation consultancy: to enhance the access to lactation consultants and to take away financial and practical barriers for consulting them. ${ }^{9}$

Exclusive breastfeeding was defined according the WHO definitions ${ }^{10}$ as breastfeeding without supplemental liquids or solid foods other than medicines or vitamins; and complementary breastfeeding was defined as breast milk complemented by formula food or solid food. Formula feeding meant feeding an infant with formula feeds with no breastfeeding at all. In this study, breastfeeding meant all feeding practices in combination with breast milk (exclusive plus complementary breastfeeding). 


\section{METHODS}

\section{Study design and sample size}

We used a cluster-randomized design for the trial. The sample size was calculated for an expected absolute increase of at least $10 \%$ breastfeeding at three months (from $21 \%$ in the control regions, i.e. the pre-intervention rate in the three participating Home Care organizations, to $31 \%$ in the intervention regions). Power calculations with an alpha of 0.05 (for an one-tailed test), and a power of $80 \%$ revealed that 253 participants were needed in each group with complete follow up.

The study received approval from the medical ethical committee of the Academic Hospital Maastricht/ Maastricht University.

\section{Selection and randomization of centers}

Three out of five home health care organizations in the province of Limburg, the most Southern province of the Netherlands, participated. In these organizations, ten geographically separated centers of maternity and child health care were selected. They were grouped into two clusters A and B, based on similarity of breastfeeding rates in 1999 from the annual reports of the home health care centers (pre-randomization rate) and on the number of children born in 1999 receiving care in the centers (prerandomization size), so that clusters $\mathrm{A}$ and $\mathrm{B}$ had comparable overall pre-randomization rates and sizes. On a meeting of the steering committee, who were unaware of the characteristics of the centers, a coin flip determined that the B centers would receive the experimental intervention and the A centers would receive the control intervention. The pre-randomization breastfeeding rate was $19.0 \%$ in the intervention centers and $21.6 \%$ in the control centers.

\section{Recruitment, informed consent and follow-up}

Study candidates were pregnant women who applied for maternity care in the intervention or control centers of the three home health care organizations from December 2000-December 2002. About 77\% of pregnant mothers were users of this maternity care; the remaining mothers used similar care from commercial organizations (not included in this study).

Typically, pregnant Dutch women apply between the sixth and seventh months of pregnancy for maternity care; then they receive a home visit by a maternity care nurse in the seventh or eighth month. The candidates from the intake list of the maternity care were sent an informed consent letter with the first questionnaire (T0) to be returned during the prepartum home visit. Those who agreed to participate received three followup questionnaires, the first (T1) fourteen days postpartum during the postpartum home visit of the child health care nurse and the second (T2) and third (T3) questionnaires at two and five months postpartum during the consultations at the child health center. The questionnaires had to be returned during the consultations at one, three, and six months postpartum. If participants failed to return a questionnaire, they were telephoned in order to obtain the most essential follow-up information including breastfeeding continuation. 
The information in the informed consent letter did not reveal which center was in the control group as it was identical for the intervention and control groups. Care was taken that no other information was made public on whether a center belonged to the intervention or to the control groups, in order to avoid selection by pregnant women towards the intervention of their choice.

Participants with infants with a birth weight less than $2000 \mathrm{~g}$ were excluded from the analysis.

\section{The intervention program}

To assess the behavioral determinants in our local situation, a preceding study based on the Integrated model for motivational and behavioral change (I-Change model) ${ }^{6-8}$ was started in 1999. The program was targeted at pregnant women in their seventh month of the pregnancy. The operational goals were addressed by the following elements:

(1) Health counseling: In order to facilitate the counseling process for caregivers, the Health Counseling model was chosen ${ }^{11,12}$ since this model had already been applied successfully to other health promoting behaviors, such as smoking prevention. ${ }^{13,14}$ Both process and effect evaluations revealed its feasibility, appeal and effectiveness. ${ }^{14}$ The Health Counseling model was based on theories of behavioral change. The Health Counseling process consists of three phases: Preparation of the advice, Implementation of the advice and Maintenance. These phases were worked out in six steps addressing the behavioral determinants from our previous study. ${ }^{5}$ We used a program matrix ${ }^{15}$ adapted for health promotion ${ }^{16,17}$ (Table 1).

Table 1 An application of the program matrix to breastfeeding

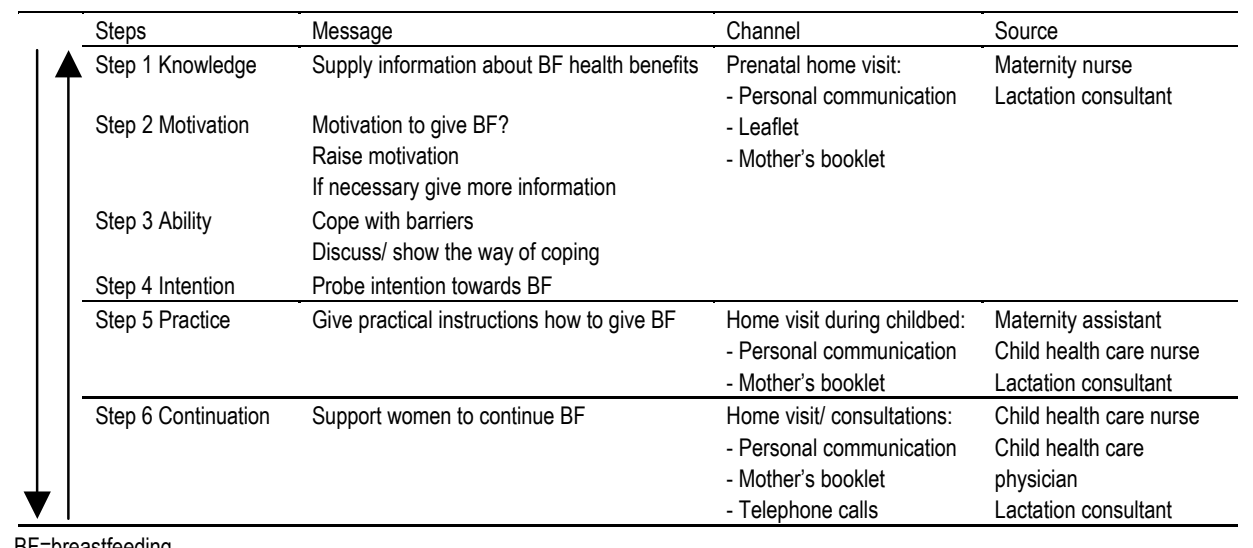

(2) Cooperation and continuity: A mother's booklet was developed to enhance cooperation between caregivers of the maternity and child health care, to give early signaling of breastfeeding problems and to transfer information between caregivers. In this booklet, we described the six healths counseling steps and mentioned the breastfeeding barriers mothers could encounter during each regular contact with caregivers. The mother's booklet was handed out, if the woman had decided to 
breastfeed or was still contemplating it during this visit, and the women were asked to $\log$ their breastfeeding barriers, problems, and motivation to continue breastfeeding before each next regular contact with the caregivers. The mother could also find a telephone number in order to reach the caregiver in case breastfeeding questions or problems arose. The caregivers in the intervention centers used the mother's booklet during each consultation and used health-counseling principles with the help of the program.

(3) Lactation consultancy: to enhance access to lactation consultants and to reduce financial and practical barriers for consulting them, three lactation consultants in our region were appointed and paid by Maastricht University and their services were free of charge. The lactation consultants in the intervention regions were 24 hours obtainable by fax. An agreement was reached on the indications and procedures for referrals to the lactation consultants. The caregivers could fax their concerns or queries about breastfeeding on a structured form to the lactation consultant. After receiving the fax, the lactation consultants contacted the caregiver or the mother within 24 hours and tried to resolve the problems. If needed they could made home visits or follow-up calls.

For the caregivers, a counseling protocol was developed with a one-page summary for each group: for the maternity and child health care nurse and for the physician. The aim of the summary was a prompt for the steps and a resource for answering questions. The summary consisted of answers to the most frequent questions and barriers regarding early weaning which women encountered with breastfeeding.

The following caregivers were involved with the program: the maternity nurse (prepartum home visits), the nurse (postpartum home visits and consultations) and physicians (consultations) of the child health care and lactation consultants. The participation of midwives in our study could not be guaranteed since their workload had increased in recent years.

At the end of 2000, the caregivers of the maternity and child health care were trained in a four-hour session in using the program and in counseling skills by demonstration and role-play. They received instruction how to use the devices for early signaling of breastfeeding problems and for cooperation between caregivers. The training was followed by a lesson of two hours on the role of lactation consultants and the indications for referring mothers to them. Practical problems were discussed during two refresh training sessions of two hours.

After the training, the program was started during the prepartum home visit by the maternity nurse in the intervention centers. The program started in the beginning of 2001 and executed until the last mother had completed the three months follow-up. Free access to lactation consultants was restricted to the participating mothers in the intervention group. Health counseling principles and mothers' booklets were applied for all mothers in the intervention centers, including the nonparticipants.

\section{Baseline measurements}

In the prepartum questionnaire (T0), taken from the mothers before the first intervention, the following baseline characteristics were measured: maternal age, maternal education, previous breastfeeding experience, and the intention to give breastfeeding or formula feeding, and the ASE determinants: attitude (A), social norm $(\mathrm{S})$, and self-efficacy (E). The ASE items were based on results of our previous study ${ }^{5}$ 
and are fully described elsewhere. ${ }^{18}$ Attitudes toward breastfeeding were assessed by asking the perceived advantages (pros) of breastfeeding in relation to the mother herself, to her infant, and to her partner. Beliefs regarding social norms and support were measured from significant others (such as partner, mother, sister, friends, midwife, maternity and child health care nurse and physician, colleague, employer). A distinction was made between self-efficacy to breastfeed and to formula feed, assessing both situational and stress self-efficacy for both types of feeding.

In the first postpartum questionnaire (T1), information pertinent to the exclusion criterion was sought: the birth weight of the infant. In this questionnaire, we also asked which feeding had been started after delivery.

In order to assess baseline comparability of the knowledge of the caregivers about breastfeeding, we used a multiple-choice test developed by the Dutch Association for Lactation Consultants. About three months before the start of the intervention, this test was taken by all the caregivers of the maternity and child health care in the intervention and control regions.

\section{Outcome measurements}

As the main outcome measurement, the three months postpartum questionnaire (T2) asked whether the mother used exclusive breastfeeding, complementary breastfeeding, or formula at that moment and the number of weeks of exclusive or complementary breastfeeding continuation.

In the year 2000 (one year before the start of the intervention), the caregivers in both intervention and control regions recorded registry forms during the consultations for all infants born in these regions until the last mother was included in May 2003. They recorded birth weight, feeding practices, and the timing of discontinuing of breastfeeding at birth, one, three, and six months. This registry form was pretested in one home health care organization during 1999.

\section{Process and program evaluation}

In order to get insight in the process of counseling, the questionnaire at six months postpartum (T3) in both the intervention and control groups asked whether they were satisfied with the feeding advice of the caregivers, whether the caregivers took their opinion into account, and whether they had received any contradictory feeding advice. For the evaluation of the program, we asked mothers in the intervention group who still gave breastfeeding at six months postpartum (T3 questionnaire) on the usage and usefulness of the mother's booklet.

To gain insight into the process of the intervention at the caregiver level the caregivers of the intervention and control regions filled in a questionnaire three months after the last mother had been included. This asked about how desirable they found to consult or to refer to a lactation consultant and their satisfaction with the care. For the program evaluation, extra questions for the caregivers in the intervention groups were added about their attitude, their support from others and their self-efficacy to carry out the program. Furthermore, we asked whether the program took more time than usual, as well as how much time they had spent on breastfeeding counseling per consultation, the report mark of the program, their willingness to carry out the program in the future, and 
their opinion about the implementation on a national scale. The lactation consultants themselves recorded the breastfeeding problems they encountered and the advice they had given on a structured form at each contact with the mothers.

\section{Analyses}

Chi-square tests for categorical variables and t-tests for continuous variables were used to compare breast- and formula-feeding mothers. For each ASE concept, a mean score was computed by averaging the scores on the items. Reliability analyses assessed the reliability (expressed as Cronbach's alpha) of the perceived pros and cons, social influences and self-efficacy scores. The main effect of the intervention on the primary outcome (the proportion of mothers who breastfeed (exclusive and complementary breastfeeding) at three months) was analyzed at two levels: at the level of the participating mothers (questionnaires) and at the level of the caregivers (registry forms) by comparing the proportion between the intervention and control groups, using the chisquare test. Univariate logistic regression was used to compute odds ratios with $95 \%$ confidence intervals. At the individual level, multivariate logistic regression was used to account for potential baseline differences of maternal age, maternal education, and previous breastfeeding experience. Modification of the intervention effect by these determinants was evaluated by testing for interaction, with a cut-off point of 0.10 for the P-value of the interaction term.

In a multilevel analysis, a random intercepts logistic regression model was used in order to account for variability of breastfeeding rates between the ten centers (including regional differences), using postcodes of the participants to group them into the regions belonging to the various centers. Cox's regression analysis was used to test the differences between the survival rates with correction for co-variates, where survival was defined as continuation of breastfeeding. Survival curves corrected for co-variates were derived from a stratified Cox's regression model (stratified by group). The analyses were carried out in STATA 7.0. ${ }^{19}$

\section{RESULTS}

During the study period December 2000-December 2002, ten centers were randomized into five intervention- and five control centers. Five hundred and seventy pregnant women were applied for maternity care at the five intervention centers and 518 did so at the five control centers (Figure 1). Of these candidates, 408 (72\%) and $373(72 \%)$ agreed to participate. At the mothers' first consultation at the center at one month after birth, 362 mothers in the intervention group and 318 in the control group returned the first follow-up questionnaire (T1). From most non-responders, backup data on birth weight and breastfeeding were obtained from the registry forms, so that information was complete on 408 mothers in the intervention group, and 368 in the control group. Thirty-six and 38 mothers from the respective groups were excluded, so that 371 (91\%) mothers remained in the intervention group, and $330(88 \%)$ in the control group (Total T1). Reasons to exclude respondents were as follows: mothers did not return the baseline questionnaire or filled in this questionnaire after the prepartum home visit when the intervention had already started $(\mathrm{N}=15)$; mothers had cancelled the maternity 
care of the home health care before the home visit $(\mathrm{N}=31)$; the kind of maternity care was not filled in by the participant $(\mathrm{N}=23)$; birth weight of the infants was less than $2000 \mathrm{~g}(\mathrm{~N}=15)$ or was unknown $(\mathrm{N}=21$, the totals exceeded the totals of 36 and 38 , respectively, because combinations of reasons were possible).

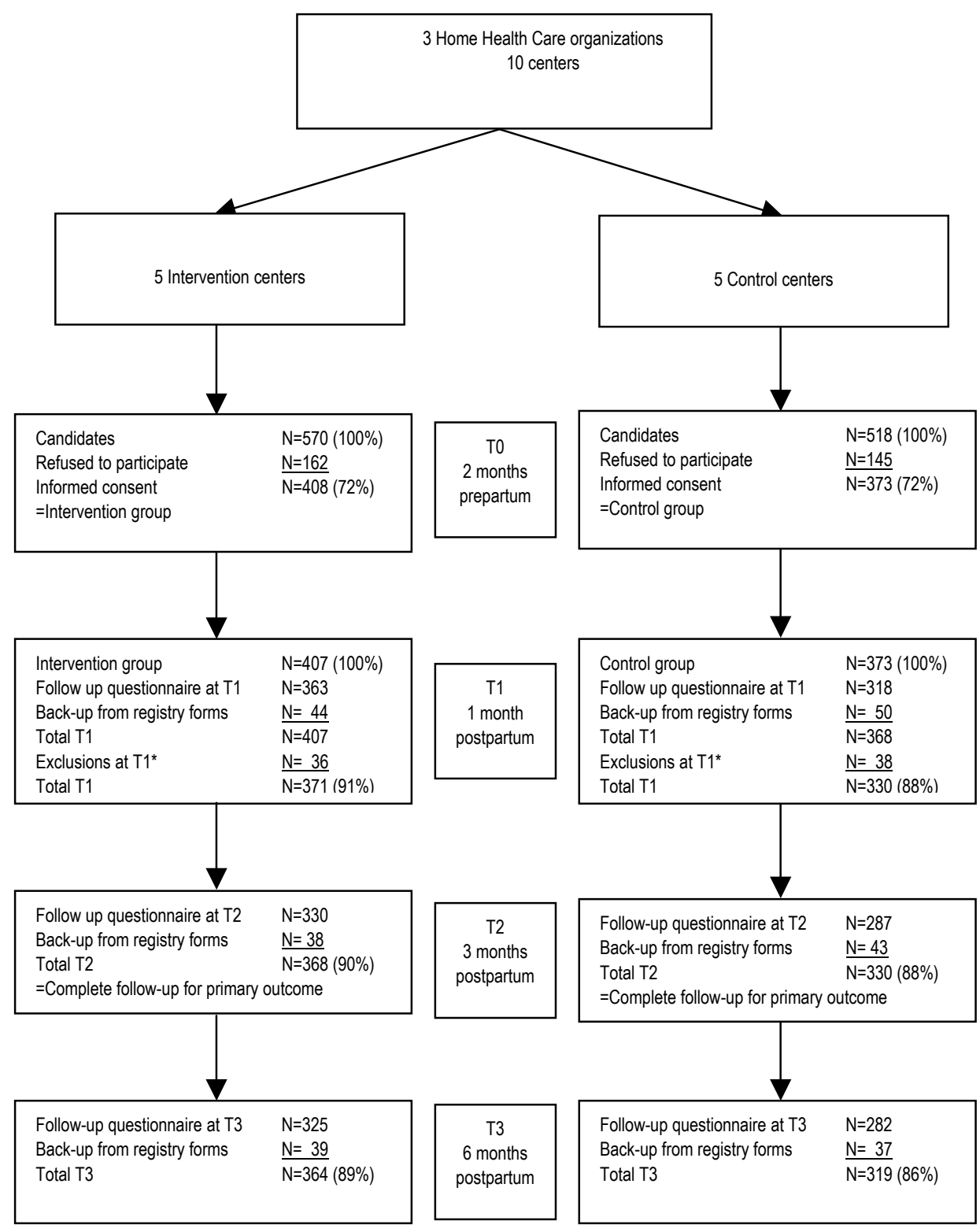

*Exclusion: no T0 or filled in T0 to late for baseline (after prepartum home visit); no maternity care or no data available; birth weight $<2000 \mathrm{~g}$ or no birth weight data available

Figure 1 The trial profile 
At three months postpartum, the additional nonresponse to the questionnaires could almost be fully backed up with registry data, so that the number of participants with complete follow-up for the primary outcome (Total T2) was $368(90 \%)$ in the intervention group and $330(88 \%)$ in the control group. At six months postpartum, the additional nonresponse was similarly backed up with the help of the registry data (Figure 1). The caregivers filled in 2734 registry forms, namely 947 forms in 2000, 1378 in 2001, and 409 forms in 2002. These numbers are higher than the number of participating mothers because registry forms were filled in for all infants born in the intervention and control centers (including those of mothers not on the intake list for maternity care, and those of mothers who refused to participate or who were excluded). It was possible to link 406 registry forms to the mothers' questionnaire data in an anonymous way, showing only 17 (4\%) discrepancies on the duration of breastfeeding.

\section{Baseline characteristics of the participants and caregivers}

No dropout analyses were performed since only three participants were lost to follow-up in the intervention group and none in the control group (Figure 1).

Table 2 Comparison of the baseline characteristics of the complete follow-up of the intervention and control group at three months ( $\mathrm{N}=698)$

\begin{tabular}{|c|c|c|c|c|c|c|c|c|}
\hline \multirow[t]{3}{*}{ Characteristics } & & & & \multicolumn{5}{|c|}{ Complete follow up at 3 months } \\
\hline & & & & \multicolumn{2}{|c|}{ Intervention group } & \multicolumn{2}{|c|}{ Control group } & \multirow[t]{2}{*}{ P-value 1} \\
\hline & & & & $\mathrm{N}$ & $\%$ & $\mathrm{~N}$ & $\%$ & \\
\hline All mothers & & & & 368 & 100 & 330 & 100 & \\
\hline Intention to breastfeed & & & & 243 & 66 & 233 & 71 & 0.20 \\
\hline \multirow[t]{3}{*}{ Maternal age } & $<25$ & & & 37 & 10 & 26 & 8 & \\
\hline & $25-30$ & & & 163 & 44 & 148 & 45 & \\
\hline & $\geq 31$ & & & 168 & 46 & 156 & 47 & 0.60 \\
\hline \multirow[t]{3}{*}{ Maternal education ${ }^{2}$} & Low & & & 77 & 21 & 61 & 18 & \\
\hline & Middle & & & 196 & 53 & 194 & 59 & \\
\hline & High & & & 95 & 26 & 75 & 23 & 0.34 \\
\hline \multirow[t]{3}{*}{ Previous BF } & No, multiparas & & & 63 & 17 & 45 & 14 & \\
\hline & Yes, multiparas & & & 98 & 27 & 102 & 31 & \\
\hline & No, primiparas & & & 207 & 56 & 183 & 55 & 0.29 \\
\hline ASE determinants & & Scale & Cronbach's Alpha & Mean $^{3)}$ & SD & Mean $^{3)}$ & SD & P-value ${ }^{3)}$ \\
\hline \multirow[t]{2}{*}{ Attitude } & Pros BF & $1-5^{4)}$ & 0.80 & 3.27 & 0.60 & 3.24 & 0.62 & 0.42 \\
\hline & Cons BF & $1-5^{4)}$ & 0.73 & 2.84 & 0.45 & 2.80 & 0.43 & 0.21 \\
\hline \multirow[t]{2}{*}{ Social norm } & Significant others & $\left.1-5^{5}\right)$ & 0.78 & 3.45 & 0.59 & 3.48 & 0.59 & 0.43 \\
\hline & Work & $1-5^{5)}$ & 0.54 & 3.07 & 0.35 & 3.10 & 0.44 & 0.41 \\
\hline \multirow[t]{2}{*}{ Social support BF } & Significant others & $1-5^{6)}$ & 0.83 & 2.52 & 1.16 & 2.60 & 1.10 & 0.33 \\
\hline & Work & $1-5^{6)}$ & 0.79 & 1.39 & 0.82 & 1.48 & 0.93 & 0.15 \\
\hline \multirow[t]{2}{*}{ Social support FF } & Significant others & $1-5^{6)}$ & 0.88 & 2.13 & 0.98 & 2.15 & 1.08 & 0.85 \\
\hline & Work & $1-5^{6)}$ & 0.82 & 1.18 & 0.88 & 1.41 & 0.89 & 0.61 \\
\hline \multirow[t]{2}{*}{ Self-efficacy BF } & Situational & $1-7^{7)}$ & 0.81 & 4.04 & 1.15 & 4.08 & 1.09 & 0.62 \\
\hline & Stress & $1-7^{7)}$ & 0.83 & 3.19 & 1.08 & 3.17 & 1.10 & 0.78 \\
\hline \multirow[t]{2}{*}{ Self-efficacy FF } & Situational & $1-7^{7)}$ & 0.76 & 5.37 & 0.90 & 5.37 & 0.92 & 0.93 \\
\hline & Stress & $1-7^{7)}$ & 0.84 & 5.11 & 1.06 & 5.05 & 1.07 & 0.45 \\
\hline
\end{tabular}

1)From Pearson chi square test

2)Low: primary or basic vocational school; middle: secondary vocational or high school; high: higher vocational school or university. ${ }^{3)}$ From t-test

4)1=fully agree, $5=$ fully disagree with advantages (pros) or disadvantages (cons) of breastfeeding

5) $1=1$ must certainly breastfeed, $5=1$ must certainly formula feed

6) $1=$ very often support, $5=$ never support for breastfeeding or formula feeding

7)1=very difficult, 7=very easy to give breastfeeding or formula feeding 
Table 2 shows the baseline personal and ASE characteristics of the participants from the prepartum questionnaire (T0). The mean age of the pregnant mothers was 31 year ranging from 19 to 43 years; most of the mothers had a middle level of education and were primiparas. The intervention and control groups did not differed only slightly at baseline for age, maternal education, previous breastfeeding experience, and for ASE determinants. In the intervention group, fewer mothers had the intention to breastfeed $(66 \%)$ than in the control group $(71 \%)$.

The scores of the baseline knowledge test in caregivers were unsatisfactory $(<5.5$ on a $1-10$ scale) in $19 \%(6 / 31)$ at the intervention centers and $29 \%(6 / 21)$ at the control centers, but the mean scores were comparable (6.0 (SD 1.00), and 5.8 (SD 1.32), respectively).

\section{Breastfeeding outcomes}

The percentage of mothers who started breastfeeding was 68 in the intervention cohort and 72 in the control group, which was not very different from the prepartum intention in either group (66 and 71, respectively; Table 3 ).

Table 3 Questionnaires from the mothers: breastfeeding at birth and at three months

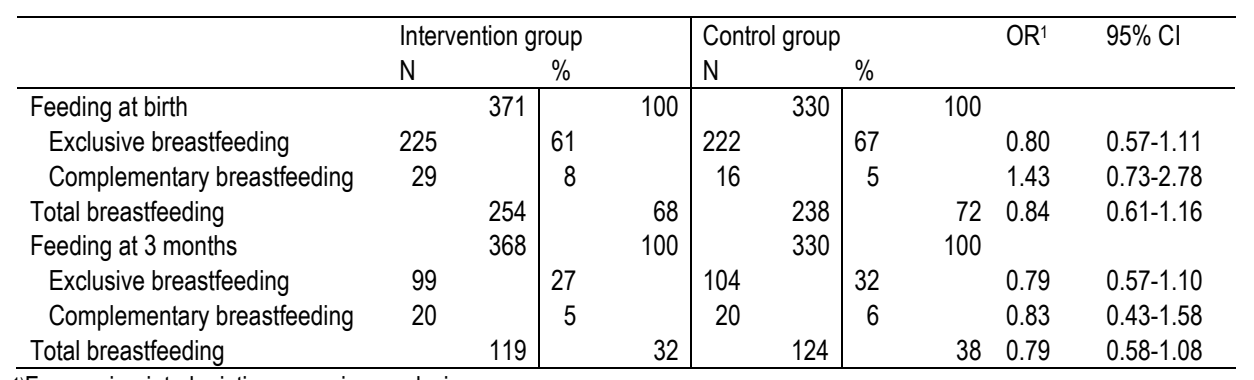

1)From univariate logistic regression analysis

Total breastfeeding=exclusive breastfeeding + complementary breastfeeding

At three months, 32\% continued breastfeeding in the intervention group and $38 \%$ in the control group. The multivariate logistic regression analysis (random intercepts model) did not reveal significant effect of the intervention either $(\mathrm{OR}=0.82,95 \% \mathrm{CI}=0.58$ 1.14), Table 4.

Predictors of breastfeeding continuation until at least three months were: maternal education (high level $\mathrm{OR}=4.36$; middle level $\mathrm{OR}=1.98$ ) compared with low level; multiparity with previous breastfeeding experience $(\mathrm{OR}=10.56)$ and primiparity $(\mathrm{OR}=5.74)$ compared with multiparity without previous breastfeeding experience

In order to evaluate whether the effect of the intervention depended on maternal age, maternal education, or previous breastfeeding experience, these variables were entered as interaction terms with the intervention in the multivariate logistic regression model. None of the interactions between the main outcome and the co variables reached statistical significance at the level of $\mathrm{P}<0.10$. Because the prepartum intention to give breastfeeding was a very strong determinant of breastfeeding initiation, it was not 
possible to adjust for intention in the same model. Consequently a stratified analysis of Table 3 by intention was run.

Table 4 Determinants of breastfeeding at three months in multivariate logistic regression analysis

\begin{tabular}{|c|c|c|c|c|c|}
\hline & \multirow[b]{2}{*}{$\mathrm{N}=698$} & \multicolumn{2}{|c|}{$\begin{array}{l}\text { Conventional analysis } \\
\text { Fixed effects model }\end{array}$} & \multicolumn{2}{|c|}{$\begin{array}{l}\text { Multilevel analysis } \\
\text { Random intercepts model }\end{array}$} \\
\hline & & OR & $95 \% \mathrm{Cl}$ & OR & $95 \% \mathrm{Cl}$ \\
\hline Control & 330 & 1.00 & Reference & 1.00 & Reference \\
\hline Intervention & 368 & 0.82 & $0.62-1.07$ & 0.82 & $0.58-1.14$ \\
\hline \multicolumn{6}{|l|}{ Maternal age } \\
\hline$<25 \mathrm{yr}$ & 63 & 1.00 & Reference & 1.00 & Reference \\
\hline $25-30 \mathrm{yr}$ & 311 & 0.99 & $0.56-1.75$ & 0.99 & $0.53-1.85$ \\
\hline$\geq 31 \mathrm{yr}$ & 324 & 1.13 & $0.60-2.12$ & 1.14 & $0.59-2.16$ \\
\hline \multicolumn{6}{|c|}{ Maternal education ${ }^{1)}$} \\
\hline Low & 138 & 1.00 & Reference & 1.00 & Reference \\
\hline Middle & 390 & $1.98^{*}$ & $1.27-3.10$ & $1.98^{*}$ & $1.20-3.28$ \\
\hline High & 170 & $4.36^{\star * *}$ & $2.75-6.91$ & $4.36^{\star \star *}$ & $2.50-7.59$ \\
\hline \multicolumn{6}{|c|}{ Previous BF experience } \\
\hline No, multiparas & 108 & 1.00 & Reference & 1.00 & Reference \\
\hline Yes, multiparas & 200 & $10.56^{* * *}$ & $5.60-19.9$ & $10.56^{* * *}$ & $4.83-23.1$ \\
\hline No, primiparas & 390 & $5.74^{\star \star \star}$ & $2.59-12.7$ & $5.74^{* \star *}$ & $2.65-12.4$ \\
\hline
\end{tabular}

1)Low: primary or basic vocational school; middle: secondary vocational or high school; high: higher vocational school or university

$\mathrm{BF}=$ breastfeeding

${ }^{*} \mathrm{P}<0.05 ;{ }^{* * *} \mathrm{P}<0.001$

Interaction terms:

Intervention group $X$ intention $\mathrm{P}=0.57$

Intervention group $X$ maternal age $P=0.18$

Intervention group $X$ maternal education $P=0.22$

Intervention group $X$ previous $B F$ experience $P=0.83$

Of the women who intended to breastfeed, 98\% (238/244) in the intervention group and $98 \%(228 / 233)$ in the control group initiated breastfeeding at birth $(\mathrm{OR}=0.86,95 \% \mathrm{CI}$ $0.26-2.89) ; 48 \%(116 / 243)$ and 53\% (122/233), continued at least three months $(\mathrm{OR}=0.83,95 \%$ CI $0.58-1.19)$. This indicates that the differences in prepartum intention between control and intervention groups did not confound the main results. In the Cox's regression analysis the hazard ratio for discontinuation of breastfeeding was 0.99 (95\% CI 0.93-1.06) when comparing intervention and control groups (controlling for maternal age, maternal education, and previous breastfeeding experience). The survival curves indicated only a marginal difference in the rate of continuation between the intervention and control groups (Figure 2).

At the level of the caregivers, in the year before the intervention (2000) the rate of breastfeeding reported in the registry forms in the intervention centers was $25.8 \%$ $(123 / 477)$, but $31.1 \%(146 / 470)$ in the control centers. In the first year of the intervention period (2001), the rate was $31.0 \%$ (207/668) in the intervention centers and $27.6 \%(196 / 710)$ in the control centers. In the last half-year of the intervention period (2002) the rates were $30.0 \%(76 / 253)$, and 30.1\% (47/156), respectively. When the rates of 2001 and 2002 were taken together, none of the differences was statistically significant (difference in trend between 2000 and $2001+2002$. $\mathrm{P}=0.32$; difference 
between intervention and control group $\mathrm{P}=0.97$; interaction between trend and group $\mathrm{P}=0.09$; from multilevel logistic regression analysis with random intercepts for the child health centers). In sum, no intervention effect was found.

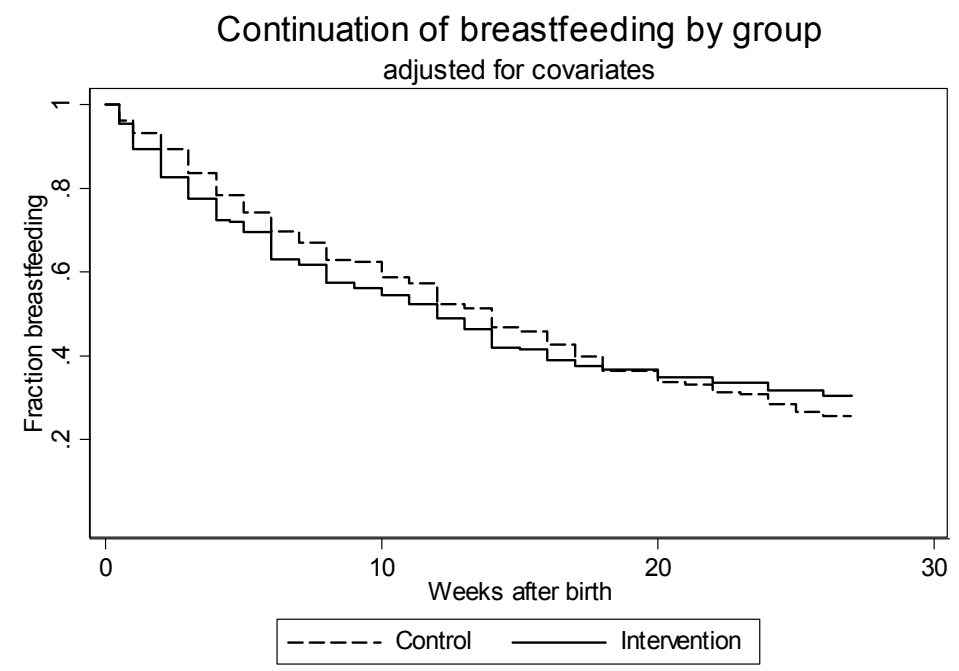

Figure 2 The survival curve of the continuation of breastfeeding adjusted for covariates (maternal age, maternal education, and previous breastfeeding experience; intervention group $\mathrm{N}=245$, control group $\mathrm{N}=224$, from Cox's regression analysis)

\section{Process evaluation}

Opinions of mothers about the feeding advices given by the caregivers were not more positive in the intervention group than in the control group, with the exception that they reported slightly less contradictory feeding advice $(\mathrm{P}=0.04)$. (Table 5)

Eighty percent of the caregivers reported that they obtained good or sufficient behavioral skills to carry out the program. Of the 25 caregivers in the intervention centers, $96 \%$ paid attention to the pros of breastfeeding, $52 \%$ to the cons, $72 \%$ to the barriers, and $68 \%$ to the social influences of breastfeeding during the contacts with the mothers. Eighty-eight percent always (or mostly) experienced support from their colleagues, $80 \%$ from the lactation consultants, and $72 \%$ from the management. However, only $33 \%$ almost (or mostly) experienced support from the midwives. All the caregivers $100 \%$ reported that they knew the materials and generally used them. Only two out of 25 caregivers from the intervention centers reported that they had been substituted by caregivers from the control centers (for $10 \%$ and $25 \%$ of their time, respectively) and three out of 25 caregivers had substituted for a caregiver in the control centers (for $5 \%, 5 \%$ and $10 \%$ of their time). 
Caregivers in the intervention centers were slightly more positive about the lactation consultants than those in the control centers, but the differences did not reach statistical significance (Table 5).

Table 5 Opinions of mothers about the feeding advices and opinions of caregivers about the care of the lactation consultants

\begin{tabular}{|c|c|c|c|c|c|c|c|c|c|}
\hline & \multirow[b]{2}{*}{$\mathrm{N}$} & \multirow[b]{2}{*}{ Scale ${ }^{1)}$} & \multicolumn{3}{|c|}{ Intervention group } & \multicolumn{3}{|c|}{ Control group } & \multirow[b]{2}{*}{ P-value ${ }^{2}$} \\
\hline & & & $\mathrm{N}$ & Mean') & SD & $\mathrm{N}$ & Mean') & SD & \\
\hline Opinions of mothers) about feeding advices & 617 & & & & & & & & \\
\hline \multicolumn{10}{|l|}{ Are you satisfied with feeding advice by } \\
\hline Hospital nurse & 342 & $1-5$ & 187 & 2.53 & 1.09 & 155 & 2.35 & 1.07 & 0.13 \\
\hline General practitioner & 242 & $1-5$ & 139 & 2.31 & 0.84 & 105 & 2.31 & 0.89 & 0.96 \\
\hline Pediatrician & 226 & $1-5$ & 127 & 2.35 & 0.95 & 99 & 2.30 & 0.89 & 0.73 \\
\hline Child health care nurse & 568 & $1-5$ & 300 & 1.98 & 0.75 & 268 & 2.05 & 0.76 & 0.30 \\
\hline Child health care physician & 566 & $1-5$ & 297 & 2.01 & 0.79 & 269 & 2.10 & 078 & 0.16 \\
\hline Lactation consultant & 101 & $1-5$ & 73 & 2.07 & 0.84 & 28 & 2.18 & 1.02 & 0.58 \\
\hline \multicolumn{10}{|l|}{ Did the caregivers reckon with your own opinion? } \\
\hline Hospital nurse & 484 & $1-5$ & 262 & 3.29 & 1.02 & 222 & 3.30 & 1.04 & 0.87 \\
\hline General practitioner & 487 & $1-5$ & 260 & 3.41 & 0.85 & 227 & 3.39 & 1.00 & 0.78 \\
\hline Pediatrician & 462 & $1-5$ & 244 & 3.29 & 0.88 & 218 & 3.33 & 0.93 & 0.60 \\
\hline Child health care Nurse & 591 & $1-5$ & 312 & 3.76 & 0.92 & 279 & 3.71 & 1.05 & 0.60 \\
\hline Child health care Physician & 597 & $1-5$ & 317 & 3.76 & 0.91 & 280 & 3.67 & 1.04 & 0.27 \\
\hline Lactation consultant & 395 & $1-5$ & 211 & 3.40 & 0.92 & 184 & 3.27 & 0.97 & 0.15 \\
\hline Satisfaction with the reach of caregivers? & 610 & $1-5$ & 327 & 2.05 & 0.87 & 283 & 2.03 & 0.84 & 0.84 \\
\hline Did you receive contradictory feeding advice? & 616 & $1-5$ & 329 & 1.71 & 0.45 & 287 & 1.79 & 0.41 & 0.04 \\
\hline $\begin{array}{l}\text { Opinions of caregivers) about the care } \\
\text { of lactation consultants }\end{array}$ & 40 & & & & & & & & \\
\hline \multicolumn{10}{|l|}{ How desirable is it for you to have the possibility } \\
\hline To refer to them? & & $1-5$ & 25 & 3.92 & 0.28 & 15 & 3.73 & 0.88 & 0.34 \\
\hline To consult them? & & $1-5$ & 25 & 3.96 & 0.20 & 15 & 3.86 & 0.35 & 0.27 \\
\hline \multicolumn{10}{|l|}{ Satisfaction with } \\
\hline Their reach & & $1-5$ & 25 & 2.60 & 0.76 & 15 & 2.40 & 0.91 & 0.48 \\
\hline Their quality of care & & $1-5$ & 25 & 2.96 & 0.79 & 15 & 2.80 & 0.68 & 0.50 \\
\hline Their quickness of response to caregivers & & $1-5$ & 25 & 2.64 & 0.76 & 15 & 2.60 & 0.74 & 0.87 \\
\hline Their quickness of response to mothers & & $1-5$ & 25 & 2.80 & 0.76 & 15 & 2.67 & 0.62 & 0.55 \\
\hline Their report to caregivers & & $1-5$ & 25 & 2.76 & 0.97 & 15 & 2.27 & 0.70 & 0.07 \\
\hline
\end{tabular}

1) $1=$ not at all, $5=$ =very much

2)From t-test

\section{Program evaluation}

The introduction training was followed by 19 of the 25 caregivers. The other six persons were absent during this training or started to work after the training and received a group introduction. Twenty-two caregivers followed the refresh trainings. Ninety-six percent of the mothers in the intervention group received the mother's booklet, which was used in most contacts by $57 \%$, by $58 \%$ of the child health care nurses and by $53 \%$ of the child health care physicians.

With regard to the program, $56 \%$ of the caregivers found it (fairly) difficult to carry out, but $64 \%$ succeeded in carrying it out always (or mostly) at each contact. Ninety-six percent found the program clear and understandable, and $92 \%$ were stimulated by the program to give attention to breastfeeding always (or mostly). When we asked whether this program would merit implementation on a national scale, $84 \%$ reported that this would be (very) meaningful and 54\% were willing to carry it out in the future. Fortyfour percent reported that the program took more time than usual: $80 \%$ reported that 
they had longer home visits (12 minutes more per caregiver), $27 \%$ had more home visits (4 more per month per caregiver), $72 \%$ had longer consultations ( 7 minutes more per caregiver), and $44 \%$ had more consultations (12 consultations more per month per caregiver). During the first three months, the mean time they spent on breastfeeding counseling during the home visits was 16.6 minutes (SD 9.4, N=16) in the intervention group, and 16.9 minutes (SD 6.1, N=14) in the control group; the mean time spent during the consultations at the child health care centers was 9.1 (SD 7.4, N=19) minutes in the intervention group and $5.8(\mathrm{SD} 1.5, \mathrm{~N}=18)$ in the control group. The caregivers gave the program a report mark of 7.3 (SD 0.74$)$, on a scale of $1-10(1=$ very low to $10=$ excellent). Sixty-four mothers $(16 \%)$ from the intervention group were referred to the lactation consultants, namely $19(30 \%)$ by caregivers of the maternity care, 44 $(69 \%)$ by caregivers of the child health care, while one mother $(2 \%)$ contacted the lactation consultant directly. Most common reasons for referral were doubt about drinking of the infant (21\%), crying infant (11\%), and pain during feeding (11\%).

\section{DISCUSSION}

There were no significant differences between the intervention and control groups in the rates of breastfeeding at birth, three months, or later. Before discussing the implications, we will review the methodological quality of the trial: the comparability of the centers, caregivers, and participants; the contrast between the intervention and control groups, and the comparability of co-interventions; the comparability of the outcome measurement; and the statistical power.

With respect to the comparability of the centers, self-selection of the centers was excluded because all the Home Health Care organizations agreed to participate before the start of the trial, and all ten centers continued without dropout. In order to avoid selfselection of pregnant women to the intervention of their choice, no information was made public whether a center participated in the intervention or control groups; and nonparticipation in the trial occurred before the information was given about the intervention. We had no selective dropout by migration of mothers to another center if they were not pleased with the intervention. At baseline, there was no difference in knowledge between the caregivers. Two years before the start of the intervention (1999), the three months breastfeeding rates did not differ between the intervention and control regions due to the pre-stratification and cluster randomization; however in the year before the intervention (2000), the rate was lower in the intervention centers $(25.8 \%)$ than in the control centers $(31.1 \%)$. We were surprised by this difference, but noted that breastfeeding rates varied greatly between the centers as well as over the years. The variability between the centers was taken into account in the multilevel analysis. Participating mothers in the intervention and control groups were reasonably comparable with regard to prognostic variables at baseline, but a difference in the intention to breastfeed was present to the detriment of the intervention group $(66 \% \mathrm{vs}$. $71 \%$ in the control group). However, in a stratified analysis no intervention effect was found in the subgroups of women with and without prepartum intention to carry out breastfeeding.

With respect to the contrast between intervention and control groups, the execution of the intervention was according to the planning: all the caregivers followed the training 
and received two refresh trainings; during the intervention period there were few new caregivers; who also received a short individual training. Caregivers reported that they gave attention to the attitudes, social support and self-efficacy problems during most of the consultations, had self-confidence in carrying out the program and felt support from others. The majority of mothers and caregivers used the materials. To avoid an intervention effect resulting from the informed consent procedure and the questionnaires, the informed consent letter was identical for the intervention and the control groups, blinding the aim of increasing breastfeeding rates; and the questionnaires had similarly phrased questions about the ASE determinants for formula feeding and breastfeeding. The centers were geographically separated. Hence, exchange of information between caregivers of intervention and control centers was avoided. Nevertheless, we cannot exclude that the caregivers had exchanged their knowledge of the training in the health counseling and stimulated each other to promote breastfeeding. However, the specific effect of such an exchange could have only been minimal, because health counseling is a specific approach, which only can be learned by training. The instruction materials and other supporting measures (the mother's booklet and free access to lactation consultants) were only available in the intervention group. With respect to co interventions, no new activities that could have diminished the contrast between the intervention and control groups were introduced during the intervention period.

With respect to the comparability of outcome measurement, the participants and the caregivers could not be blinded for the intervention; consequently, the outcome measurement could have been influenced by social desirability or by expectations about the intervention effect. However, if this were the case, this would have led to discrepancies between the breastfeeding data from the questionnaires and from the registry forms of the individual mothers. A comparison found only $4 \%$ discrepancies. The follow-up was nearly complete; differential loss to follow-up between the intervention and control groups can therefore be excluded.

The intended size of our trial $(253+253)$ was determined in order to detect an absolute difference of $10 \%$ between the breastfeeding rates at three months in the intervention group (31\%) and the control group (21\%) with $80 \%$ power (alpha 0.05 , one sided). The actual number of participants $(368+330)$ far outnumbered this, and the actual breastfeeding rate in the control group was higher (38\%) to the effect that a $10 \%$ higher rate in the intervention group ( $48 \%$ ) could have been detected with a power of $83 \%$. In the multilevel analysis, some power is lost due to the variation between clusters. The upper confidence limit of the odds ratio of the main intervention effect (1.14) indicates that it is unlikely that a large intervention effect was missed.

\section{CONCLUSION}

We have no indications of major biases in the design or execution of the trial. Studies in other fields have shown that the effectiveness of health promotion programs is greatly dependent on the quality of planning. ${ }^{20}$ In our study we addressed the steps identified by most planning models ${ }^{4}$ and developed our health-counseling model on the determinants resulting from the study. ${ }^{5}$ Furthermore, we reviewed intervention trials for breastfeeding promotion programs. Effective programs were programs containing a mix of 
interventions. In spite of fulfilling these conditions, the present program was not shown to be effective.

Several explanations for the lack of effectiveness can be given. First, the choice of professionals included in the intervention was limited. We could not employ midwives, maternity assistants or pediatricians in our research study since their practices overlapped the child health care centers to such an extent that it would not be possible to create separate intervention and control centers and had therefore a gap in support in the perinatal period. Mothers received only an intervention during the home visits two months before and fourteen days after the parturition and the following intervention took place at one month. We could not use mass media or regional magazines to support the program, since contamination had to be avoided.

A second explanation is that health counseling in this setting has certain limitations. The Health Counseling model has been successfully applied to smoking prevention; nevertheless, there is a difference between breastfeeding and smoking. Discontinuation of breastfeeding is mostly irreversible, contrary to smoking relapse for which repeated opportunities are possible. In addition, there is a cheap and easy alternative available for breastfeeding (formula feeding) and especially easy for working mothers. Possibly health counseling lays too much emphasis on the difficulties of breastfeeding, while women like to see breastfeeding as easy and cozy. Such an adverse effect may also have been evoked by attention to early detecting of breastfeeding problems. A third explanation is that the necessary conditions were possibly not present to let the program be successful. A precondition of the program was that the knowledge of caregivers about breastfeeding was sufficient in the region. We assumed that knowledge would be sufficient, because the home health care organizations organized annual breastfeeding introduction and booster trainings, before and during the study period (and not different between intervention and control groups). Furthermore, baseline results as measured in the trial revealed that most caregivers scored sufficiently on a breastfeeding knowledge test. A limitation of this test may be, however, the lack of reference data for this test in The Netherlands. Hence, we cannot be completely confident that the condition of sufficient knowledge of breastfeeding was met.

A fourth explanation for the absence of effectiveness might be a diffuse increase of breastfeeding attention in both regions, at the level of the participants by a possible intervention effect of the repeated questionnaires and, at the level of the caregivers by increased attention for BF in their organizations. On the other hand, much attention was devoted to early detection of BF problems. We compared the percentages from our study with the annual national percentages. ${ }^{21}$ During the last five years (1997-2002) there was a rise in percentages of exclusive breastfeeding at birth from $70 \%$ to $80 \%$ (and at three months from $17 \%$ to $35 \%$ ). Possibly the increased attention by professionals and mass media may have contributed to this increase. In the Netherlands, the certification of the maternity care in relation to the Baby Friendly Hospital Initiative had a positive effect on the initiation but not on the duration of breastfeeding. ${ }^{21}$ Planned programs such as our program or the Baby Friendly Hospital Initiative appear not to contribute to this increasing trend in breastfeeding duration. Lastly, availability of free lactation consultancy was not shown to make a difference in breastfeeding continuation in spite of its high uptake in the intervention group. We have found no trials in which were lactation consultancy was evaluated as an isolated intervention, but one trial which that included it in combination with early discharge showed that it was effective. ${ }^{22}$ 


\section{Recommendations}

To summarize, we found no effect of our breastfeeding promotion and support program, and no major flaws in the design or execution of the trial could explain this. We conclude that none of the elements in our program is effective (health counseling; early signaling and referral for free lactation consultancy). Programs of breastfeeding promotion reviewed by Fairbank et al. ${ }^{2}$ or breastfeeding support reviewed by Sikorski et al. ${ }^{3}$ were shown to be effective in many trials, but ineffective in many others, and when comparing them it is hard to tell which mix or intensity of interventions is decisive. Points of improvement in our program are the categories of caregivers involved (maternity assistants, midwives, peer counselors), the number and duration of contacts, especially in the first weeks after parturition, and more emphasis on the continuation steps in health counseling with avoidance of overemphasis on breastfeeding problems. Further improvements of breastfeeding support may need a combination of attention to behavioral determinants at the caregivers' level (meso level) and environmental and cultural change (macro level), such as the conditions for combining work and breastfeeding. The latter may have great impact, as can be seen by the high breastfeeding rates in Scandinavian countries, but goes beyond the kind of programs that can be experimentally tested.

\section{ACKNOWLEDGEMENTS}

The development and evaluation plan was submitted as a grant proposal for the National Prevention Program of ZONMw ("Netherlands Organization for Health Research and Development"), was approved in 1999, and started in 2000. The authors thank ZONMw and the CZ-group for their financial support. Furthermore, we would like to express our gratitude to the following home health care organizations for their collaboration: The Home Health Care West-Mining Area, The Home Health Care Middle-Limburg, and ZorggroepThuis South-East Limburg. Finally, we would like to thank the members of the steering committee for their advice and support during the research project.

\section{REFERENCES}

1. Lanting CI, Herschderfer K, Van Wouwe JP, Reijneveld SA. Peiling melkvoeding van zuigelingen 2001/2002 en het effect van certificering op de borstvoedingscijfers. Leiden: TNO-PG, 2002.309, 2002.

2. Fairbank L, O'Meara S, Renfrew MJ, Woolridge M, Sowden AJ, Lister-Sharp D. A systematic review to evaluate the effectiveness of interventions to promote the initiation of breastfeeding. Health Technol Assess 2000; 4:1-171.

3. Sikorski J, Renfrew MJ, Pindora S, Wade A. Support for Breastfeeding Mothers (Cochrane Review). The Cochrane Library: Oxford: update Software, 2003:1-38.

4. Kools EJ, Thijs C, De Vries H. The ABC of Breastfeeding. A Planning model for health promotion applied to breastfeeding in the Netherlands. A window to the future. Submitted for publication 2004.

5. Termote M, De Vries H, Kools EJ, Thijs C. Psycho-social factors associated with the duration of breastfeeding. A longitudinal study. Submitted for publication 2004. 
6. De Vries H, Mesters I, H. Van der Steeg, Honing C. The general public's information needs and perception regarding hereditary cancer: an application of the integrated change model. Pat Educ Couns (in press).

7. De Vries H, Lezwijn J, Hol M, Van der Steeg M. Skin Cancer Prevention: Behavior and Motives of Dutch Adolescents. European Journal of Cancer prevention (accepted).

8. De Vries H, Mudde A, Kremers S, Wetzels J, Uiters E, Ariza C, Duarte Victoria P, Fielder A, Holm K, Janssen K, Lehtuvuori R, Candel M. The European smoking prevention frame work approach: short terms effects. Health Educ Res 2003; 18:649-63.

9. Ilca. International Lactation Consultant Association. Available at: http//www.ilca.org

10. Kramer MS, Kakuma R. The optimal duration of exclusive breastfeeding. A systematic review. Geneva Switzerland: WHO, WHO/NHD/01.08WHO/FCH/CAH/01.23, 2002.

11. Gerards F, Hospers H. Health Counseling: a strategy to accompany patient guidance. Nederlands Tijdschrift voor Diëtisten 1991; 46(5):132-37.

12. Gerards F. Health Counseling. In: Damoiseaux V, van der Molen HT, \& Kok GJ. (Eds). Health education and behavioral change. Assen: Van Gorcum 1993:353-36.

13. Pieterse ME, Seydel ER, De Vries H, Mudde AN, Kok GJ. Effectiveness of a minimal contact smoking cessation program for Dutch general practitioners: a randomized controlled trial. Prev Med 2001; 32:182-90.

14. Bolman C, De Vries H, Van Breukelen G. A minimal-contact intervention for cardiac inpatients: long-term effects on smoking cessation. Prev Med 2002; 35:181-92.

15. Mc Guire EM. Attitudes and attitude change. New York: Lawrence Erlbaum Associates, 1985.

16. De Vries H, Kok GJ. From determinants of smoking behavior to the implications for a prevention program. Health Educ Res 1986;1:85-94.

17. De Vries H. Planning and evaluating health promotion. In: Scott D, Weston R, eds. Evaluating Health Promotion. Cheltenham: Stanley Thornes, 1998:92-108.

18. Kools EJ, Thijs C, De Vries H. The behavioral Determinants of Breastfeeding in the Netherlands: Predictors for the initiation of Breastfeeding. Submitted for publication 2003.

19. StataCorp. Stata statistical software release 7.0: In: College Station TX: Stata corporation, 2001.

20. Green LW, \& Kreuter MW. Health Promotion Planning: An Educational and Ecological Approach. 3th. ed: California: Mayfield Publishing Company, 1999.

21. Lanting CI, Herschderfer K, Van Wouwe JP, Reijneveld SA. Effect van invoering van het "Baby Friendly Hospital Initiative" op het geven van borstvoeding in Nederland. Leiden: TNO Preventie en Gezondheid, PG/Jeugd 2003.212, 2003.

22. McKeever P, Stevens B, Miller K-L, MacDonell JW, Gibbins S, Guerriere D, Dunn MS, Coyte PC. Home versus Hospital Breastfeeding Support for Newborns: A Randomized Controlled Trial. Birth 2002; 29:258-65. 


\section{General Discussion}


This chapter discusses the main findings of the four studies described in this thesis. Furthermore, we discuss their strengths and weaknesses, and give recommendations for further research, for promotion and support of breastfeeding in practice, and for health care policy with regard to breastfeeding.

\section{Analyzing the problem}

As one of the first steps in the project, an analysis of the problem was made. For this purpose the $\mathrm{ABC}$ health promotion planning model ${ }^{1}$ was used, as described in chapter 2 . The main findings are summarized below.

First, evidence is abundant showing that breastfeeding for six months has health benefits for mother and child. In the Netherlands, the initiation rate of breastfeeding is high, but there is a rapid decline in the first months. We concluded that three months breastfeeding is a realistic goal with considerable health benefits for a broad segment of the population.

Second, with regard to target population the findings from various studies suggest that promotion and support of breastfeeding is beneficial for the whole population. Hence, we defined the whole population of pregnant women as target group for the promotion and support of breastfeeding. In the Netherlands, almost every woman can be reached through the maternity care, so this was chosen as the main access point.

Third, many intervention programs have been shown to be effective for promotion and support of breastfeeding, but many others have been ineffective. Effective programs were characterized by having a mix of methods, but it is unclear which particular method was most effective.

Four, the results of studies show that the main psychosocial determinants of breastfeeding intention were positive attitudes towards breastfeeding, positive social norms concerning breastfeeding and low social support for formula feeding. Positive previous breastfeeding experience was found to predict breastfeeding intention as well. The strongest independent predictors of the continuation of breastfeeding were the intention to continue, self-efficacy, and social norm at work. Studies in the Netherlands suggested that mothers need more information and support for the realization of their choice. Thus, for the promotion of breastfeeding initiation, the emphasis should lie on attitudinal and social support, while for the continuation of breastfeeding early signaling of breastfeeding difficulties, support at work and self-efficacy need emphasis.

Fifth, with regard to future continuation of effective breastfeeding promotion, cooperation between the various stakeholders is of crucial importance. However, in the Netherlands, we noted a lack of cooperation and continuity of care and (in addition) insufficient uniformity in advice between the caregivers of different organizations. ${ }^{2}$ Finally, we concluded that the use of lactation consultants may improve breastfeeding rates but scientific evidence for this recommendation is weak. Lactation consultancy is possibly underused.

The main findings from this analysis described above thus far formed the basis to formulate the objective of the new program aimed at the promotion and support of breastfeeding. The main goal was to prevent mothers discontinuing and to enhance the breastfeeding rate at three months by $10 \%$, from $21 \%$ (in 1999) to $31 \%$. The rationale for the choice for three months was based on the health benefits of breastfeeding for six 
months and the high rate of cessation in the first months; hence the greatest benefits for the population would be gained by increasing breastfeeding rates in the first months.

At the individual or micro level, we targeted our intervention on pregnant women in their seventh month prepartum until six months postpartum in order to draw attention and to create positive motivation towards breastfeeding, and to support breastfeeding after birth. At the meso level, we targeted our program on the maternity nurses (prepartum home visits), and on the nurses (postpartum home visits and consultations) and physicians (consultations) of the child health care.

\section{The behavioral determinants of breastfeeding in the Netherlands}

In two separate studies we evaluated the factors that predicted the initiation of breastfeeding at birth (Chapter 3) and the factors that explained the continuation of breastfeeding at least three months postpartum once mothers had initiated breastfeeding (Chapter 4). We summarize the findings, and compare them with our previous study ${ }^{3}$ and with studies elsewhere. First, intention was a very strong predictor of the initiation of breastfeeding. Second, previous breastfeeding experience was a predictor of breastfeeding initiation as well of duration: multiparas with breastfeeding experience had a higher chance of breastfeeding initiation than mothers with a first-born infant, while multiparas without breastfeeding experience had a much lower chance. This was in agreement with other studies. ${ }^{4-7}$ Third, non-smoking mothers started breastfeeding more often and continued longer than smoking mothers. This has also been reported in other studies. ${ }^{6,8}$ Fourth, a strong predictor of breastfeeding continuation was the intention at one month postpartum to return to work. Surprisingly, women with the intention to return to work had more chance to continue breastfeeding than women without this intention. This is contrary to a similar study by Scrimshaw et al., ${ }^{9}$ which reported that the intention to work postpartum was associated with shorter intended duration of breastfeeding. Furthermore, we noticed that the prepartum social support of breastfeeding at work was positively related to the initiation and duration of breastfeeding. Finally, in our study we did not assess prepartum intention to return to work so that we cannot relate this factor to breastfeeding initiation. Other studies reported no association, ${ }^{10,11,12}$ or a negative association between prepartum intention to return to work and the initiation of breastfeeding. ${ }^{9,13-17}$ Instead of prepartum intention, other studies focused on actual return to work in relation to breastfeeding continuation. The results of these studies were inconsistent, and depended on the number of hours worked per week. Most studies reported a negative association between actual return to work and breastfeeding duration, especially for mothers working full-time ${ }^{12.17-24}$, while others reported that employed mothers breastfed longer, ${ }^{25,26}$ or as long as non-employed mothers. ${ }^{27,28} \mathrm{~A}$ problem when interpreting these results from other studies is that often no clear distinction is made between intention and actual return and that different causal directions cannot be distinguished if the timing is not adequately addressed (Figure 1), for example: when a pregnant woman has the intention to return to work, she may be reluctant to start breastfeeding because she anticipates problems with the combination of breastfeeding and work. When a mother returns to work, she stops breastfeeding; when a mother wants to continue, and does not have the possibility to combine breastfeeding and work she may postpone return to work or reduce the work time. Our 
conclusion is that more prospective studies about the intention to return to work and breastfeeding initiation and duration with repeated measurements are needed.

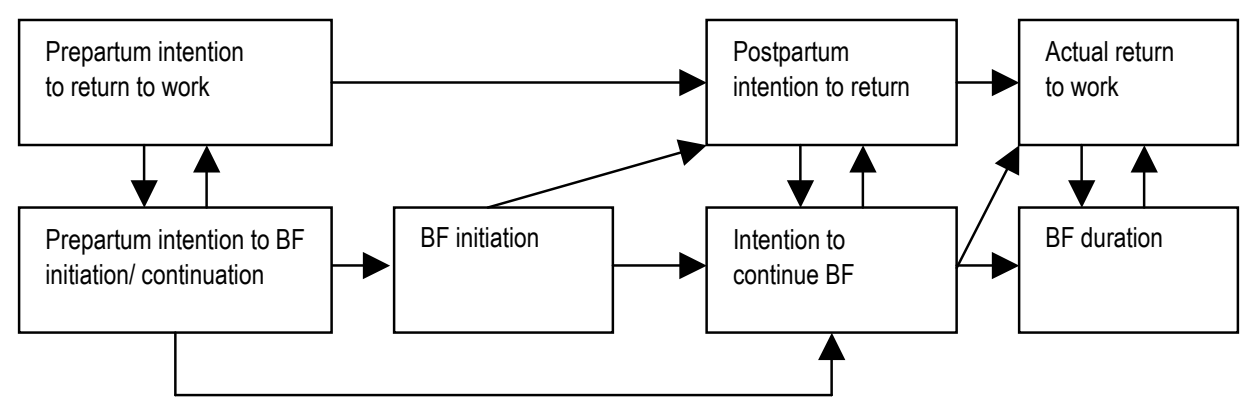

Figure 1 Potential directions in relations between returning to work and breastfeeding $\mathrm{BF}=$ breastfeeding

The knowledge about important motivational determinants of breastfeeding forms the basis for interventions, since this information provides indications about motives of women that adopt and not adopt breastfeeding and/or continue or not continue with breastfeeding. First, it should be determined which factors and salient beliefs from social cognitive models, such as the ASE model, are relevant for breastfeeding in our target population. The results of various studies indeed show that these factors do predict breastfeeding, ${ }^{3,29,30}$ because it has been shown that ASE determinants are predictive for intention to breastfeed, as well as for actual behavior (initiation and continuation of breastfeeding). Second, it is important to study the variables within the ASE constructs in specific target groups, since the composition of these factors can be culturally and regionally bound ${ }^{31,32}$ in advance of starting an intervention, because there are cultural differences that hamper the application of studies from different countries to a local situation. Moreover, it is important to consider the distribution of the ASE scores in the population, because this analysis can illuminate the advantages of the desired behavior on which the target group is not yet convinced (because if many people have low scores, there is more room for improvement compared to when everyone has high scores). This "room for improvement" is missed if the analysis is only focused on regression methods, such as is common in many publications.

We found that almost all ASE factors in our study were related to both the initiation and continuation of breastfeeding. An exception occurred only for breastfeeding duration, which was not related to the social support of breastfeeding from significant others. We found low levels of self-efficacy in the study population. This indicates that increasing self-efficacy expectations has to be an important educational objective for program development in our target group. Furthermore, we found differences between the ASE determinants of initiation and duration that were revealed when comparing the results from multivariate analyses (Table 1). 
Table 1 Independent ASE determinants for breastfeeding initiation and duration, results from multivariate logistic regression analyses

\begin{tabular}{|c|c|c|}
\hline Determinants & Breastfeeding initiation & Breastfeeding duration \\
\hline A & Attitudes (pros and cons) & \\
\hline S & $\begin{array}{l}\text { Social norm towards breastfeeding of } \\
\text { significant others }\end{array}$ & $\begin{array}{l}\text { Low social support of formula feeding from significant } \\
\text { others }\end{array}$ \\
\hline $\mathbf{E}$ & & High situational self-efficacy for breastfeeding \\
\hline
\end{tabular}

This is consistent with the different impact of the ASE determinants during different phases of starting and continuing breastfeeding. Attitudes (pros and cons) towards breastfeeding and the social norm to breastfeeding of significant others were the strongest determinants for breastfeeding initiation, but not for continuation. By contrast, for breastfeeding continuation the strongest independent determinants were low social support for formula feeding from significant others and high situational self-efficacy for breastfeeding. It is also possible that self-selection played a role in this difference. For instance, the perceived advantages of breastfeeding were found to be a major determinant of breastfeeding initiation, and mothers who actually initiated breastfeeding may all have been fairly convinced of these advantages, so that the room for an influence on breastfeeding continuation could be limited.

Retrospectively, we asked at three months postpartum the reasons, and influences for introducing or supplementing formula feeding. The main reasons were: the quantity of breastfeeding decreased, the breastfeeding was painful, the baby was crying too much, formula feeding was better to combine with work and doubts about the growth of the infant. These reasons are in agreement with other Dutch studies. ${ }^{33,34}$ The main influences were: own initiative, partner, and family and friends. Disadvantages of retrospective studies are biased recall of reasons, by attribution of mother's intentions to external influences, and by justification of one's behavior with hindsight. Retrospective studies are therefore prone to over reporting the socially accepted reasons. ${ }^{35}$ In addition, reasons are subject to misconceptions, but it is important to signal misconceptions, because they may be resolved by health counseling. Therefore, a point open for discussion is whether the reason "the breastfeeding decreased" is a socially accepted reason, a misconception, or a real physiological reason. In the literature, terms like perceived insufficient milk or lactation crisis suggest a medical ground, while the Dutch term "regeldagen" (frequency days) refers to a physiological process of finding a new balance when the infant's need exceeds the mother's milk supply. In practice, but also in the literature, these terms are not well defined. It has been shown that women with perceived insufficient milk have lower self-efficacy. ${ }^{36}$ Similarly, "doubts about the growth of the infant" may be real or reflect low self-confidence. In addition, reasons such as "breastfeeding was painful" may be related to self-efficacy to resolve problems. Perhaps the reason "formula feed is better to combine with work" is related to the social support at work and with self-efficacy to combine breastfeeding and work. This indicates that interventions could be focused on strengthening self-efficacy by professional support. Misconceptions about breastfeeding and growth may also be due to different growth patterns of breastfed and formula fed infants. Some studies reported that breastfed infants have higher weight gain in the first three months than formula fed infants, and lower after three months, ${ }^{37-39}$ whereas other studies have reported that 
breastfed and formula fed infants had similar growth rates. ${ }^{40,41}$ Inconsistencies between studies may be due to differences in the composition of the breastfed groups (e.g. duration of breastfeeding) and the formula fed groups (exclusive formula or combined feeding). Not all studies were controlled for external factors, such as birth weight. In two Dutch studies, breastfed infants had a higher birth weight than exclusive formula fed infants, ${ }^{42,43}$ possibly due to self-selection (birth weight was related to initiation of breastfeeding) or to common underlying causes (e.g. smoking).

To summarize, we believe that more attention could be devoted in future studies to differences of ASE determinants in different phases of breastfeeding; the role of selfefficacy in perceived insufficient milk or insufficient growth; and the role of different growth patterns between breast and formula fed infants.

\section{A breastfeeding promotion and support program in the Netherlands: The randomized trial.}

The most striking finding of this thesis is the lack of effectiveness of the program in this trial. There were no significant differences in the rates of breastfeeding at birth, and at three or six months between intervention and control groups. We discuss the strengths and weaknesses of the program in the light of the following potential questions.

Were the goals of the program not adequately chosen and sufficiently addressed by the program?

The ABC approach described in Chapter 2 formed the basis for the development of the program. We formulated our operational goals as follows: to strengthen the support of continuation of breastfeeding (in addition to promotion of the initiation of breastfeeding), by:

(1) Health counseling: intervening on behavioral determinants of the duration of breastfeeding by enhancing the caregiver's performance to promote and support breastfeeding using health counseling principles.

(2) Cooperation and continuity: to enhance cooperation, early signaling of breastfeeding problems and continuity of care by transfer of information on individual mothers between caregivers.

(3) Lactation consultancy: to enhance the access to lactation consultants and to take away financial and practical barriers for consulting them.

We had limited possibilities to evaluate each operational goal separately in the program evaluation, so that it is difficult to assess whether the goals were realistic or whether the program failed to reach some of them. However, the findings show that most caregivers reported that they obtained good or sufficient behavioral skills to carry out the program and experienced support from their colleagues, the lactation consultants, and from the management. Furthermore, many mothers were referred to the lactation consultants. The program failed only in the cooperation with the midwives, because not many caregivers experienced support from the midwives. In conclusion, we maintain that the goals were realistic. 
Was the analysis of the behavioral determinants of breastfeeding in our region inadequate, or was the program insufficiently adapted to these determinants?

Before we developed the program, we performed a study of the behavioral determinants of breastfeeding continuation. ${ }^{3}$ In the $\mathrm{ABC}$ paper (Chapter 2), we reviewed determinants of breastfeeding initiation and duration, and noted that they may differ for each phase of breastfeeding. Therefore, we chose an individual approach to promote and support breastfeeding using the Health Counseling model that was aimed at addressing the ASE variables. The results of the ASE determinants in our studies (Chapters $3 \& 4$ ) were only slightly different from the ASE determinants in other studies on which our program was based. Therefore, we concluded that the program was sufficiently adapted to these determinants.

Were the necessary conditions absent to let the program be successful?

A precondition of the program was that the knowledge of caregivers about breastfeeding was sufficient in the region. We assumed that knowledge would be sufficient, because the Home health Care organizations organized annual breastfeeding introduction and booster trainings, before and during the study period (and not different between intervention and control groups). Furthermore, baseline results as measured in the trial revealed that most caregivers scored sufficiently on a breastfeeding knowledge test. A limitation of this test may be, however, the lack of reference data for this test in The Netherlands. Hence, we cannot be completely confident that the condition of sufficient knowledge of breastfeeding was met. Another assumption for the program was that health counseling would not cost much more time than caregivers normally spend during the home visits and the consultations. However, in the program evaluation of the trial, the majority of caregivers reported that the home visits and consultations did take more time, indicating that the program implementation may have been hindered by time constraints. Despite this, the program evaluation also showed that most caregivers succeeded in carrying out the program in the time available. Nevertheless, program implementation could have been more successful if the caregivers had more time for health counseling.

Is the Health Counseling model easy to apply for a behavior that has a reasonable alternative?

The Health Counseling model was chosen since the model had already been applied successfully to other health promoting behaviors, namely to smoking cessation. ${ }^{4-46}$ When comparing smoking with breastfeeding, it can be noted that with regard to breastfeeding the preferred behavior is initiation and continuation, while whereas with smoking it is quitting and continuation of non-smoking. Moreover, discontinuation of breastfeeding is mostly irreversible, while relapse to smoking can be followed by a renewed quit attempt. Beside it, and perhaps most importantly, when feeding a baby two relatively healthy alternatives are available. While breastfeeding can still be regarded as the preferred option, the alternative is acceptable for nutrition and health. Finally, specific child reactions also play an important role in early stopping of breastfeeding, for example, when a mother is confronted with an excessively crying child. In conclusion, the conditions for counseling differ between breastfeeding and smoking cessation. This may make it more difficult for any counselor to become convincingly 
effective. We recommend that the conditions of effective health counseling for breastfeeding need more study.

Was the program limited by the Home Health Care setting, the trial characteristics, or by other limitations?

The Home Health Care initiated our program and this setting limited the choices of target groups and access points at the meso level. We could not involve many caregivers because it was too expensive to train them all in health counseling principles. Hence, only the following caregivers were chosen as the main intermediary group and received training: the maternity nurses and the child health care nurses and physicians of the Home health Care organizations. For our study, we used a randomized trial design, because it is the gold standard to evaluate effectiveness. Randomization gives the strongest evidence for effectiveness; group randomization ensures that and it prevents selection (of mothers, caregivers and organizations) and selective dropout of organizations so that the groups are prognostically comparable. However, the stringent characteristics of a randomized trial implied certain restrictions to the intervention. First, the use of maternity assistants, midwives, general practitioners, or pediatricians in the program appeared to be impossible, since they both worked in the experimental and control practices. Future studies should avoid this situation by choosing experimental and control conditions not hindered by this limitation. Second, we were limited in raising awareness creating support for the intervention using mass media or regional magazines to support the program, since contamination of the control region with elements from the program had to be avoided. Furthermore, our study was confronted by other limitations. First, with regard to the intensity of the program, all caregivers of the intervention centers followed the training in health counseling. The training lasted three shifts; but we had no time reserved for supervision and casuistry, to let the method sink in. In retrospection, our conclusion is that more training in health counseling was needed. Second, the program consisted only of individual interventions targeting the micro level (mothers) and the meso level (caregivers). The Health Counseling model pays no attention to collective interventions aimed at changing, for instance, the social norm. However, this factor plays an important role in breastfeeding initiation. Third, too many different functions for a large field study had to be fulfilled by one person. Consequently, research, data entry, training of intermediaries, program championship, linking agent ship had to be combined. Consequently, not sufficient time was available to fulfill all roles largely, resulting in insufficient time to keep in touch with the caregivers and to keep them enthusiastic. Four, in the ABC paper (Chapter 2), it was noted that a possible alternative to promote and support breastfeeding would be interventions by lay support. Lay support has been shown to be effective in supporting breastfeeding mothers and probably lay support influences the social norm. Another alternative is the use of mass media, to show role models of breastfeeding mothers. These alternatives exceeded the scope of the Home Health Care.

\section{Are there indications of methodological weaknesses in the trial?}

We discussed in Chapter 5 the methodological quality of the trial and the comparability of the centers, caregivers, and participants; the contrast between intervention and control groups; the comparability of co-interventions; the comparability of the outcome measurement; and the statistical power. The number of participants with complete 
follow-up for the primary outcome was very high in both intervention and control groups. We conclude that there were no indications of major biases in the methods or the execution of the trial.

Did we under use elements that have been shown to be effective in other trials?

Fifteen (quasi-) randomized trials of breastfeeding support were discussed in a recent updated review of Sikorsky et al. ${ }^{47}$ The studies consisted of three cluster-randomized studies; the remaining studies were single site studies or the randomization was not stated. To obtain renewed illumination about the effectiveness of methods used in other trials to be able to answer this question at the end of this trial, we selected the trials with a follow-up of at least three months and we arranged them according to the type of support: extra professional support (Table 2), lay support, and training programs (Table 3 ). We considered a program as effective when it reduces the risk of discontinuation of exclusive breastfeeding, but also any breastfeeding (i.e. introduction of formula feeding in combination with breastfeeding).

Table 2 Randomized trials of the effect of extra professional support programs on the duration of breastfeeding (adapted from Sikorski 2001)

\begin{tabular}{|c|c|c|c|c|}
\hline $\begin{array}{l}\text { Author Year Ref } \\
\text { Country/allocation }\end{array}$ & Intervention vs. usual care & $\begin{array}{l}\text { In combination } \\
\text { with }\end{array}$ & Outcome & \\
\hline & Extra professional support & & Any $\mathrm{BF}^{1}$ & $\mathrm{EBF}^{1}$ \\
\hline & & & \multicolumn{2}{|c|}{$\operatorname{RR}^{2}(95 \% \mathrm{Cl})^{3}$} \\
\hline $\begin{array}{l}\text { Sjolin } 1979^{52} \\
\text { Sweden/Quasi }\end{array}$ & $\begin{array}{l}\text { Interview with pediatrician in hospital+ at home; phone } \\
\text { contacts+ home visit if problem noted vs. usual care }\end{array}$ & & $0.61(0.38-0.99)$ & $0.76(0.54-1.07)$ \\
\hline $\begin{array}{l}\text { Jones } 1985^{53} \\
\text { UK/Quasi }\end{array}$ & $\begin{array}{l}\text { Individual support+ problem solving by lactation nurse in } \\
\text { hospital+ at home vs. usual care }\end{array}$ & & $0.78(0.64-0.94)$ & \\
\hline $\begin{array}{l}\text { Moore } 1985^{54} \\
\text { UK/Random }\end{array}$ & $\begin{array}{l}\text { Package of home visit+ phone line by health visitor or } \\
\text { medical officer vs standard hospital feeding advice }\end{array}$ & & & $1.01(0.91-1.11)$ \\
\hline $\begin{array}{l}\text { Lynch } 1986^{55} \\
\text { Canada/Not } \\
\text { stated }\end{array}$ & $\begin{array}{l}\text { Home visit+ phone calls by } \mathrm{BF}^{1} \text { consultant vs. } \\
\text { postpartum home visit by public health nurse }\end{array}$ & & $1.06(0.78-1.45)$ & \\
\hline $\begin{array}{l}\text { Frank } 19877^{56} \\
\text { USA/Random }\end{array}$ & $\begin{array}{l}\text { Counselor in hospital postpartum phone contacts+ } \\
\text { research discharge packs vs. usual care }\end{array}$ & & & $0.97(0.90-1.05)$ \\
\hline $\begin{array}{l}\text { Grossman } 1990^{57} \\
\text { USA/Quasi }\end{array}$ & $\begin{array}{l}\text { Postpartum package (face to face meeting with lactation } \\
\text { counselor, booklet, phone contacts+ helpline) vs. routine } \\
\text { postpartum teaching by obstetrical nurse }\end{array}$ & & $1.16(0.84-1.60)$ & \\
\hline $\begin{array}{l}\text { Barros } 1994^{58} \\
\text { Brazil/Not stated }\end{array}$ & $\begin{array}{l}3 \text { routine home visits postpartum by social assistant or } \\
\text { nutritionist vs. no routine home visits }\end{array}$ & & $0.92(0.81-1.05)$ & \\
\hline $\begin{array}{l}\text { Froozani } 199948 \\
\text { Iran/Quasi }\end{array}$ & $\begin{array}{l}5 \text { contacts postpartum at home or in lactation clinic by } \\
\text { nutritionist trained WHO BF counseling vs. usual care }\end{array}$ & $\begin{array}{l}\text { WHO/UNICEF } \\
\text { courses }\end{array}$ & & $0.64(0.49-0.82)$ \\
\hline $\begin{array}{l}\text { Kramer } 2001^{49} \\
\text { Belarus/Cluster } \\
\text { Random }\end{array}$ & $\begin{array}{l}\text { Monthly consultations in hospital+ community policlinics } \\
\text { by staff }\left.\mathrm{BHF}\right|^{4} \text { trained vs. usual care }\end{array}$ & $\begin{array}{l}\text { WHO/UNICEF } \\
\text { courses }\end{array}$ & $0.74(0.61-0.89)$ & $0.59(0.48-0.72)$ \\
\hline & Pooled RR (95\% Cl) & & $0.86(0.75-1.00)$ & $0.79(0.65-0.97)$ \\
\hline & Test for overall effect & & $P=0.05$ & $P=0.02$ \\
\hline & Test for heterogeneity & & $P=0.0364$ & $P<0.00001$ \\
\hline
\end{tabular}

EBF=exclusive breastfeeding, $\mathrm{BF}=$ breastfeeding

${ }^{2} R R=$ relative risk of breastfeeding discontinuation before 3 months postpartum; for instance. When the $R R$ is 0.6 , this means that the percentage of mothers who discontinue breastfeeding is a factor 0.6 lower in the intervention than in the control groups, or $40 \%$ lower $395 \% \mathrm{Cl}=95 \%$ Confidence interval

${ }^{4} \mathrm{BFHI}=$ Baby Friendly Hospital Initiative

Results which are statistically significant on the alpha $=0.025$ level (one-sided) are printed in black 
General discussion

Table 3 Randomized trials of the effect of lay support and WHO/ UNICEF course and La Leche League training programs on the duration of breastfeeding (adapted from Sikorski 2001)

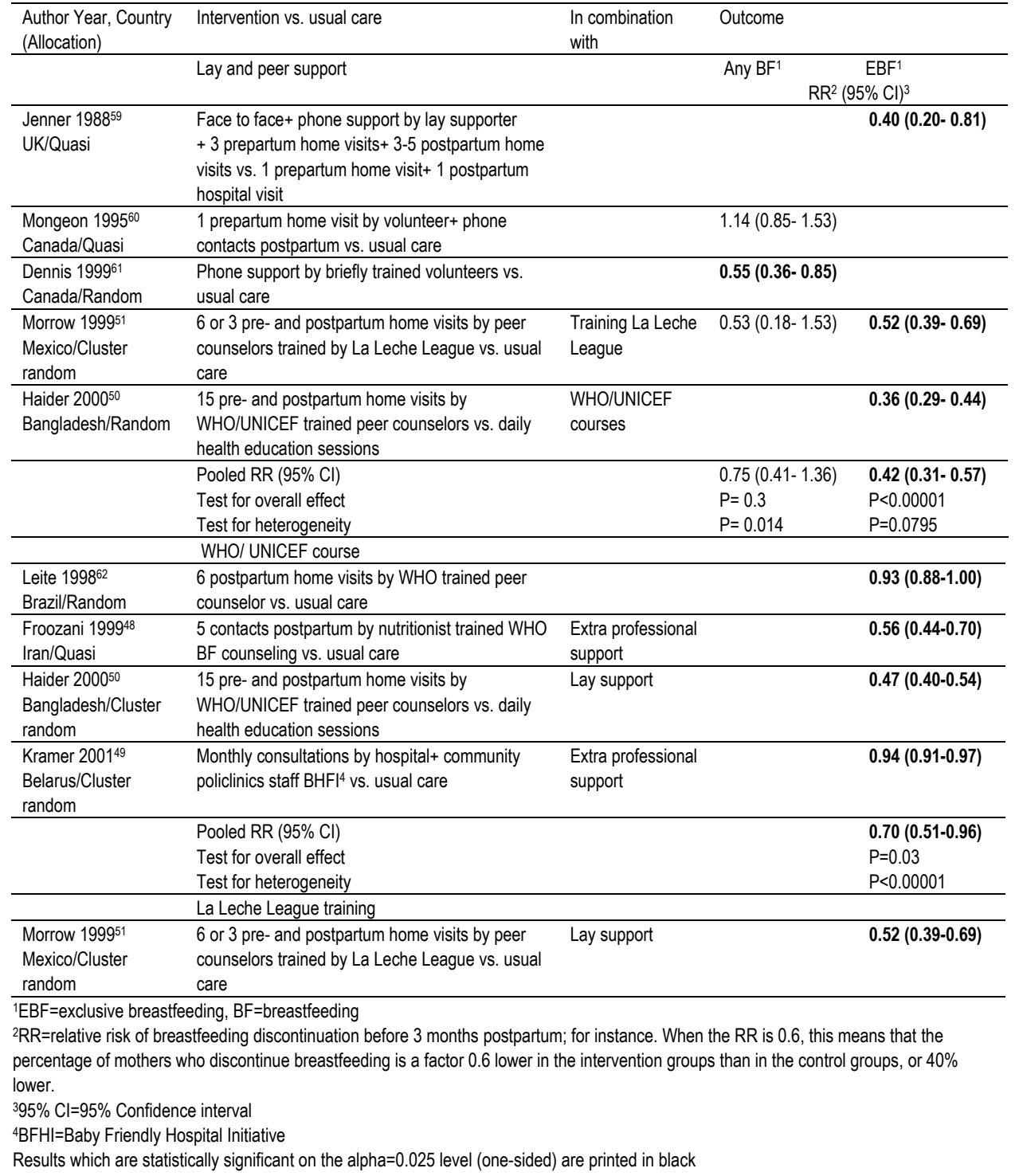

The results of Sikorsky and colleagues show that extra professional support was effective in four out of nine studies, and lay support in four out of five studies. In two studies, which showed that extra professional support was effective, this intervention was combined with the professionals, trained with WHO/UNICEF courses. ${ }^{48,49}$ Of the four effective lay support studies, two studies included the WHO/UNICEF courses ${ }^{50}$ or the La Leche League training. ${ }^{51}$ It seems that studies with a combination of professional or lay support with a training program were the most effective ones, possibly due to synergism. Two of the three most effective studies (i.e. with relative risk of 
breastfeeding discontinuation below 0.55 in table 3 ) included the combination of lay support with training programs. ${ }^{50,51}$

With regard to lactation consultancy, one older trial of a lactation nurse was effective, ${ }^{53}$ (included in the review by Sikorsky, Table 2), but it was unknown whether the nurse was a certified lactation consultant, because her education was not described. A recent randomized trial ${ }^{63}$ showed that in-home lactation support had a positive effect on the duration of breastfeeding of mothers of term newborns in the first two weeks postpartum, but then there was no follow-up until three months. Because we do not know whether the necessary conditions for effectiveness are present in the Netherlands, it seems worthwhile to evaluate the effectiveness of lactation consultancy separately. This can be studied in a relatively small trial because it can be focused on high-risk groups with individual randomization after the caregivers pose the indication for the referral to them. Because the effectiveness is dependent on the early signaling of breastfeeding problems, referral criteria have to be taken up in the program development and evaluation of such a trial. The referral criteria that were used in the program may be suitable, because they were well defined and stringent. In addition to the review above, in 2003 it was shown in the Netherlands that Baby Friendly Hospital Initiativetrained and certified hospitals and maternity organizations had a higher rate of breastfeeding initiation compared with non-certified organizations. However, it is hard to tell whether this is a self-selection or a training effect. The duration of breastfeeding did not differ. ${ }^{64}$

Our conclusion is that interventions were effective in many trials, but also ineffective in many others; and when comparing them it is hard to conclude which mix or intensity of interventions was decisive. None of the trials was based on health counseling according to our definition. We discussed the strengths and weaknesses of our trial, and we identified the following potential weaknesses: limitations in the ability to evaluate each separate goal; limitations due to the experimental approach and limitations of the Home Health Care setting. While many health promotion programs use a comprehensive approach, this approach limits the identification of factors that are crucial to behavior change. While public health promotion needs may require the development and implementation of these types of programs, future public health promotion research should aim at identifying these factors using a dismantling approach, a notion also made with regard to other public health programs. ${ }^{65,66}$ Consequently, to analyze the effectiveness of separate elements (such as health counseling, lactation consultancy), it is recommended for future projects to study their impact using experimental trials for specific target groups in specific phases of breastfeeding, with interventions by separate groups of caregivers such as midwives, maternity assistants and lactation consultants. This approach may have several advantages: the program evaluation can be focused more on the specific goals, and the statistical power may be higher (namely, if the specific target groups are also the high-risk groups with the highest intervention effect), so that smaller groups are needed to show the efficacy, under highly restricted and optimal conditions. Disadvantages of evaluating separate elements are that the results are not immediately fully comparable with daily practice and there is a chance to miss synergism. In a next phase, more complex assemblages of effective elements can be tested for their effectiveness as a whole, under common practice conditions. Therefore, a phased evaluation of complex interventions has been proposed ${ }^{67}$ In the next section, we make recommendations to further evaluate breastfeeding promotion programs. 


\section{RECOMMENDATIONS}

We distinguish between recommendations for further research, those for promotion and support of breastfeeding in practice, and those for health care policy with regard to breastfeeding. Furthermore, in the ABC paper, we noted some other problems on which we did not target our intervention. This was due to the choices we had to make because our organizational setting was the Home Health Care. These problems may hamper the promotion and support of breastfeeding.

In our review of the health effects of breastfeeding, we found many studies with convincing evidence of protective effects but also many studies with ambiguous evidence (such as the effect on diabetes mellitus, or ovarian cancer in the mother). New studies with hard evidence of the health effects of breastfeeding on severe diseases may bring the benefits of breastfeeding better into the limelight. However, it is also possible that we cannot get more evidence or that studies come up showing contradictory effects. For instance, a recently published study has caused much controversy because it showed that breastfeeding may increase the risk of asthma and allergy ${ }^{68}$ If we get more evidence, it will not necessarily imply that caregivers, mothers and significant others change their behavior. The intention to change behavior depends on the attitudes, social support, and self-efficacy expectations. ${ }^{69}$ Knowledge of health effects may play a small part compared with other advantages, such as economic advantages.

With regard to the collation of European data, our study revealed that this process was hindered by several factors: the data were not up to date or were incomplete, and some were not based on WHO definitions.

With regard to the task and responsibilities of each professional group in relation to breastfeeding, our analysis suggests that these tasks and responsibilities are not sufficiently delineated. For instance, in the Guideline for Infant Feeding, a coproduction of the Dutch Health Care Inspectorate and the Nutrition Center, no mention is made of tasks and responsibilities of each professional group. In The Netherlands, breastfeeding research and policies is scattered over several institutions. The Nutrition Center (Voedingscentrum) coordinates the national promotion and support of breastfeeding, while the National Institute for Public Health and the Environment (Rijksinstituut voor Volksgezondheid en Milieuhygiene) bundles the knowledge of the benefits of breastfeeding in the Public Health future Exploration (Volksgezondheid Toekomst Verkenning) ${ }^{70}$ and the Netherlands Organization for Applied Scientific Research (TNO) investigates the determinants and the breastfeeding percentages. In general, it has been noted that the Netherlands lacks a strong Public Health authority, ${ }^{71}$ so that this situation may not only be confined to breastfeeding.

\section{Recommendations for further research}

1. Determinants of breastfeeding should be studied in depth for each phase of breastfeeding. More attention should be given to different breastfeeding barriers in each phase (for instance breastfeeding and employment), and to misconceptions (for instance parents' doubts about infant's growth, insufficient milk, the influence of breastfeeding on the body shape). The relation between breastfeeding and work has shown to be inconsistent and is possibly more complex than previously thought. These relationships can best be studied in a 
prospective longitudinal design, in order to account for selection effects and to establish causality.

2. More insight is needed how employers and employees use the statutory regulations concerning lactation and work, for instance how employees are informed and to what extent possibilities are created for giving breastfeeding or expressing milk at the workplace and how working hours may be adapted. Qualitative studies are needed for this.

3. The conditions of effective health counseling need more attention. It is conceivable that this approach can only be effective when all preconditions are realized, such as the inclusion of midwives and maternity assistants in the chain of care; sufficient knowledge of breastfeeding at the caregivers and enough time for health counseling. More program development has to be done, and evaluated in an exploratory trial, before this can be tested in a randomized trial. Because some studies have shown that a lactation consultancy is effective in increasing the duration of breastfeeding, it seems worthwhile to evaluate the effectiveness of a lactation consultancy separately. This could be studied in a relatively small trial, because this can be focused on high-risk groups with individual randomization after the caregivers have posed the indication for referral to the consultancy. In contrary when a multi intervention trial is developed again, the limitations of a trial have to be avoided. For instant contamination can be prevent by spreading the participated Home Health Care organizations over the whole country. Because the effectiveness is dependent on the early signaling and referral criteria, these have to be taken up in the program development and evaluation of such a trial. In addition, peer group support and lay support have shown promise for the support of breastfeeding, especially in combination with established training programs of WHO/ UNICEF and La Leche League. In the Netherlands, this approach is possibly underused and could be further developed and tested. Points of interest here are the reach and the continuity and how lay support can be supported by home health care organizations.

4. Smoking mothers started breastfeeding less often and continued for a shorter time than non-smoking mothers. In addition, pregnancy is a strong stimulation for smoking cessation. ${ }^{72}$ Therefore, the need for a combined intervention for breastfeeding continuation and smoking cessation can be assessed. Such an intervention may derive health benefits for mother and child. If it is difficult to achieve these two goals in one intervention, the alternative is then to offer two separate interventions, whereby the combination of breastfeeding and smoking deserves special attention. If such an intervention results in a longer duration of breastfeeding as well as in smoking cessation, than double profit may be reached. Moreover, smoking cessation has also a preventive effect on the next generation, because a mother plays a role model for her children. 
5. In parallel to accruing more knowledge on the health effects of breastfeeding one could also study how health beliefs are influenced by knowledge, what their relative impact is on attitudes, and how the health message can be translated in an understandable and effective way. This can be studied in Europe, so that cultural and regional variations and differences in health care and social arrangements can be included.

\section{Recommendations for promotion and support of breastfeeding in practice}

1. With regard to the caregivers

Because the choice for breastfeeding is made before or early in the pregnancy, midwives may focus their attention on breastfeeding by informing pregnant women about the benefits of breastfeeding, even during the first consultation early in the pregnancy. In pregnant women intending to breastfeed, the emphasis of maternity nurses, midwives, and other caregivers could be shifted towards the support of the continuation of breastfeeding. They have to inform these women about breastfeeding organizations, low threshold consultation hours, breastfeeding support groups, and about the statutory regulations of lactation and work.

- $\quad$ Caregivers need to focus their interventions on strengthening self-efficacy in pregnant women with the intention to breastfeed and on professional support of breastfeeding women. They have to pay attention to coping with breastfeeding problems, such as perceived insufficient milk and insufficient growth of the infant. Special attention is necessary for low social class, poorly educated groups, younger women, smoking women, and ethnicity.

- It is important to change the social norm of significant others. Caregivers can encourage women to let partners be present at the pre-and postpartum home visits and at the support group meetings of the Home Health Care (including lay support groups). Other activities to reach partners should be explored as well.

2. The Home Health Care organizations may organize the following:

- Low threshold consultation hours for breastfeeding mothers, to strengthen their self-efficacy and ability to cope with problems and to take away the doubts about the growth of the infant by weighing the infants to see whether the doubts are justified or not. Organizational barriers should be taken away.

- $\quad$ Pre- and postpartum exercise groups and breastfeeding support groups with laypersons trained with WHO/UNICEF or La Leche League training programs. In these support groups the self-efficacy to breastfeed in public can be raised by increasing the (pregnant) mothers' confidence in coping with breastfeeding in public and by influencing the social norm so that giving breastfeeding becomes more accepted.

\section{Recommendations for health policy with regard to breastfeeding}

1. To create a continuity of care for breastfeeding, the responsibilities of breastfeeding have to be reflected in the job descriptions of maternity assistants, 
midwives, general practitioners, and pediatricians. This can be regulated by the government through the law Professionals in Health (BIG), and executed by the professional associations. Various organizations are involved with breastfeeding research, but no strong Public Health authority is responsible. The government (the ministry of public health) as the national public health authority should take responsibility for the breastfeeding policy. The existing institutes that are involved with breastfeeding research and development have no power to influence the execution of the promotion and support of breastfeeding of the Home Health Care organizations, the midwives, or the hospitals. Furthermore, it should be taken up in the job description that the company doctor is the mediator in controversial breastfeeding issues between mothers and employers.

2. For monitoring, an efficient and valid national and European surveillance system for breastfeeding should be built up. National and European coordination centers (appointed by the governments) should collect the breastfeeding data. Furthermore, the data should be comparable at international level and between nations and regions. Therefore, definitions of breastfeeding (exclusive and combined breastfeeding based on the WHO definitions) as well as of breastfeeding determinants (maternal education, previous breastfeeding experience, smoking) should be uniform, so that they also are comparable. Next, at the intake consultation the data of breastfeeding determinants have to be registered with uniform definitions. Postpartum, caregivers have to register at internationally fixed times whether the infants receive exclusive breastfeeding, complementary breastfeeding, or formula feeding (in accordance with the WHO definitions) including the duration of breastfeeding in weeks and when formula feeding was introduced.

3. To achieve sufficient knowledge of breastfeeding, the subject should be part of the education of maternity assistants, nurses and physicians. Annual refresher trainings should be compulsory during their activities and then their knowledge has to be tested. Therefore, knowledge tests have to be developed with reference data. Breastfeeding should also be introduced as a subject into teaching materials for the general education of youngsters as an intrinsic aspect of raising children, and in lessons of biology and care at primary and secondary school.

4. To create positive social norms of breastfeeding, mass media approaches can be adopted as an additional tool, because they have been shown to be effective for breastfeeding promotion. ${ }^{73,74}$ Images of idols such as pop and film stars can be presented in mass media so that they become a role model for others. National celebrities recruited as breastfeeding ambassadors, could promote breastfeeding in the mass media. Furthermore, commercials and free publicity have to be used to bring breastfeeding to the notice of the public.

5. In order to take away barriers for breastfeeding outdoors, separate or mobile rooms should be created in public places, such as stores, restaurants, airports, railway and petrol stations in order to breastfeed or to express milk.

6. Breastfeeding support needs a broader approach; we may have to look for positive and negative incentives. Three options to improve breastfeeding duration can be explored: First, tax can be introduced on formula feed for infants until six months. For smoking, the price policy has stimulated smoking prevention. ${ }^{75,76}$ Second, breastfeeding mothers and their families might pay a lower health 
insurance premium. However, this particular set of measures requires an independent check whether a mother gives breastfeeding and may compromise the relation with the caregivers if such a check is asked from them. A disadvantage is that mothers who have a medical indication not to breastfeed are unnecessarily taxed or have to pay, and will need compensation. Third, the maternity leave can be extended beyond the present ten weeks (for instance to six months postpartum) with full pay, as in the Scandinavian countries or with the possibility of returning to work gradually, and breastfeeding rates are higher in these countries. These measures are difficult to test experimentally; therefore, internal monitoring of the data of breastfeeding and its determinants may be helpful.

\section{REFERENCES}

1. Kools EJ, Thijs C, De Vries H. The ABC of Breastfeeding. A Planning model for health promotion applied to breastfeeding in the Netherlands. Submitted for publication 2004.

2. Anten-Kools E. Borstvoedingsbeleid. Een multidisciplinair samenwerkingsverband in Oostelijk Zuid-Limburg. Tijdschrift voor verloskundigen 1999:423-25.

3. Termote M, De Vries H, Kools EJ, Thijs C. Psycho-social factors associated with the duration of breastfeeding. A longitudinal study. Submitted for publication 2004.

4. Rogers IS, Emmett PM, Golding J. The incidence and duration of breast feeding. Early Hum Dev 1997;49 Suppl:S45-74.

5. Nagy E, Orvos H, Pal A, Kovacs L, Loveland K. Breastfeeding duration and previous breastfeeding experience. Acta Paediatr 2001;90:50-6.

6. Lande B, Andersen L, Baerug A, Trygg K, Lund -Larsen K, Veierod M, et al. Infant feeding practices and associated factors in the first six months of live: The Norwegian Infant Nutrition Survey. Acta Paediatr 2003;92:152-61.

7. Contento IR, Randell JS, Basch CE, Amir LH. Review and analysis of evaluation measures used in nutrition education intervention research. Maternal smoking and reduced duration of breastfeeding: A review of possible mechanisms. J Nutrition Educ Behav 2002;34:2-25.

8. Scott JA, Aitkin I, Binns CW, Aroni RA. Factors associated with the duration of breastfeeding amongst women in Perth, Australia. Acta Paediatr 1999;88:416-21.

9. Scrimshaw SC, Engle PL, Arnold L, Haynes K. Factors affecting breastfeeding among women of Mexican origin or descent in Los Angeles. Am J Public Health 1987;77:46770.

10. Littman H, Medendorp SV, Goldfarb J. The decision to breastfeed. The importance of father's approval. Clin Pediatr Phila 1994;33:214-9.

11. Birenbaum E, Fuchs C, Reichman B. Demographic factors influencing the initiation of breastfeeding in an Israeli urban population. Pediatrics 1989;83:519-23.

12. Gielen AC, Faden RR, O'Campo P, Brown CH, Page DM. Maternal employment during the early postpartum period: effects on initiation and continuation of breastfeeding. Pediatrics 1991;87:298-305.

13. Kurinij N, Shiono PH, Ezrine SF, Rhoads GG. Does maternal employment affect breastfeeding? Am J Public Health 1989;79:1247-50.

14. Clements MS, Mitchell EA, Wright SP, Esmail A, Jones DR, Ford RP. Influences on breastfeeding in southeast England. Acta Paediatr 1997;86:51-6.

15. Nolan L, Goel V. Sociodemographic factors related to breastfeeding in Ontario: results from the Ontario Health Survey. Can J Pub Health 1995;86:309-12. 
16. Noble S, Team. TAS. Maternal employment and the initiation of breastfeeding. Acta Pediatr 2001;90:423-8.

17. Visness CM, Kennedy KI. Maternal Employment and Breast-feeding: Findings from the 1988 National Maternal and Infant Health Survey. Am J Public Health 1997;87:945-50.

18. Fein SB, Roe B. The effect of work status on initiation and duration of breast-feeding. Am J Public Health 1998;88:1042-6.

19. Martinez GA, Dodd DA, Samartgedes JA. Milk feeding patterns in the United States during the first 12 months of life. Pediatrics 1981;68:863-8.

20. Martinez GA, Krieger FW. 1984 Milk-feeding patterns in the United States. Pediatrics 1985;76:1004-8.

21. Duberstein- Lindberg L. Women's decisions about breastfeeding and maternal employment. Journal of Marriage and the Family 1996;58:239-251.

22. Taveras EM, Capra AM, Braveman PA, G. JN, Escobar GJ, Lieu TA. Clinical Support and Psychosocial Risk factors Associated with Breastfeeding Discontinuation. Pediatrics 2003;112:108-15.

23. Ryan AS, Wysong JL, Martinez GA, Simon SD. Duration of Breast-feeding Patterns established in the Hospital. Influencing factors. Results from a National Survey. Clin Pediatr Phila 1990;29:99-107.

24. Roe B, Whittington LA, Beck Fein S, Teisl MF. Is there competition between breastfeeding and maternal employment? Demography 1999;36:157-171.

25. Stahlberg M. Breastfeeding and social factors. Acta Paediatr Scand 1985;74:36-9.

26. Whaley S, Meehan K, Lange L, Slusser W, Jenks E. Predictors of Breastfeeding Duration for Employees of the Supplemental Nutrition program for Women, Infants and Children (WIC). J Am Diet Assoc 2002;102:1290-3.

27. Cohen R, Mrtek MB. The impact of two corporate lactation programs on the incidence and duration of breast-feeding by employed mothers. Am-J-Health-Promot 1994;8:43641.

28. Dodgson JE, Tarrant M, Fong DY, Peng XH, Hui WH. Breastfeeding patterns of primiparous mothers in Hong Kong. Birth 2003;30:195-202.

29. Kloeblen Tarver AS, Thompson NJ, Miner KR. Intent to breast-feed: the impact of attitudes, norms, parity, and experience. Am J Health Behav 2002;26:182-7.

30. Humphreys AS, Thompson NJ, Miner KR. Assessment of breastfeeding intention using the Transtheoretical Model and the Theory of Reasoned Action. Health Educ Res 1998; 13:331-341.

31. De Vries H, Mudde A. Predicting stage transitions for smoking cessation applying The Attitude-Social Influence- Efficacy model. Psych Health 1998;13:369-85.

32. De Vries H. Socio-economic differences in smoking: Dutch adolescents' beliefs and behavior. Soc Sci Med 1995;41:419-24.

33. Bulk-Bunschoten AMW, Pasker-de Jong P, Van Bodegom S, Reerink J, De Groot C. Borst- en flesvoeding in de eerste 4 levensmaanden van 4438 zuigelingen. Ned Tijdschr Geneesk. 2002;146:2028-32.

34. Burgmeijer RJF, Reijneveld SA. Reasons of early weaning. Leiden: Netherl Org Applied Scientific Research; 2001 March. Report No.: PG/JGD/2001.51.

35. Meertens RM. Desirability and credibility. The influence of the social context on causal explanations for success and failure. Nijmegen: Datawyse Maastricht/Krips Repro Meppel; 1990.

36. McCarter ea. Parenting Self-efficacy and perception of insufficient breast milk. J Obstet Gynecol Neonatal Nurs 2001;30:515-522.

37. De Onis M, Onyange A. The Centers for Disease Control and Prevention 2000 growth charts and the growth of breastfed infants. Acta Paediatr. 2003;92:413-9. 
38. Agostoni C, Grandi F, Gianni ML, Silano M, Torcoletti M, Giovannini M, et al. Growth patterns of breast fed and formula fed infants in the first 12 months of life: an Italian study. Arch Dis Child 1999;81:395-9.

39. Cole T, Paul A, Whitehead R. Weight reference charts for British long-term breastfed infants. Acta Paediatr 2002;91:1296-300.

40. Aarts C, Hofvander Y, Gebre Medhin M. Growth under priviliged conditions of healthy Swedish infants exclusively breastfed from birth to 4-6 monts: a longitudinal prospective study based on daily records of feeding. Acta Paediatr 2003;92:145-51.

41. Kramer MS, Guo T, Platt R, Sevkovskaya Z, Dzikovich I, Collet JP, et al. Infant growth and health outcomes associated with 3 compared with 6 mo of exclusive breastfeeding. Am-J-of-Clin-Nutr 2003;78:291-5.

42. Zegers M. Wat is de relatie tussen het stoppen met borstvoeding en de groei van het kind? Scriptie. Maastricht: Universiteit Maastricht; 2002 december. Report No.: 1962407.

43. Burgmeijer RJF. Groei van borstgevoede kinderen. In: Centrum TNO Preventie en Gezondheid/ Leids Universitair Medisch Centrum, editor. De vierde Landelijke Groeistudie. Presentatie nieuwe groeidiagrammen; 1998:37-53.

44. Pieterse ME, Seydel ER, De Vries H, Mudde AN, Kok GJ. Effectiveness of a minimal contact smoking cessation program for Dutch general practitioners: a randomized controlled trial. Prev Med 2001;32:182-90.

45. Bakker MJ, Mullen PD, De Vries H, Van Breukelen G. Feasibility of implementation of a Dutch smoking cessation and relapse prevention protocol for pregnant women. Patient Educ Couns 2003;49:35-43.

46. Bolman C, De Vries H, Van Breukelen G. A Minimal-Contact Intervention for Cardiac Inpatients: Long-Term effects on Smoking Cessation. Prev Med 2002;35:181-92.

47. Sikorski J, Renfrew MJ, Pindora S, Wade A. Support for Breastfeeding Mothers (Cochrane Review). In: The Cochrane Library: Oxford: update Software; 2003:1-38.

48. Froozani MD, Permehzadeh K, Motlagh AR, Golestan B. Effect of breastfeeding education on the feeding pattern and health of infants in their first 4 months in the Islamic Republic of Iran. Bull World Health Organ 1999;77:381-5.

49. Kramer MS, Chalmers B, Hodnett ED, Sevkovskaya Z, Dzikovich I, Shapiro S, et al. Promotion of Breastfeeding Intervention Trial (PROBIT) A Randomized Trial in the Republic of Belarus. JAMA 2001;285:1-14.

50. Haider R, Ashworth A, Kabir I, Huttly SRA. Effect of community-based peer counselors on exclusive breastfeeding practices in Dhaka, Bangladesh: a randomized controlled trial. Lancet 2000;356:1643-1647.

51. Morrow AL, Guerrero ML, Shults J, Calva JJ, Lutter C, Bravo J, et al. Efficacy of homebased peer counseling to promote exclusive breastfeeding: a randomized controlled trial. Lancet 1999;353:1226-31.

52. Sjolin S, Hofvander Y, Hillervik C. A prospective study on individual courses of breastfeeding. Acta Paediatr Scand 1979;68:521-9.

53. Jones DA, West RR. Lactation nurse increases duration of breast feeding. Arch Dis Child 1985;60:772-4.

54. Moore WJ, Midwinter RE, Morris AF, Colley JR, Soothill JF. Infant feeding and subsequent risk of atopic eczema. Arch Dis Child 1985;60:722-6.

55. Lynch SA, Koch AM, Hislop TG, Coldman AJ. Evaluating the effect of a breastfeeding consultant on the duration of breastfeeding. Can J Public Health 1986;77:190-5.

56. Frank DA, Wirtz SJ, Sorenson JR, Heeren T. Commercial discharge packs and breastfeeding counseling: effects on infant-feeding practices in a randomized trial. Pediatrics 1987;80:845-54.

57. Grossman LK, Harter C, Sachs L, Kay A. The effect of postpartum lactation counseling on the duration of breastfeeding in low-income women. Am J Dis Child 1990;144:471-4. 
58. Barros FC, Halpern R, Victora CG, Teixeira AM, Beria JU. Promocao da amamentacao em localidade urbana da regiao sul do Brasil: estudo de intervencao randomizado. Rev Saude Publica 1994;28:277-83.

59. Jenner S. The influence of additional information, advice, and support on the success of breastfeeding in working class primiparas. Child Care Health Dev 1988;14:319-28.

60. Mongeon M, Allard R. Essai controle d'un soutien telephonique regulier donne par une benevole sur le deroulement et l'issue de l'allaitement. Can J Public Health 1995;86:124-7.

61. Dennis CL. A randomized controlled trial evaluating the effect of peer (mother- tomother) support on breastfeeding duration among primiparous women. Ontario: University of Toronto; 1999.

62. Leite AJM, Puccini R, Attallah A, Cunha A, Machado M, Capiberibe A, et al. Impact of breastfeeding practices promoted by lay counselors: a randomized and controlled clinical trial. Clinical Epidemiology 1998;51(Suppl: 105).

63. McKeever P, Stevens B, Miller K, MacDonell J, Gibbins S, Guerriere D, et al. Home versus hospital breastfeeding support for newborns: a randomized controlled trial. Birth 2002;29:258 -65.

64. Lanting CI, Herschderfer K, Van Wouwe JP, Reijneveld SA. Effect van invoering van het "Baby Friendly Hospital Initiative" op het geven van borstvoeding in Nederland. Leiden: TNO Preventie en Gezondheid; 2003 Augustus. Report No.: PG/Jeugd 2003.212.

65. De Vries H, Mudde A, Kremers S, J W, Uiters E, Ariza C, et al. The European Smoking Prevention Framework Approach (ESFA): short-term effects. Health Educ Res 2003;18:649-63.

66. McCaul K, Glasgow R. Preventing adolescent smoking: what have we learned about treament construct validity. Health Psychol 1985;4(4):361-87.

67. Campbell M, Fitzpatrick R, Haines A, Kinmonth AL, Sandercock P, Spiegelhalter D, et al. Framework for design and evaluation of complex interventions to improve health. BMJ 2000;321:694-696.

68. Sears MR, Greene JM, Willan AR, Taylor DR, Flannery EM, Cowan JO, et al. Long-term relation between breastfeeding and development of atopy and asthma in children and young adults: a longitudinal study. Lancet 2002;360:901-7.

69. Rogers EM. Diffusion of Innovations. New York: The Free Press; 1995.

70. Overberg R, Van Drongelen K, Herschderfer K. Volksgezondheid Toekomst Verkenning. In: Nationaal Kompas Volksgezondheid. Bilthoven: RIVM, $\mathrm{http} / /$ www.nationaalkompas.nl $>$ Preventie gericht op determinanten $>$ Preventie gericht op leefstijl>Bevorderen van Borstvoeding; 2003.

71. Mackenbach JP. Sociale geneeskunde en "Public Health": historische kanttekening bij de Nederlandse situatie. Tijdschrift voor Gezondheidsweten-schappen 2003;8:450-458.

72. Wijga A, Smit HA, Brunekreef B, Gerritsen J, Kerkhof M, Koopman LP, et al. Are children at high familial risk of developing allergy born into a low risk environment? The PIAMA Birth Cohort Study. Prevention and Incidence of Asthma and Mite Allergy. Clin Exp Allergy 2001;31:576-81.

73. Friel JK, Hudson NI, Banoub S, Ross A. The effect of a promotion campaign on attitudes of adolescent females towards breastfeeding. Can J Public Health 1989;80:195-9.

74. Coles E, Cotter S, Valman H. Increasing prevalence of breastfeeding. BMJ 1978;2:1122.

75. Cox H, Williams J, De Courten M, Chitson P, Tuomilehto J, Zimmet P. Decreasing prevalence of cigarette smoking in the middle income country of Maritius: questionnaire survey. BMJ 2000;321:345-349.

76. Gruber J, Sen A, Stabile M. Estimating price elasticities when there is smuggling: the sensitivity of smoking to price in Canada. J Health Econ 2003;22:821-42. 


\section{SUMMARY}

Breastfeeding for six months has health benefits for mother and child. In Europe, rates of breastfeeding vary, but are in general low. In the Netherlands, $80 \%$ of mothers start to breastfeed their newborn, but only a small percentage continues to do so longer than a few months. Therefore, a project "Promotion and Support of Breastfeeding" was developed. The project consisted of three parts: the application of a health promotion planning model to breastfeeding (including the development of an intervention program); two studies of behavioral determinants of breastfeeding; and a randomized trial of the effectiveness of the intervention program.

Chapter 1 (Introduction) describes the main objective of the project: to enhance the breastfeeding rate at three months. The rationale for the choice for three months took into account the health benefits of prolonged breastfeeding and the high rate of cessation in the first months, so that the greatest benefits for the population would be gained by increasing breastfeeding rates in the first months.

Chapter 2 (The $\mathrm{ABC}$ of Breastfeeding) describes a planning model for health promotion applied to breastfeeding in the Netherlands. The model is an integration of various health promotion planning and theoretical models for changing health behavior. It distinguishes three basic phases in the process of health education and promotion: Analysis (A); Behavioral Change (B); and Continuation (C).

In the Analysis phase (A), we analyzed the problem of low breastfeeding rates. National and international studies have shown that determinants of breastfeeding intention are a positive social norm, attitude, and low social support to formula feeding. Positive previous breastfeeding experience predicts breastfeeding intention. The most important predictors of the duration of breastfeeding are the intention to continue, self-efficacy, and social norm at work. We concluded that studies of determinants at the level of the mothers and barriers at the level of caregivers based on the ASE (Attitude, Social influence, self Efficacy) model were important, and that development and implementation of interventions based on this model are needed. Dutch studies suggest that mothers need more information and support for the realization of their choice. We noted a lack of cooperation and continuity of care and insufficient uniformity in advices between the professionals of different organizations. Lactation consultancy is possibly underused. Hence, we formulated the operational goals for our project as follows: to strengthen the promotion and support of breastfeeding by:

(1) Health counseling: to enhance the caregiver's performance to promote and support breastfeeding, using health-counseling principles.

(2) Cooperation and continuity: to enhance cooperation, early signaling of breastfeeding problems and continuity of care by transfer of information on individual mothers between caregivers.

(3) Lactation consultancy: to enhance access to lactation consultants and to take away financial and practical barriers for consulting them.

In the phase of the behavioral change (B), an intervention program was developed. The Health Counseling model was chosen since this model has already been successfully applied to other health promoting behavior, such as smoking prevention. The participation of the midwives in our study could not be guaranteed, since their workload 
had increased in recent years. Therefore, caregivers in the maternity and child health care and lactation consultants were chosen as the most appropriate intermediaries. We developed a training program for caregivers, with a step-by-step approach-based on health counseling principles. We designed supporting materials such as a mother's booklet to support breastfeeding, to enhance cooperation between caregivers of the maternity and child health care, for early signaling of breastfeeding problems and for transfer of information between caregivers. For the caregivers we developed a manual for health counseling and a one-page summary for each group of caregivers: for the maternity nurse and for the child health care nurse and physician. A randomized trial was chosen as the most appropriate design for the evaluation of the effectiveness of the intervention program.

In the Continuation phase $(\mathrm{C})$, we anticipated on the implementation of the program if its effectiveness were to be demonstrated in the trial.

Chapters 3 and 4 (The behavioral determinants of breastfeeding in the Netherlands) describes the factors predicting the start of breastfeeding at birth (initiation) and the factors predicting the duration of breastfeeding until at least three months postpartum (continuation). This was studied by repeated questionnaires obtained from the participants in the control group of the randomized trial. We found that intention was a very strong predictor of the initiation of breastfeeding. Previous breastfeeding experience was a predictor of breastfeeding initiation as well of continuation: compared to mothers with a first child, mothers who had previously breastfed a child had a higher chance of starting breastfeeding this time and to continue longer; while mothers who did not breastfeed previous children had a lower chance of starting breastfeeding this time and, if they start they did not continue so long. Independent ASE determinants of breastfeeding initiation were attitudes and social norm towards breastfeeding. Determinants of continuation were low social support for formula feeding and high selfefficacy for breastfeeding. Non-smoking mothers started breastfeeding more often and continued longer than smoking mothers. Finally, we found to our surprise that breastfeeding mothers who intended to return to work continued breastfeeding longer than breastfeeding mothers who did not intend to return to work. We also asked about reasons to start and to stop breastfeeding. The main reasons to start breastfeeding were "breastfeeding is the most natural feeding", "the health of mother and infant" and "contact between mother and infant." The main reasons to stop breastfeeding were: "the quantity of breastfeeding decreased", "the breastfeeding was painful", and "the baby was crying too much." Although reasons to stop are always given on hindsight, they may give further insight into the meaning of the predicting factors. For instance, when mothers report that they stop breastfeeding because they have insufficient milk, it may be related to low self-efficacy to resolve problems such as the perceived insufficient milk syndrome. When breastfeeding mothers were asked who the most influential persons were for the decision to stop breastfeeding, most reported that it was their own initiative, followed by partner, family and friends.

Chapter 5 (A Breastfeeding Promotion and Support Program in the Netherlands, The Randomized Trial) examines the effectiveness of the intervention program to increase the continuation of breastfeeding until at least three months. This was evaluated in a randomized trial. Ten child health care centers of three Home Health Care organizations 
participated. The centers were randomly allocated to five intervention and, five geographically different control centers. Elements in the program were health counseling; measures to enhance the cooperation between caregivers and continuity of care; early signaling of breastfeeding problems and free lactation consultancy. In the intervention centers, the Maastricht University appointed three lactation consultants and their services were made free of charge. All caregivers of the child health care centers in the intervention group followed the health counseling training and a refresher course. Caregivers in the control centers were not allowed to take notice of the course materials or the supporting materials. The intervention started at the first prepartum home visit. The maternity care nurse began with health counseling and handed out the mother's booklet and discussed its use. The health counseling continued at the next home visit (in the second week postpartum) by the child health care nurse, and at each consultation of the child health care (monthly) by the child health care physician or nurse. If breastfeeding problems were notified, the mother was referred to the lactation consultant. Study candidates were pregnant women who applied for maternity care in the intervention and control centers of the three Home Health Care organizations, from December 2000-December 2002. Of the 1078 candidates, $72 \%$ pregnant women in the intervention centers and $72 \%$ in the control centers agreed to participate. They were followed up from pregnancy until six months postpartum by repeated written questionnaires. The primary outcome measure was the continuation of breastfeeding until three months. The results showed that the program was not effective: there was no difference in the rates of initiation and continuation for three months of breastfeeding between the intervention and control groups (multilevel analysis accounting for the random effects of child care centers). There was also no effect on continuation after three months (survival analysis until 6 months). The program itself was evaluated at two levels: at the level of the caregivers and at the level of the participants. All the caregivers in the intervention centers had followed the training. Nearly all the caregivers found the program clear and understandable, and were stimulated by the program to give attention to breastfeeding. Most caregivers in the intervention centers reported that they obtained good or sufficient behavioral skills to carry out the program, and that they paid attention to the behavioral determinants during the contacts with the mothers. Forty-four percent reported that the program took more time than usual. The caregivers gave the program a report mark of 7.3, on a scale of $1-10$ (1=very low to $10=$ excellent). Sixteen percent of the mothers from the intervention group were referred to the lactation consultants. Most common reasons for referral were doubt about drinking of the infant, crying infant, and pain during feeding. Opinions of mothers about the feeding advices, given by the caregivers, were not more positive in the intervention group than in the control groups. We found no major biases in the design or execution of the trial that could explain the lack of effectiveness. We conclude that the program in its present form is not achieving its goal to increase breastfeeding rate at three months. Possible points for improvement are involvement of maternity assistants and midwives, and increasing the number and duration of contacts in the first weeks after childbirth.

Chapter 6 (General discussion) discusses the main findings and the strengths and weaknesses of the studies in this thesis. Although the program was sufficiently adapted to the behavioral determinants, we found low levels of self-efficacy for breastfeeding in the study population; this indicates that increasing self-efficacy may be an important 
educational objective for program development. Our finding that mothers with the intention to return to work had longer breastfeeding duration was unexpected. We hypothesize that this is due to a selection effect. Such a selection effect may explain the inconsistent results of earlier studies on work and breastfeeding. To account for selection effects we concluded that studies on work and breastfeeding should be longitudinal. Such studies may underpin targeted interventions for supporting breastfeeding in combination with work. The knowledge about important motivational determinants forms the basis for interventions. We believe that more attention could be devoted in future studies to differences of ASE determinants in different phases of breastfeeding; the role of self-efficacy in perceived insufficient milk or insufficient growth, and the role of different growth patterns between breast and formula fed infants. With regard to the breastfeeding promotion and support program, we identified the following potential weaknesses: limitations due to the experimental approach; limitations in the ability to evaluate each separate goal; and limitations of the Home Health Care setting. An explanation for the absence of the effect of the intervention on the continuation might be that the choice of a randomized trial to evaluate the program implied that we could not employ midwives, maternity assistants, and pediatricians in our program, since they worked in regions where there were both intervention and control centers. Hence, we may not fully have reached our goals of enhancing cooperation, early signaling of breastfeeding problems and continuity of care. We had limited possibilities to evaluate each operational goal separately in the program evaluation, so that it is difficult to tell whether the goals were realistic or whether the program failed to reach all of them. Most caregivers succeeded in carrying out the program in the time available. Nevertheless, the program could have been more successful if the caregivers had more time for health counseling. The Health Counseling model has been effective for smoking cessation, but breastfeeding and smoking cessation differ in many respects so that one may question whether health-counseling principles can be rightly converted from one type of behavior to another. We reviewed published intervention trials to study which interventions were effective and whether we did under-use elements that had been shown to be effective. The results suggest that interventions with a combination of professional or lay support with a training program were the most effective ones, possibly due to synergism. Two of the three most effective interventions included the combination of lay support with training programs. Two trials of lactation consultancy showed promising but not decisive results. None of the interventions were based on health counseling-grounded-on theories of behavioral change. Our conclusion is that interventions were effective in many trials, but also ineffective in many others; and when comparing them it is hard to tell which mix or intensity of interventions was successful.

Recommendations for further research are the following: first, the determinants of breastfeeding should be studied for each phase of breastfeeding. More attention should be given to different breastfeeding barriers and to wrong interpretations. Second, more insight is needed how employers and employees use the statutory regulations concerning lactation and work. Third, the conditions of effective health counseling need more attention, such as the inclusion of midwives and maternity assistants in the chain of care; increasing the knowledge of breastfeeding at the level of the caregivers and ensuring enough time for health counseling. More program development has to be done, and evaluated in an exploratory trial, before this can be tested in a randomized trial. 
Because some studies have shown that a lactation consultancy is effective in increasing the duration of breastfeeding, it seems worthwhile to evaluate the effectiveness of a lactation consultancy separately. Fourth, the need for a combined intervention for breastfeeding continuation and smoking cessation can be assessed, because smoking mothers started breastfeeding less often and continued for a shorter time than nonsmoking mothers. Fifth, it should be studied how health beliefs are influenced by knowledge, what their relative impact is on attitudes, and how the health message can be translated in an understandable and effective way.

Recommendations for promotion and support of breastfeeding in practice were the following: first, caregivers need to focus their interventions on strengthening selfefficacy in pregnant women and on support of breastfeeding mothers. To change the social norm, caregivers can encourage women to let partners be present at the home visits and at the support group meetings (including lay support groups). Second, the Home Health Care organizations may organize low threshold consultation hours for breastfeeding mothers, pre- and postpartum exercise groups and breastfeeding support groups with trained laypersons.

Recommendations for health care policy are the following: first, the responsibilities of breastfeeding have to be reflected in the job descriptions of maternity assistants, midwives, general practitioners, and pediatricians. Second, for monitoring, an efficient and valid national and European surveillance system for breastfeeding should be built up. National and European coordination centers (appointed by the governments) should collect the breastfeeding data. The data should be comparable at international level and between nations and regions. Third, the subject of breastfeeding should be part of the education of maternity assistants, nurses and physicians. Annual refresher trainings should be stimulated and then their knowledge has to be tested. Therefore, knowledge tests have to be developed with reference data. Fourth, to create positive social norms of breastfeeding, mass media approaches can be adopted as an additional tool, because they have been shown to be effective for breastfeeding promotion. Fifth, in order to take away barriers for breastfeeding outdoors, separate or mobile rooms should be created in public places. Sixth, we may have to look for positive and negative incentives to improve breastfeeding duration, such as tax on infant formula or reduction in health insurance premiums for breastfeeding mothers. 


\section{SAMENVATTING}

Borstvoeding gedurende zes maanden heeft voordelen voor de gezondheid van moeder en kind. In Europa start $80 \%$ van de moeders met de borstvoeding, maar slechts een klein percentage moeders houden de borstvoeding langer dan een paar maanden vol. Daarom hebben wij een project "Bevordering en Ondersteuning van Borstvoeding" ontwikkeld. Het project omvatte drie delen: een planningsmodel voor gezondheidsbevordering toegepast op borstvoeding (inclusief de ontwikkeling van een interventieprogramma), twee studies over gedragsdeterminanten van borstvoeding en een gerandomiseerde trial naar de effectiviteit van het interventieprogramma.

Hoofdstuk 1 (Introductie) beschrijft de belangrijkste doelstelling van dit project. Dit was het verhogen van het percentages borstvoeding op de leeftijd van drie maanden. De reden van de keuze voor drie maanden was gebaseerd op de gezondheidsvoordelen van het langer doorgaan met borstvoeding en op het hoge percentage moeders die stoppen in de eerste maanden zodat de grootste voordelen op populatieniveau worden verkregen door de borstvoedingscijfers te laten stijgen in de eerste maanden.

Hoofdstuk 2 (Het $\mathrm{ABC}$ van Borstvoeding) beschrijft een planningsmodel voor gezondheidsbevordering toegepast op borstvoeding. Dit model is een integratie van verschillende planningsmodellen van gezondheidsbevordering en van theoretische modellen van gedragsveranderingen. Het model onderscheidt drie basale fases in het proces van gezondheidseducatie en bevordering: analyse (de A van Analysis); gedragsverandering (de B van Behavior change) en continue preventie door diffusie (de $C$ van Continuing).

In de analyse fase (A) werd het probleem van de lage borstvoedingscijfers geanalyseerd. Nationale en internationale studies hebben aangetoond dat determinanten van de intentie om borstvoeding te geven een positieve sociale norm, een positieve attitude, en lage sociale druk voor kunstvoeding zijn. Daarnaast voorspelt een positieve eerdere ervaring met borstvoeding de intentie om borstvoeding te geven bij het volgende kind. De belangrijkste voorspellers van de duur van borstvoeding zijn de intentie om door te gaan met de borstvoeding, de eigen effectiviteit, en de sociale norm op het werk. Geconcludeerd werd dat studies van determinanten op het niveau van de moeders en barrières op het niveau van zorgverleners gebaseerd op het ASE (Attitude, Social influence, self Efficacacy) model belangrijk waren en dat de ontwikkeling en implementatie van interventies gebaseerd op dit model nodig zijn. Nederlandse studies deden vermoeden dat moeders meer informatie en steun nodig hebben voor om de keuze borst- of flesvoeding te maken. Daarnaast signaleerden wij een gebrek aan samenwerking en continuïteit van zorg en onvoldoende uniformiteit in adviezen tussen de zorgverleners van de verschillende organisaties. Verder leek het dat lactatiekundigen niet vaak worden geconsulteerd. Zodoende formuleerden wij de volgende operationele doelstellingen voor ons project: het versterken van de bevordering en ondersteuning van borstvoeding door middel van:

(1) Health counseling: het verbeteren van de voorlichting door zorgverleners om borstvoeding te bevorderen en ondersteunen met behulp van de principes van health counseling. 
(2) Samenwerking en continuïteit: het verbeteren van de samenwerking, vroegtijdige opsporing van borstvoedingsproblemen en van de continuïteit van zorg door overdracht van informatie van individuele moeders tussen zorgverleners.

(3) Consultatie door lactatiekundige: het vergroten van de toegang tot lactatiekundigen en het wegnemen van financiële en praktische barrières om hen te consulteren.

In de fase van gedragsverandering (B) werd een interventieprogramma ontwikkeld. Om de advisering door zorgverleners te vergemakkelijken werd het Health Counseling model gekozen, aangezien dit model al met succes was toegepast bij andere gedragingen van gezondheidsbevordering, zoals bij de preventie van roken. Verloskundigen konden niet meedoen aan dit onderzoek, omdat hun werkbelasting de laatste jaren was toegenomen. Zodoende werden zorgverleners van de kraamzorg, jeugdgezondheidszorg en lactatiekundigen gekozen als de meest geschikte intermediairen. We ontwikkelden een scholingsprogramma voor de zorgverleners met een stapsgewijze benadering gebaseerd op health counseling. We makten ondersteunende materialen zoals een boekje voor moeders om hen steun te geven bij de borstvoeding, om borstvoedingsproblemen vroegtijdig te signaleren, om de samenwerking tussen zorgverleners van kraamzorg en consultatiebureaus te verhogen, en om de overdracht van informatie tussen zorgverleners te bevorderen. Voor de zorgverleners werd een handboek voor health counseling samengesteld en een samenvatting op een pagina voor iedere groep: voor de kraamzorgverpleegkundige en voor de arts en verpleegkundige van het consultatiebureau. We gebruikten een gerandomiseerde trial omdat dit het meest geschikte model is om effectiviteit van een interventie te evalueren.

In de fase van continue preventie (C) anticipeerden we op de implementatie van het programma in geval het programma effectief zou zijn.

Hoofdstukken 3 en 4 (De gedragsdeterminanten van borstvoeding in Nederland) beschrijven de factoren die voorspellen het starten met borstvoeding bij de geboorte, en de duur van borstvoeding tot tenminste drie maanden. Dit werd onderzocht met de herhaalde vragenlijsten van de deelnemers van de controlegroep van de gerandomiseerde trial. We vonden dat intentie een zeer sterke voorspeller van het starten met borstvoeding was. Een eerdere ervaring met borstvoeding was een voorspeller zowel voor het starten met borstvoeding als voor de duur van borstvoeding: vergeleken met moeders met een eerste kind hadden moeder die eerder een kind borstvoeding hadden gegeven een hogere kans met borstvoeding te starten en er langer mee door te gaan. Moeders die niet een vorig kind borstvoeding hadden gegeven hadden een veel lagere kans en als zij starten gingen zij er niet zo lang mee door. Onafhankelijk ASE determinanten van het starten met borstvoeding waren de voor- en nadelen van borstvoeding en de sociale norm ten opzichte van borstvoeding. Determinanten van het doorgaan met de borstvoeding waren lage sociale norm voor kunstvoeding en hoge eigen effectiviteit van borstvoeding. Niet rokende moeders startten vaker met borstvoeding en gingen er langer mee door dan rokende moeders. Verder vonden wij tot onze verrassing dat borstvoedende moeders met de intentie om weer te gaan werken langer borstvoeding gaven dan moeders die deze intentie niet hadden. De belangrijkste redenen om met borstvoeding te beginnen waren: "borstvoeding is de meest natuurlijke voeding", "de gezondheid van moeder en kind", en "het contact tussen moeder en kind." 
De belangrijkste redenen om te stoppen met de borstvoeding waren: "de hoeveelheid borstvoeding nam af", "de borstvoeding was pijnlijk", "de baby huilde teveel." Hoewel redenen om te stoppen altijd achteraf gegeven worden, kunnen zij verder inzicht geven in de betekenis van de voorspellende factoren. Bijvoorbeeld als moeders aangeven dat zij stoppen met borstvoeding omdat zij onvoldoende melk hebben, kan dit gerelateerd zijn aan een lage eigen effectiviteit om problemen op te lossen zoals het "onvoldoende melk syndroom." Voor borstvoedende moeders waren de meest invloedrijke personen om met borstvoeding te stoppen: eigen initiatief; gevolgd door partner, familie en vrienden.

Hoofdstuk 5 (Een programma Bevordering en Ondersteuning van Borstvoeding in Nederland: een gerandomiseerde trial) onderzoekt de effectiviteit van het interventieprogramma om de duur van borstvoeding te verhogen tot minstens drie maanden. Dit programma werd geëvalueerd in een gerandomiseerde trial. Tien consultatiebureaus van drie Thuiszorgorganisaties in Limburg namen hieraan deel. De consultatiebureaus werden at random toegewezen aan vijf onderzoeksgroepen en aan vijf geografisch gescheiden controle groepen. Elementen in het programma waren health counseling en maatregelen om de samenwerking tussen zorgverleners te bevorderen, om borstvoedingsproblemen vroegtijdig te signaleren en om de continuïteit van zorg te verbeteren. Ten behoeve van de onderzoeksconsultatiebureaus werden drie lactatiekundigen aangesteld door de Universiteit Maastricht, waardoor hun consulten gratis werden. Alle zorgverleners van kraamzorg en van de consultatiebureaus in de onderzoeksgroep volgden een scholing in health counseling en fresh-up scholingen. Zorgverleners in de controle groep hadden geen inzage in lesmaterialen of ondersteunende materialen. De interventie startte bij het eerste huisbezoek in de zevende zwangerschapsmaand. De kraamzorgverpleegkundige begon dan met health counseling, reikte het moederboekje uit en besprak het gebruik. Bij het volgende huisbezoek (in de tweede week na de bevalling) ging de verpleegkundige jeugdgezondheidszorg hiermee door, en daarna werd de health counseling voortgezet bij elk maandelijks consultatiebureaubezoek door de arts en/of verpleegkundige. Wanneer borstvoedingsproblemen werden gesignaleerd werd de moeder doorverwezen naar de lactatiekundige. De onderzoekspopulatie bestond uit zwangere vrouwen die zich aanmelden voor de kraamzorg bij de interventie en controle locaties van de drie Thuiszorgorganisaties van december 2000-december 2002. Van de 1078 kandidaten gaven $72 \%$ in de interventie groep en $72 \%$ in de controle groep toestemming voor deelname aan het onderzoek. Zij werden gevolgd vanaf de zwangerschap tot zes maanden na de bevalling door middel van vier vragenlijsten. De primaire uitkomst maat was de duur van borstvoeding tot drie maanden. De resultaten toonden aan dat het programma niet effectief was: er was geen verschil in de percentages van het starten en van de duur van borstvoeding tussen de interventie groep en de controle groep (multilevel analyse rekening houden met het feit dat de consultatiebureaus aselect getrokken zijn). Er was ook geen effect op de duur van borstvoeding na drie maanden (overlevingsanalyse tot zes maanden). Het programma zelf werd geëvalueerd op twee niveaus: op het niveau van de zorgverleners en op het niveau van de deelnemers. Alle zorgverleners van de interventie groep volgden de scholing. Bijna alle zorgverleners vonden het programma duidelijk en begrijpelijk en werden gestimuleerd door het programma om aandacht te geven aan borstvoeding. De meeste zorgverleners in de 
interventie groep vermeldden dat zij voldoende bekwaam waren op het gebied van gedrag om het programma uit te voeren en dat zij aandacht besteedden aan de gedragsdeterminanten tijdens de contacten met de moeders. Vier en veertig procent van de zorgverleners vermeldden dat het programma meer tijd kostte dan gebruikelijk. Zij gaven het programma een rapportcijfer van 7.3, op een schaal van 1 tot $10(1=$ erg laag tot $10=$ uitstekend). Zestien procent van de moeders werden verwezen naar de lactatiekundigen. De meest voorkomende redenen waren twijfels over het drinken van de baby, huilend kind en pijn tijdens het voeden. De moeders in de interventie groep waren niet meer positief over de voedingsadviezen van de zorgverleners dan de moeders in de controlegroep. We vonden geen grote bias in het design of in de uitvoering van de trial die het gebrek aan effectiviteit konden verklaren. We concluderen, dat het programma in zijn huidige vorm niet het doel bereikte om het percentage borstvoeding op drie maanden te verhogen. Mogelijke punten ter verbetering zijn het betrekken van kraamverzorgenden en verloskundigen bij het programma en het verhogen van de contacten in de eerste weken na de bevalling.

Hoofdstuk 6 (Algemene discussie) bediscussiëert de belangrijkste bevindingen en de sterke en zwakke kanten van de studies in dit proefschrift. Hoewel het programma voldoende toegespitst was op de determinanten van gedrag vonden wij in de studie populatie lage niveaus van eigen effectiviteit voor borstvoeding. Toename van de eigen effectiviteit kan een belangrijk opvoedkundig doel voor programma ontwikkeling zijn. Verrassend was onze bevinding dat moeders met de intentie om weer te gaan werken langer doorgingen met borstvoeding. Wij veronderstellen dat dit te wijten is aan een selectie effect. Een dergelijk selectie effect kan de inconsistente resultaten van eerdere studies over borstvoeding en werk verklaren. Rekening houdend met selectie effecten concluderen wij dat studies over borstvoeding en werk longitudinaal moeten zijn. Dergelijke studies kunnen doelgerichte interventies voor de ondersteuning van borstvoeding in combinatie met werk onderbouwen. De kennis over belangrijke motiverende determinanten vormen de basis van interventies. In toekomstige studies moet meer aandacht gegeven worden aan verschillen in ASE determinanten in verschillende fases van borstvoeding; de rol van eigen effectiviteit bij onvoldoende melk of onvoldoende groeien en de rol van verschillende groeipatronen bij zuigelingen met borst en kunstvoeding. Met betrekking tot het programma onderkennen wij de volgende mogelijke zwaktes: beperkingen ten gevolgen van de experimentele benadering; beperkingen om ieder apart doel te kunnen evalueren en de beperkingen van de Thuiszorg setting. Een verklaring voor de afwezigheid van het effect van de interventie op de duur kan zijn dat de keuze van een gerandomiseerde trial om het programma te evalueren inhield dat we geen verloskundigen, kraamverzorgenden en kinderartsen konden betrekken bij ons programma, daar zij werkten zowel in de interventie als in de controle groep. Zodoende konden wij onze doelen verbetering van samenwerking, vroegtijdige signalering van borstvoedingsproblemen en continuïteit van zorg niet volledig bereiken. In de programma evaluatie hadden we beperkte mogelijkheden om ieder operationeel doel apart te evalueren, zodat het moeilijk is te zeggen welke doelen realistisch waren en of het programma er in faalde om iedereen te bereiken. De meeste zorgverleners slaagden er in om het programma uit te voeren in de beschikbare tijd. Maar het programma zou kunnen succesvoller zijn als de zorgverleners meer tijd hadden voor health counseling. Het Health Counseling model is effectief 
geweest bij stoppen met roken, maar borstvoeding en stoppen met roken verschillen in menig opzicht zodat het de vraag is of health counseling principes wel van het ene type gedrag naar het andere omgezet kunnen worden. We beoordeelden gepubliceerde interventie trials om te bestuderen welke interventies effectief waren en of er elementen effectief bleken te zijn die wij onvoldoende gebruikt hebben. De resultaten doen vermoeden dat interventies van professionele ondersteuning of van ondersteuning met leken in combinatie met een scholingsprogramma het meest effectief waren, waarschijnlijk dank zij synergisme. Twee van de meest effectieve interventies bevatten een combinatie van ondersteuning door leken met scholingsprogramma's. Twee trials met lactatiekundige advisering toonden veel belovende maar geen doorslaggevende resultaten. Geen enkele interventie was gebaseerd op health counseling en op theorieën van gedragsverandering. Onze conclusie is dat interventies in veel trials effectief waren, maar ook in vele andere trials dit niet waren; en als we deze vergelijken is het moeilijk te zeggen welke mix of intensiteit van interventies succesvol was.

Aanbevelingen voor verder onderzoek waren de volgende: ten eerste de determinanten van borstvoeding moeten in iedere fase van borstvoeding (tijdens de zwangerschap, maar ook na de geboorte, etc.) bestudeerd worden. Meer aandacht moet gegeven worden aan verschillende barrières ten aanzien van borstvoeding en aan verkeerde interpretaties. Ten tweede, er is meer inzicht nodig in hoe werkgevers en werknemers de wettelijke regels over borstvoeding en werk gebruiken. Ten derde er is meer aandacht nodig voor de voorwaarden voor effectieve health counseling, zoals de opname van verloskundigen en kraamverzorgenden in de ketenzorg; meer kennis over borstvoeding op het niveau van de zorgverleners en zekerheid over voldoende tijd voor health counseling. Er moet meer aan programma ontwikkeling worden gedaan en dit moet geëvalueerd worden in een verkennende onderzoek, voordat dit kan worden getest in een gerandomiseerde trial. Omdat sommige studies hebben aangetoond dat lactatiekundige advisering effectief is wat betreft een langere duur van borstvoeding, lijkt het waardevol om de effectiviteit van lacatiekundige advisering apart te onderzoeken. Ten vierde, de behoefte aan een gecombineerde interventie om langer met borstvoeding door te gaan en om te stoppen met roken dient te worden onderzocht, omdat rokende moeders minder vaak starten met borstvoeding en minder lang er mee doorgaan dan niet rokende moeders. Ten vijfde, onderzocht moet worden hoe irrationele gezondheidsovertuigingen worden beïnvloed door kennis, wat hun relatieve impact is op gedrag en hoe de gezondheidsboodschap kan vertaald worden op een begrijpelijke en effectieve manier.

Aanbevelingen voor bevordering en ondersteuning van borstvoeding in de praktijk zijn de volgende: ten eerste, zorgverleners moeten hun interventies richten op het verhogen van de eigen effectiviteit van zwangeren en op ondersteuning van borstvoedende moeders. Om de sociale norm te veranderen kunnen zorgverleners moeders aanmoedigen om hun partners aanwezig te laten zijn bij huisbezoeken en bij de voorlichtingsbijeenkomsten. Ten tweede, Thuiszorgorganisaties moeten, pre- and postpartum zwangerschapsgymnastiek en -begeleiding, laagdrempelige weeguurtjes voor borstvoedende moeders en groepsvoorlichting met getrainde leken organiseren.

Aanbevelingen voor beleid in de gezondheidszorg zijn de volgende: ten eerste, de verantwoordelijkheden ten aanzien van borstvoeding moeten opgenomen worden in taakomschrijving van kraamverzorgenden, verloskundigen, huisartsen en kinderartsen. Ten tweede, ten behoeve van monitoring moet een efficiënt en betrouwbaar nationaal en 
Europees systeem van toezicht ingesteld worden. Nationale en Europese coördinatie centrums (aangesteld door de regering) moeten borstvoedinggegevens verzamelen. De gegevens moeten vergelijkbaar zijn op internationaal niveau, nationaal en regionaal niveau. Ten derde, het onderwerp borstvoeding moet een onderdeel zijn van de opleiding van kraamverzorgenden, verpleegkundigen en artsen. Jaarlijkse opfrisscholingen moeten worden gestimuleerd en hun kennis moet getoetst worden. Daarvoor moeten toetsten ontwikkeld worden met referentie gegevens om deze te beoordelen. Ten vierde, om een positieve sociale norm ten opzichte van borstvoeding te creëren kunnen massa media gebruikt worden als een toegevoegd hulpmiddel, omdat deze effectief zijn gebleken voor de bevordering van borstvoeding. Ten vijfde, om de barrières weg te nemen om buitenshuis borstvoeding te geven moeten er aparte of mobiele kamers gecreëerd worden op openbare plaatsen. Ten zesde, gekeken kan worden naar positieve en negatieve stimulansen om de duur van borstvoeding te bevorderen, zoals belasting op kunstvoeding of een lagere van de verzekeringspremie voor borstvoedende moeders. 


\section{DANKWOORD}

Komende uit een artsenfamilie lag het voor de hand dat ik geneeskunde ging studeren. $\mathrm{Na}$ mijn artsexamen wilde ik graag net als mijn vader huisarts worden. In die tijd waren de mogelijkheden voor een vrouw zonder een huisarts als echtgenoot beperkt. Daarbij ging de specialisatie van Bert voor en was voor mij de plaats weggelegd om als stabielere factor in een wervelend gezin te fungeren. Zo werd ik schoolarts, als compromis tussen carrière en kinderwens. Na korte tijd werd ik districtsarts, later medisch manager en de laatste twee jaren stafarts. Toen onze drie kinderen het nest waren uitgevlogen, brak er voor mij een heel andere fase aan. Na een jarenlang gevoel van gemiste kansen kon ik nu voluit gaan en mijn aandacht gaan wijden aan verdieping van mijn interesse.

Bij de Thuiszorg was bevordering van borstvoeding een van mijn aandachtsvelden. Om de ketenzorg rond borstvoeding te realiseren werd in 1998 een transmuraal samenwerkingsverband "Borstvoeding Onze Zorg" opgericht. Deelnemende organisaties waren de Vroedvrouwenschool, de ziekenhuizen Heerlen, Kerkrade en Brunssum (nu Atrium Medisch Centrum), verloskundigen en Kraamzorg en Jeugdgezondheidszorg ZorggroepThuis Oostelijk Zuid-Limburg. De doelstelling van dit samenwerkingsverband was borstvoeding te bevorderen door een betere samenwerking en afstemming van beleid. Toen dit project geëvalueerd moest worden, stapte ik in 1998 naar Cor Spreeuwenberg met de vraag hoe ik daarbij ondersteuning konden krijgen. Hij zette mijn vraag op de mail en de volgende dag kreeg ik een enthousiast telefoontje van Carel Thijs. Na het krijgen van financiering van ZONMw, ontstond het project "Promotion and Support of Breastfeeding". Met heel veel enthousiasme heb ik van december 2000 tot augustus 2003 halftime gewerkt aan dit project als onderzoeker op de afdeling Epidemiologie. Dit was mogelijk doordat ik vanuit de Thuiszorg gedetacheerd werd bij de Universiteit. Daarnaast bleef ik nog voor twee dagen per week bij de Thuiszorg werken. Soms was de combinatie van functies zwaar, doordat beide functies een groot appel op me deden. Het onderzoek boeide mij in al haar facetten, zoals het opzetten en het uitvoeren ervan, de analyses en het schrijven. Ik heb in die jaren enorm veel geleerd. Mijn belangstelling voor het onderwerp borstvoeding is nog steeds groeiend, omdat dit onderwerp uit het leven gegrepen is en verschillende invalshoeken heeft.

Veel mensen zijn betrokken geweest bij de tot standkoming van dit proefschrift. Graag wil ik ieder van hen bedanken voor hun inzet en betrokkenheid.

In de eerste plaats mijn copromotor Carel Thijs. Beste Carel, je was de inspirator van de opzet en de uitvoering van het onderzoek. Ik heb veel bewondering voor je wetenschappelijke expertise, maar ook voor je nauwkeurigheid en engelengeduld. Je hebt veel conceptversies gecorrigeerd, zonder mij een gefrustreerd gevoel te geven. Ik heb veel van je geleerd in een prettige sfeer. Ik hoop dat ik in de toekomst nog met je mag samenwerken.

Verder mijn twee promotores Hein de Vries en Piet van den Brandt. Beste Hein, de discussies met jou waren altijd verrassend. In zeer korte tijd drong je door tot de kern, schakelde zeer snel, en koppelde nieuwe ideeën spelenderwijs aan elkaar en dat 
gelardeerd met veel humor. Naast je wetenschappelijke inzichten heb ik ook veel bewondering voor je communicatieve vermogens. Beste Piet, als hoofd van de afdeling Epidemiologie, gaf je me niet alleen een werkplek, maar ook was je steun en kritische bijdrage onmisbaar voor dit proefschrift.

Pieter Dagnelie, hoofd van Nutrim, bedankt voor je steeds positieve benadering en steun.

De medewerkers van de afdelingen Kraamzorg en Jeugdgezondheidszorg van Thuiszorg Midden Limburg, Westelijke Mijnstreek en Oostelijk Zuid Limburg voor hun medewerking aan het onderzoek.

De lactatiekundigen Anke Reumkens, Gonneke Velthuizen, Miriam Weijers voor hun bijdrage aan het project. Jullie waren 24 uur stand-by om borstvoedingsproblemen op te lossen.

De onderzoeksassistentes Akkelien van den Berg, Alice Fleuren, Cobie Martens, Grietje Sahertian en Nicky Koumans. Jullie hebben veel werk verzet, zoals het maken van de vragenlijsten en het boekje voor de moeders, het verzamelen en invoeren van data, het bellen met moeders, consultatiebureauteams en lactatiekundigen, notuleren, te veel om op te noemen. Nathalie Slangen voor de hulp bij de lay-out van het proefschrift.

De moeders die bereid waren aan het onderzoek mee te werken en hun gegevens in vier vragenlijsten in te vullen.

Frans Gerards, die mij de principes van het health-counselingsmodel heeft geleerd, zodat ik dit model kon vertalen naar borstvoeding. Beste Frans, je hebt de kraamzorgverpleegkundigen en de consultatiebureauteams op een zeer deskundige manier geleerd wat dit model voor borstvoeding inhoudt.

Monique Termote, die van 1998 tot 1999 in het kader voor haar afstudeerscriptie Gezondheidswetenschappen stage bij mij liep op de afdeling Jeugdgezondheidszorg van de Thuiszorg in Heerlen. Dit resulteerde in een onderzoek naar factoren van invloed op de duur van borstvoeding, de basis van het Project Promotion and Support of Breastfeeding. Monique het was fijn om met jou samen te werken.

Arnold Kester en Marion de Leeuw. Beste Arnold, ik heb heel wat uurtjes naast je gezeten en met veel bewondering gekeken, hoe behendig jij bestanden aan elkaar koppelt en dan de meest ingewikkelde analyses doet. Zonder jou had ik het niet gered!

De begeleidingscommissie, Willemien Boland, Siemian Berghuijs, Remy Hira Sing, Marc Van der Hoeven, Adrienne de Reede en Mary Zwart. Bedankt voor jullie praktische kijk op het onderzoek ieder vanuit zijn eigen professionaliteit en jullie goede suggesties vanuit hun ervaring met borstvoeding.

Marieke Zegers, stagiaire Biologische Gezondheidskunde op de afdeling Epidemiologie, voor het opschonen van de vragenlijsten. 
Zorggroepthuis voor het feit dat ik in de gelegenheid werd gesteld, gedetacheerd te worden bij de Universiteit Maastricht. De consultatiebureauartsen voor hun loyaliteit. Ook veel dank aan Agine Bernhard die tijdens mijn detachering mijn taak bij de thuiszorg ontlastte.

En dan niet te vergeten onze vriend Ben Davies uit Schotland, voormalig bacterioloog in het De Wever ziekenhuis te Heerlen. Beste Ben, bedankt voor het corrigeren van de publicaties voor wat betreft de Engelse taal. Je moest je wel even verplaatsen in deze nieuwe materie, maar je weet nu wat significant others zijn. Voor ons ben jij met Sheila dat!

Last but not least, het thuisfront. Bert, bedankt voor je steun. Ik kan je nu weer wat meer gaan verwennen, mijn culinaire capaciteiten weer gaan uitoefenen en we kunnen samen gaan genieten in Antibes. Je hoeft je geen zorgen te maken hoe ik mijn gedrevenheid en energie kwijt raak als ik het niet meer zo druk heb. Ik heb nog zoveel pijlen op mijn boog dat ik echt geen postpromotionele depressie krijg. Jan-Pieter bedankt voor je niet aflatende humor en analytische kijk op zaken. Hulde aan mijn lieve paranimfen MariePaule en Monique, ik kon geen betere hebben! 


\section{ABOUT THE AUTHOR}

Els J. Kools was born in Heerlen on July 28, 1943. In 1962, she obtained her certificate, gymnasium $\beta$, at the Clara College in Heerlen. She studied medicine at the Catholic University Nijmegen, where she obtained her master's degree in 1968. She followed her study at the Klinisch Hoger Onderwijs in Rotterdam, where she was awarded her final examination in medicine in 1970. From 1970-1984, she worked at the Provinciale Vereniging Het Limburgse Groene Kruis as schooldoctor in Kerkrade, Landgraaf, Amstenrade, Oirsbeek and Onderbanken. In 1973, she started her education in Social Medicine in Nijmegen, where she obtained her diploma as Jeugdarts in 1976. From 1984-1990, she was working as district doctor in the child health care of the Home Health Care in the district southeast Limburg, from 1995-2002 as medical manager and from 2003 as member of the staff. In 1998, a grant proposal was formulated by Maastricht University to develop and evaluate a program "The Promotion and Support of Breastfeeding" based on principles of health counseling. The plan was submitted as a grant proposal for the National Prevention Program of ZONMw ("Netherlands Organization for Health Research and Development"), which was approved in 1999 and started in 2000. From 2000-2003, she combined her work at the child health care with research at the Department of Epidemiology of Maastricht University, where she worked for three days a week on this thesis. Beside her work, she fulfilled various other functions such as chairman of the committee of the Foundation SBOK (Stichting Begeleiding en Onderwijs van het in ontwikkeling bedreigde Kind), member of the council of Het Landelijk Centrum Ouder-en Kindzorg, member of the Supervisory Board of RIAGG Maastricht, chairman of the Foundation PAOG (Post Academisch Onderwijs Geneeskunde) Maastricht Jeugdgezondheidszorg and member of the committee of the AJN (Artsen Jeugdgezondheidszorg Nederland). 